\title{
Impact of the High Flux Isotope Reactor HEU to LEU Fuel Conversion on Cold Source Nuclear Heat Generation Rates
}

\section{March 2014}

Prepared by

David Chandler

Research Reactors Division

Oak Ridge National Laboratory

Approved for public release;

distribution is unlimited.

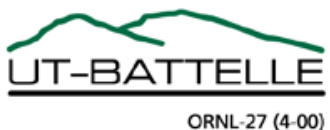




\section{DOCUMENT AVAILABILITY}

Reports produced after January 1, 1996, are generally available free via US Department of Energy (DOE) SciTech Connect.

Website http://www.osti.gov/scitech/

Reports produced before January 1, 1996, may be purchased by members of the public from the following source:

National Technical Information Service

5285 Port Royal Road

Springfield, VA 22161

Telephone 703-605-6000 (1-800-553-6847)

TDD 703-487-4639

Fax 703-605-6900

E-mail info@ntis.gov

Website http://www.ntis.gov/support/ordernowabout.htm

Reports are available to DOE employees, DOE contractors, Energy Technology Data Exchange representatives, and International Nuclear Information System representatives from the following source:

Office of Scientific and Technical Information

PO Box 62

Oak Ridge, TN 37831

Telephone 865-576-8401

Fax 865-576-5728

E-mail reports@osti.gov

Website http://www.osti.gov/contact.html

This report was prepared as an account of work sponsored by an agency of the United States Government. Neither the United States Government nor any agency thereof, nor any of their employees, makes any warranty, express or implied, or assumes any legal liability or responsibility for the accuracy, completeness, or usefulness of any information, apparatus, product, or process disclosed, or represents that its use would not infringe privately owned rights. Reference herein to any specific commercial product, process, or service by trade name, trademark, manufacturer, or otherwise, does not necessarily constitute or imply its endorsement, recommendation, or favoring by the United States Government or any agency thereof. The views and opinions of authors expressed herein do not necessarily state or reflect those of the United States Government or any agency thereof. 
Research Reactors Division

\title{
IMPACT OF THE HIGH FLUX ISOTOPE REACTOR HEU TO LEU FUEL CONVERSION ON COLD SOURCE NUCLEAR HEAT GENERATION RATES
}

\author{
David Chandler
}

Date Published: March 2014

\author{
Prepared by \\ OAK RIDGE NATIONAL LABORATORY \\ Oak Ridge, Tennessee 37831-6283 \\ managed by \\ UT-BATTELLE, LLC \\ for the \\ US DEPARTMENT OF ENERGY \\ under contract DE-AC05-00OR22725
}





\section{CONTENTS}

\section{Page}

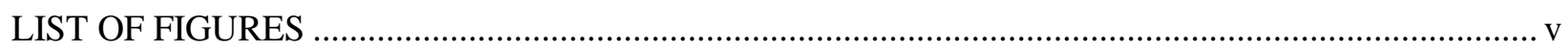

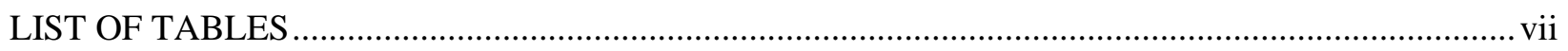

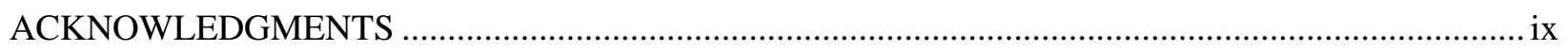

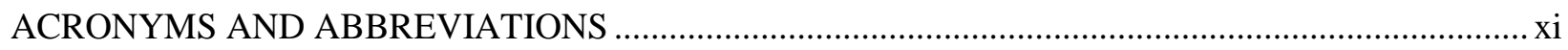

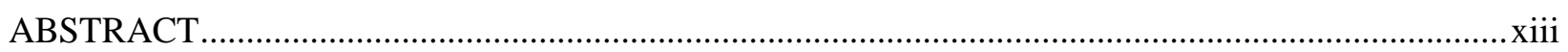

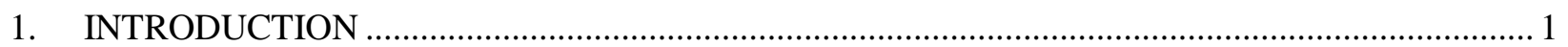

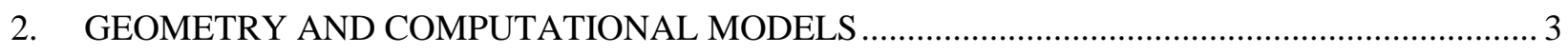

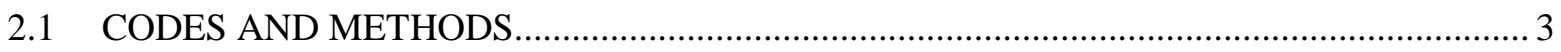

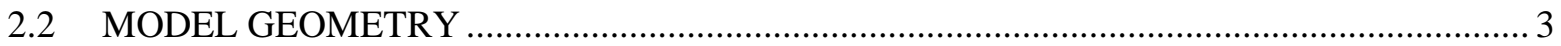

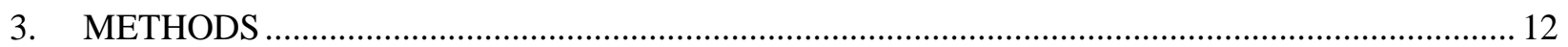

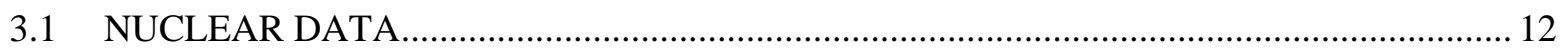

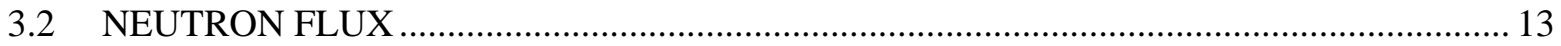

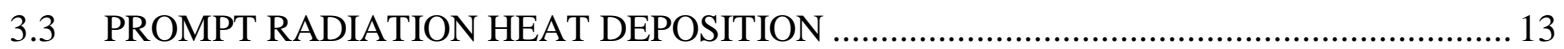

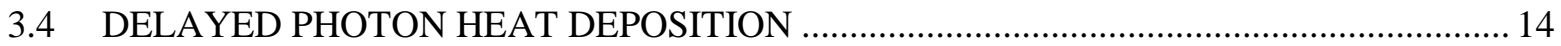

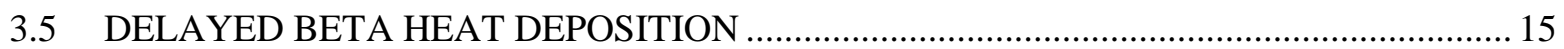

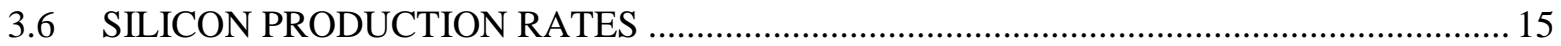

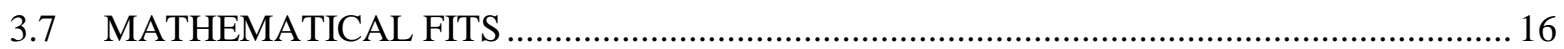

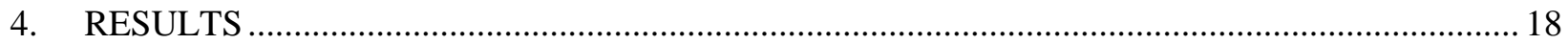

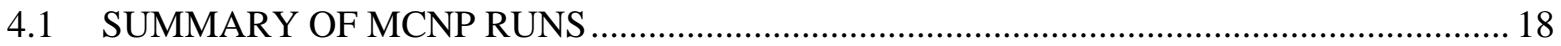

4.2 BEGINNING-OF-CYCLE HEAT GENERATION RESULTS .............................................. 18

4.3 END-OF-CYCLE HEAT GENERATION RESULTS .......................................................... 23

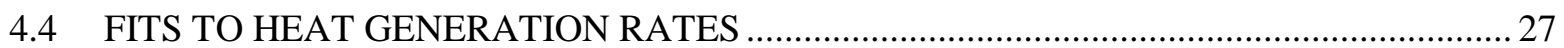

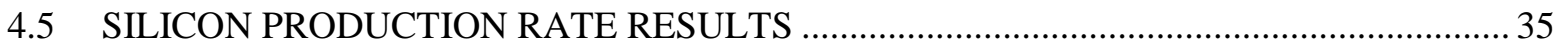

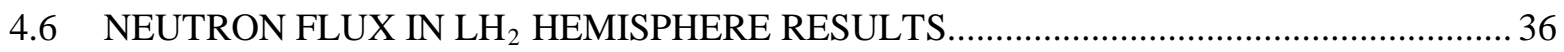

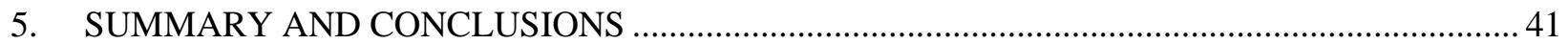

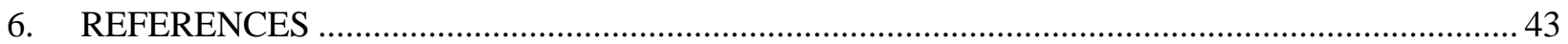

APPENDIX. METHODS AND PREVIOUS CALCULATION COMPARISONS ................................ A-1 



\section{LIST OF FIGURES}

Figure

Fig. 1. High Flux Isotope Reactor core mock-up and cold source moderator vessel. ........................ 1

Fig. 2. Cross section of MCNP as-modeled geometry. ................................................................ 4

Fig. 3. Elevation view of horizontal beam tube 4 about 10 (a), 18 (b), 20 (c), and 25 (d) cm from the midpoint between horizontal beam tube 1 and horizontal beam tube 4 ...................... 5

Fig. 4. Beginning-of-cycle heat generation rates in $\mathrm{LH}_{2}$ hemisphere. ........................................... 20

Fig. 5. Beginning-of-cycle heat generation rates in $\mathrm{LH}_{2}$ sections 2-6......................................... 20

Fig. 6. Beginning-of-cycle heat generation rates in aluminum sections......................................... 22

Fig. 7. End-of-cycle heat generation rates in $\mathrm{LH}_{2}$ hemisphere.................................................... 24

Fig. 8. End-of-cycle heat generation rates in $\mathrm{LH}_{2}$ sections 2-6............................................... 25

Fig. 9. End-of-cycle heat generation rates in aluminum sections................................................ 26

Fig. 10. Beginning-of-cycle $\mathrm{LH}_{2}$ hemisphere neutron energy deposition (W/g): HEU (a) and

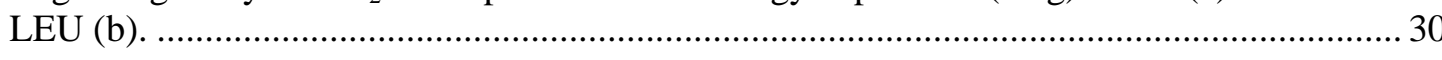

Fig. 11. Beginning-of-cycle $\mathrm{LH}_{2}$ hemisphere photon energy deposition (W/g): HEU (a) and

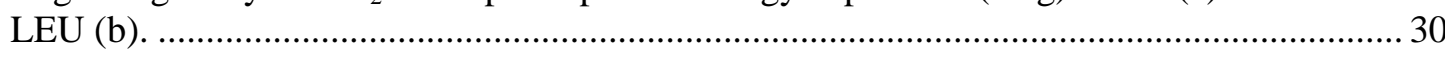

Fig. 12. Beginning-of-cycle $\mathrm{LH}_{2}$ hemisphere total energy deposition (W/g): HEU (a) and LEU

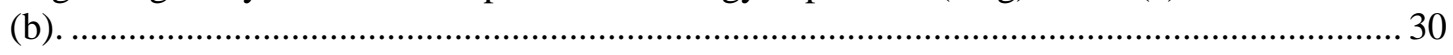

Fig. 13. End-of-cycle $\mathrm{LH}_{2}$ hemisphere neutron energy deposition (W/g): HEU (a) and LEU (b)....... 31

Fig. 14. End-of-cycle $\mathrm{LH}_{2}$ hemisphere photon energy deposition (W/g): HEU (a) and LEU (b)........ 31

Fig. 15. End-of-cycle $\mathrm{LH}_{2}$ hemisphere total energy deposition (W/g): HEU (a) and LEU (b)............ 31

Fig. 16. Beginning-of-cycle aluminum hemisphere 85 HEU to 100 LEU ratio: neutron (a), beta

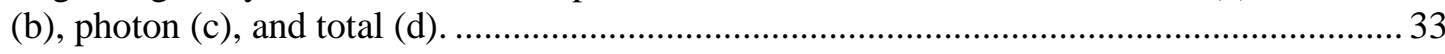

Fig. 17. End-of-cycle aluminum hemisphere 85 HEU to 100 LEU ratio: neutron (a), beta (b),

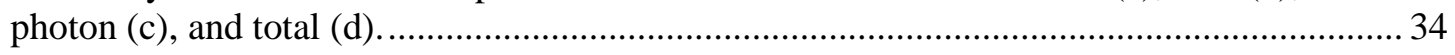

Fig. 18. Beginning-of-cycle silicon production rates in aluminum sections. .................................... 35

Fig. 19. End-of-cycle silicon production rates in aluminum sections................................................ 36

Fig. 20. Thermal $\left(\mathrm{E}_{\mathrm{n}}<0.625 \mathrm{eV}\right)$ neutron flux in $\mathrm{LH}_{2}$ hemisphere............................................. 37

Fig. 21. Epithermal $\left(0.1 \mathrm{MeV}>\mathrm{E}_{\mathrm{n}}>0.625 \mathrm{eV}\right)$ neutron flux in $\mathrm{LH}_{2}$ hemisphere........................... 37

Fig. 22. Fast $\left(20 \mathrm{MeV}>\mathrm{E}_{\mathrm{n}}>0.1 \mathrm{MeV}\right)$ neutron flux in $\mathrm{LH}_{2}$ hemisphere...................................... 38

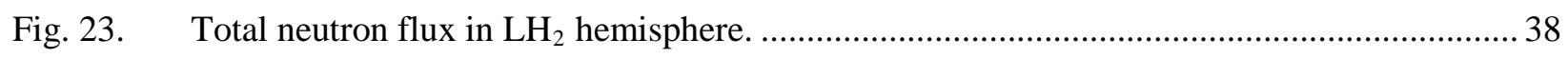





\section{LIST OF TABLES}

Table

Page

Table 1. Hemispherical region of cold source $\mathrm{LH}_{2}$ subdivided cell descriptions ................................. 7

Table 2. Sections 2-6 of cold source $\mathrm{LH}_{2}$ subdivided cell descriptions ............................................. 8

Table 3. Hemispherical region and sections 2-3 of cold source aluminum subdivided cell

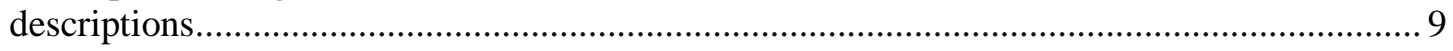

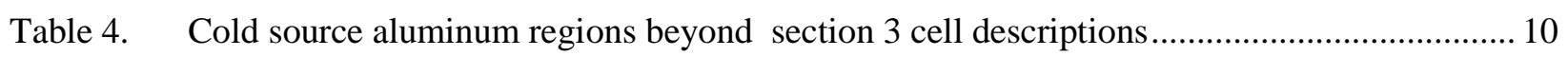

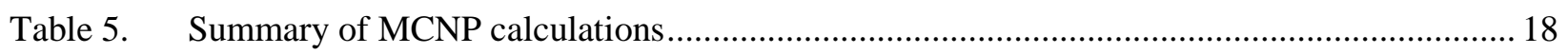

Table 6. Beginning-of-cycle total heat generation rate summary for the cold source $\mathrm{LH}_{2}$ regions ....... 21

Table 7. Beginning-of-cycle radiation-dependent heat generation rate summary for the cold

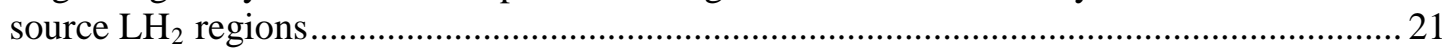

Table 8. Beginning-of-cycle total heat generation rate summary for the cold source aluminum

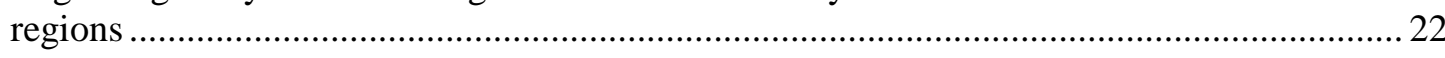

Table 9. Beginning-of-cycle radiation-dependent heat generation rate summary for the cold

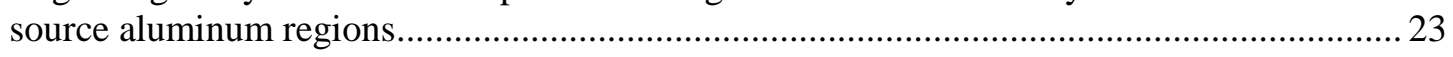

Table 10. End-of-cycle total heat generation rate summary for the cold source $\mathrm{LH}_{2}$ regions ................ 25

Table 11. End-of-cycle radiation-dependent heat generation rate summary for the cold source

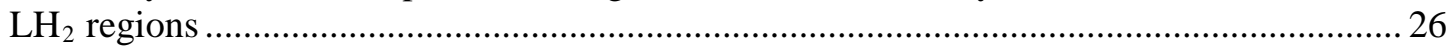

Table 12. End-of-cycle total heat generation rate summary for the cold source aluminum regions ........ 27

Table 13. End-of-cycle radiation-dependent heat generation rate summary for the cold source

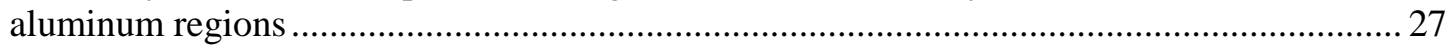

Table 14. Fitting coefficients to total heat generation rates in hemispherical part of cold source

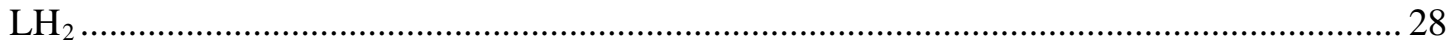

Table 15. Fits to total heat generation rates in hemispherical part of cold source $\mathrm{LH}_{2} \ldots \ldots \ldots \ldots \ldots \ldots \ldots \ldots . . . . . . . . . . .29$

Table 16. Fitting coefficients to total heat generation rates in hemispherical part of cold source

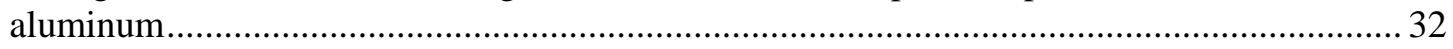

Table 17. Fit to total heat generation rates in hemispherical part of cold source aluminum................... 32 



\section{ACKNOWLEDGMENTS}

This work was sponsored by the Global Threat Reduction Initiative, Reduced Enrichment for Research and Test Reactors Program, a program of the National Nuclear Security Administration, US Department of Energy.

The author gratefully acknowledges the technical reviews of this manuscript that were performed by Eva Sunny, Reactor and Nuclear Systems Division, Oak Ridge National Laboratory (ORNL), and David Renfro, Research Reactors Division, ORNL. In addition, the author acknowledges everyone who has contributed to the development of the computational models described in this report including, but certainly not limited to, Germina Ilas, R. T. Primm III, and C. O. Slater (all of or formerly of ORNL). Finally, the author is indebted to Mary Wells, Research Reactors Division, ORNL, for assistance formatting the manuscript. 



\section{ACRONYMS AND ABBREVIATIONS}

$\begin{array}{ll}\text { BOC } & \text { beginning-of-cycle } \\ \text { CE } & \text { control element } \\ \text { CHM } & \text { core horizontal midplane } \\ \text { DOE } & \text { US Department of Energy } \\ \text { ENDF } & \text { Evaluated Nuclear Data File } \\ \text { EOC } & \text { end-of-cycle } \\ \text { FP } & \text { full reactor power (85 MW for HEU core and 100 MW for LEU core) } \\ \text { FTT } & \text { flux trap target region } \\ \text { HB } & \text { horizontal beam tube } \\ \text { HEU } & \text { high enriched uranium } \\ \text { HFIR } & \text { High Flux Isotope Reactor } \\ \text { IFE } & \text { inner fuel element } \\ \text { IKE } & \text { Institut für Kernenergetik und Energiesysteme (University of Stuttgart, Institute for } \\ & \text { Nuclear Technology and Energy Systems) } \\ \text { LANL } & \text { Los Alamos National Laboratory } \\ \text { LH } & \text { liquid hydrogen } \\ \text { LEU } & \text { low enriched uranium } \\ \text { MCNP } & \text { Monte Carlo N-Particle (code) } \\ \text { OFE } & \text { outer fuel element } \\ \text { ORIGEN } & \text { Oak Ridge Isotope Generation (code) } \\ \text { ORNL } & \text { Oak Ridge National Laboratory } \\ \text { SCALE } & \text { Standardized Computer Analysis for Licensing Evaluations }\end{array}$





\begin{abstract}
Under the sponsorship of the US Department of Energy National Nuclear Security Administration, staff members at the Oak Ridge National Laboratory have been conducting studies to determine whether the High Flux Isotope Reactor (HFIR) can be converted from high enriched uranium (HEU) fuel to low enriched uranium (LEU) fuel. As part of these ongoing studies, an assessment of the impact that the HEU to LEU fuel conversion has on the nuclear heat generation rates in regions of the HFIR cold source system and its moderator vessel was performed and is documented in this report. Silicon production rates in the cold source aluminum regions and few-group neutron fluxes in the cold source moderator were also estimated.
\end{abstract}

Neutronics calculations were performed with the Monte Carlo N-Particle code to determine the nuclear heat generation rates in regions of the HFIR cold source and its vessel for the HEU core operating at a full reactor power (FP) of $85 \mathrm{MW}(\mathrm{t})$ and the reference LEU core operating at an FP of $100 \mathrm{MW}(\mathrm{t})$. Calculations were performed with beginning-of-cycle (BOC) and end-of-cycle (EOC) conditions to bound typical irradiation conditions. Average specific BOC heat generation rates of 12.76 and $12.92 \mathrm{~W} / \mathrm{g}$, respectively, were calculated for the hemispherical region of the cold source liquid hydrogen $\left(\mathrm{LH}_{2}\right)$ for the HEU and LEU cores, and EOC heat generation rates of 13.25 and $12.86 \mathrm{~W} / \mathrm{g}$, respectively, were calculated for the HEU and LEU cores. Thus, the greatest heat generation rates were calculated for the EOC HEU core, and it is concluded that the conversion from HEU to LEU fuel and the resulting increase of FP from $85 \mathrm{MW}$ to $100 \mathrm{MW}$ will not impact the ability of the heat removal equipment to remove the heat deposited in the cold source system.

Silicon production rates in the cold source aluminum regions are estimated to be about $12.0 \%$ greater at BOC and $2.7 \%$ greater at EOC for the LEU core in comparison to the HEU core. Silicon is aluminum's major transmutation product and affects mechanical properties of aluminum including density, neutron irradiation hardening, swelling, and loss of ductility. Because slightly greater quantities of silicon will be produced in the cold source moderator vessel for the LEU core, these effects will be slightly greater for the LEU core than for the HEU core.

Three-group (thermal, epithermal, and fast) neutron flux results tallied in the cold source $\mathrm{LH}_{2}$ hemisphere show greater values for the LEU core under both BOC and EOC conditions. The thermal neutron flux in the $\mathrm{LH}_{2}$ hemisphere for the $\mathrm{LEU}$ core is about $12.4 \%$ greater at BOC and $2.7 \%$ greater at EOC than for the HEU core. Therefore, cold neutron scattering will not be adversely affected and the 4-12 $\AA$ neutrons conveyed to the cold neutron guide hall for research applications will be enhanced. 



\section{INTRODUCTION}

The High Flux Isotope Reactor (HFIR) is a multipurpose research reactor located at the Oak Ridge National Laboratory (ORNL) in Oak Ridge, Tennessee, USA. It currently operates at a full reactor power (FP) of $85 \mathrm{MW}(\mathrm{t})$ and provides cold and thermal neutron scattering, isotope production, materials irradiation, and neutron activation analysis capabilities. HFIR was designed to produce a large thermal flux-to-power ratio by including an over-moderated flux trap target region (FTT) in the center of the reactor core and a large beryllium reflector on the outside of the core. On the outside of the FTT are two concentric fuel annuli, an inner fuel element (IFE) and an outer fuel element (OFE). Two concentric poison-bearing control elements (CEs) are situated outside of the fuel elements for safety and regulation purposes, and a large beryllium reflector encompasses the core and CEs. Fig. 1 illustrates the HFIR layout, including photographs of the core and cold source moderator vessel.

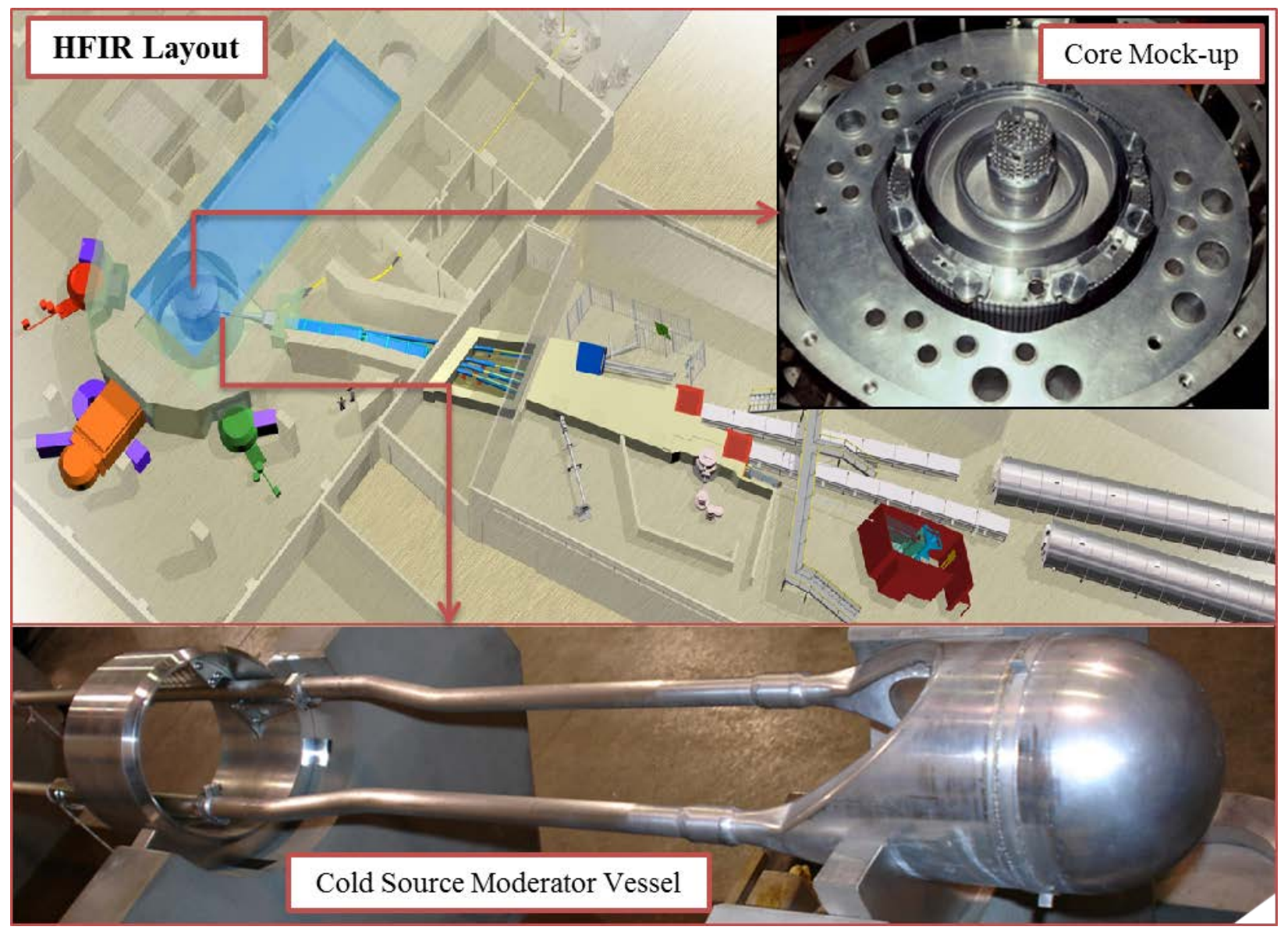

Fig. 1. High Flux Isotope Reactor core mock-up and cold source moderator vessel.

This pressurized, light water-cooled and -moderated flux-trap type reactor uses high enriched uranium (HEU) fuel enriched to about $93 \mathrm{wt} \%$ in ${ }^{235} \mathrm{U}$ in the form of $\mathrm{U}_{3} \mathrm{O}_{8}$ in an aluminum matrix. The IFE is constructed of 171 involute fuel plates, the OFE is constructed of 369 involute fuel plates, and the fuel is nonuniformly distributed along the arc of the involute and encapsulated within Al-6061 cladding. The total loading of a fresh HFIR (HEU) core is about $9.4 \mathrm{~kg}$ of ${ }^{235} \mathrm{U}$, and a typical fuel cycle length ranges from 22 to 26 days depending on the experiment loading. 
The beryllium reflector is penetrated by 42 vertical facilities used for irradiation purposes and four horizontal beam tube (HB) experiment facilities that extend outward from the reactor core at the core horizontal midplane (CHM). The beryllium reflector also serves as a neutron moderator by slowing down the high-energy source neutrons. Horizontal beam tube number 4 (HB-4) is an aluminum tube that is aligned on a tangential line about $38.5 \mathrm{~cm}$ from the reactor core center line and contains the liquid hydrogen $\left(\mathrm{LH}_{2}\right)$ cold source moderator vessel, transfer lines, and vacuum tube. At a temperature of 1820 Kelvin and a nominal flow rate of $1 \mathrm{~L} / \mathrm{s}$, the supercritical hydrogen moderator enters the supply line located on the CHM on the side away from the core and then exits on the side toward the core. Neutron collisions in the supercritical hydrogen further reduce the neutron energies to about 4-12 $\AA$ for cold neutron scattering applications. The moderator vessel is shown in Fig. 1.

Under the sponsorship of the US Department of Energy National Nuclear Security Administration, staff members at ORNL have been conducting studies to determine whether HFIR can be converted from HEU fuel to low enriched uranium (LEU) fuel. The proposed LEU fuel will be enriched to $19.75 \mathrm{wt} \%{ }^{235} \mathrm{U}$ in the form of U-10Mo, a uranium metal alloyed with molybdenum with the molybdenum composing $10 \mathrm{wt}$ $\%$ of the mixture. The fresh core uranium loading will increase from about $10.1 \mathrm{~kg}$ (HEU fuel) to about $125 \mathrm{~kg}$ (LEU fuel). Due to the self-shielding effects introduced by the large concentration of ${ }^{238} \mathrm{U}$, the critical mass of ${ }^{235} \mathrm{U}$ will be increased from about $9.4 \mathrm{~kg}$ (HEU fuel) to about $25.3 \mathrm{~kg}$ (LEU fuel). To maintain the neutron flux at the experiment facilities, FP will need to be increased from $85 \mathrm{MW}(\mathrm{t})$ to $100 \mathrm{MW}(\mathrm{t})$. A more thorough description of the reference LEU design is provided in [1].

Energy (heat) is deposited in the cold source moderator and vessel during reactor operation due to direct neutron and photon (primary, secondary, and delayed fission) sources. Beta heating, due to the decay of ${ }^{28} \mathrm{Al}$ following neutron capture in ${ }^{27} \mathrm{Al}$, is also considered for the aluminum regions. Neutrons and photons deposit their energy throughout the reactor and, therefore, must be transported in the analyses to determine the spatial energy deposition distribution. However, beta particles have very little penetrating power, so it is assumed that their energy is deposited locally (i.e., at the location where ${ }^{27} \mathrm{Al}$ captures a neutron). Nuclear heat generation calculations are required because this heat, along with any mechanically induced heat, must be removed [2]. A circulator located in the pump module pumps hydrogen through the moderator vessel, and the warm hydrogen returns to the heat exchanger module where it is cooled by helium.

Cold source nuclear heat generation rates were calculated previously for the 85 MW HEU core and reported in [2-4]. The purpose of this report is to compare the nuclear heat generation rates in the cold source for the HEU-loaded HFIR core and the reference LEU-loaded HFIR core operating at $100 \mathrm{MW}$ [1]. Heat deposition due to photons, neutrons, and beta particles (only in aluminum) and the sum of these constituents were calculated in watts per gram for the cold source $\mathrm{LH}_{2}$ moderator, the cold source moderator vessel, the HB-4 aluminum structure, and other regions of interest including stainless steel screws and titanium wires. However, only the heat generation rates in the cold source $\mathrm{LH}_{2}$ moderator and the cold source moderator vessel are discussed in this report. Heat generation rates for all regions and corresponding fitting functions are documented in detail in [5].

Silicon production in the aluminum cold source moderator vessel is another concern that is assessed because the build-up of silicon in structural aluminum contributes to mechanical property changes including swelling, hardening, and loss of ductility. As described in more detail in a later section, ${ }^{28} \mathrm{Si}$ is the product of the ${ }^{27} \mathrm{Al}(\mathrm{n}, \gamma)^{28} \mathrm{Al} \rightarrow{ }^{28} \mathrm{Si}+\beta^{-}$reaction. The fast component of the neutron flux displaces atoms and the thermal component generates ${ }^{28} \mathrm{Si}$, and both of these lead to swelling and embrittlement. Thus, the thermal-to-fast neutron flux ratio is important when performing neutron damage assessments. Because the thermal-to-fast neutron flux ratio is very high in the permanent beryllium reflector and silicon will accrue with irradiation exposure, the impact that the conversion has on the silicon production rates in the aluminum moderator vessel is also assessed in this report. 


\section{GEOMETRY AND COMPUTATIONAL MODELS}

\subsection{CODES AND METHODS}

The enhanced HEU models [1] based on the cycle 400 HEU model of the HFIR fresh core [6] and the 2011 models for the LEU core [1] were used for this set of comparison studies. Previous HEU to LEU comparison studies documented in [7] and [8] also made use of these models. The Monte Carlo N-Particle 5 (MCNP5) code, version 1.5.1 [9], which is a Monte Carlo-based neutron-photon-electron transport code developed and maintained at the Los Alamos National Laboratory (LANL), was used in this study to perform coupled neutron-photon calculations. The transport calculations made use of the Evaluated Nuclear Data File (ENDF) cross section libraries.

Calculations were performed with beginning-of-cycle (BOC) and end-of-cycle (EOC) conditions to bound typical HFIR operating conditions. The EOC inputs were obtained from previous depletion studies [1] performed with VESTA [10], a Monte Carlo-based depletion tool developed and maintained at Institut de Radioprotection et de Sûreté Nucléaire (French Institute for Radiological Protection and Nuclear Safety), which was validated against HFIR post-irradiation, spatially dependent uranium isotopic measurements [11] and compared to calculations performed with the Standardized Computer Analysis for Licensing Evaluations code package (SCALE) [12] in [13]. The fuel, CEs, and curium targets (applicable only to the LEU inputs) were depleted, and CE withdrawal was simulated during the VESTA calculations.

Each of the HEU and LEU, BOC and EOC, models were further enhanced by subdividing the cold source moderator, moderator vessel, and beam tube into smaller zones to capture the spatially dependent specific nuclear heat deposition rates [4]. MCNP tally cards were used to obtain the desired output and MATLAB [14], a commercial software package, was used to organize, post-process, and plot the results provided by the MCNP runs.

\subsection{MODEL GEOMETRY}

The BOC calculations are based on fresh fuel, and the CEs are at their initial symmetrical critical positions of 18.0 and 19.5 in. withdrawn, respectively, for the HEU and LEU calculations. The CEs are fully withdrawn ( 27 in. withdrawn) and the EOC fuel compositions are used for the EOC calculations. During the cycle, the CEs are moved vertically to maintain the reactor's critical state. The inner element moves downward and the outer plates (four) move upward, increasing the distance between the absorbing regions of the elements and the CHM, thus opening a neutron "window" (aluminum only section of CEs) and allowing more source neutrons to leak into the reflector and reflect back into the core. The symmetrical positions of 18.0 and $19.5 \mathrm{in}$. withdrawn correspond, respectively, to 1.0 and $2.5 \mathrm{in}$. gaps between the CHM and the gray (tantalum-aluminum) regions. Thus, the neutron windows are 2.0 in. (i.e., $2 \times 1.0$ in.) in length for the HEU BOC calculation and 5.0 in. in length for LEU BOC calculation.

For both the HEU and LEU inputs, the fuel elements are modeled by volumetrically homogenizing the fuel meat, filler, clad, and water in between the fuel plates. The IFE is divided into 8 radial regions and 19 axial regions, and the OFE is divided into 9 radial regions and 19 axial regions. The fuel elements are divided radially to represent the different effective fuel concentrations in the radial direction, and they are divided axially to model the EOC spatially dependent (depleted) fuel compositions. An x-y cross section of the MCNP model at the CHM is provided in Fig. 2.

The cold source vessel and moderator geometry, as provided in the reference MCNP models, was further subdivided into finer regions to determine the spatially dependent nuclear heat generation rates. The 
subdivided cold source model described in [4] was used for these changes, and the next three paragraphs are paraphrased from [4].

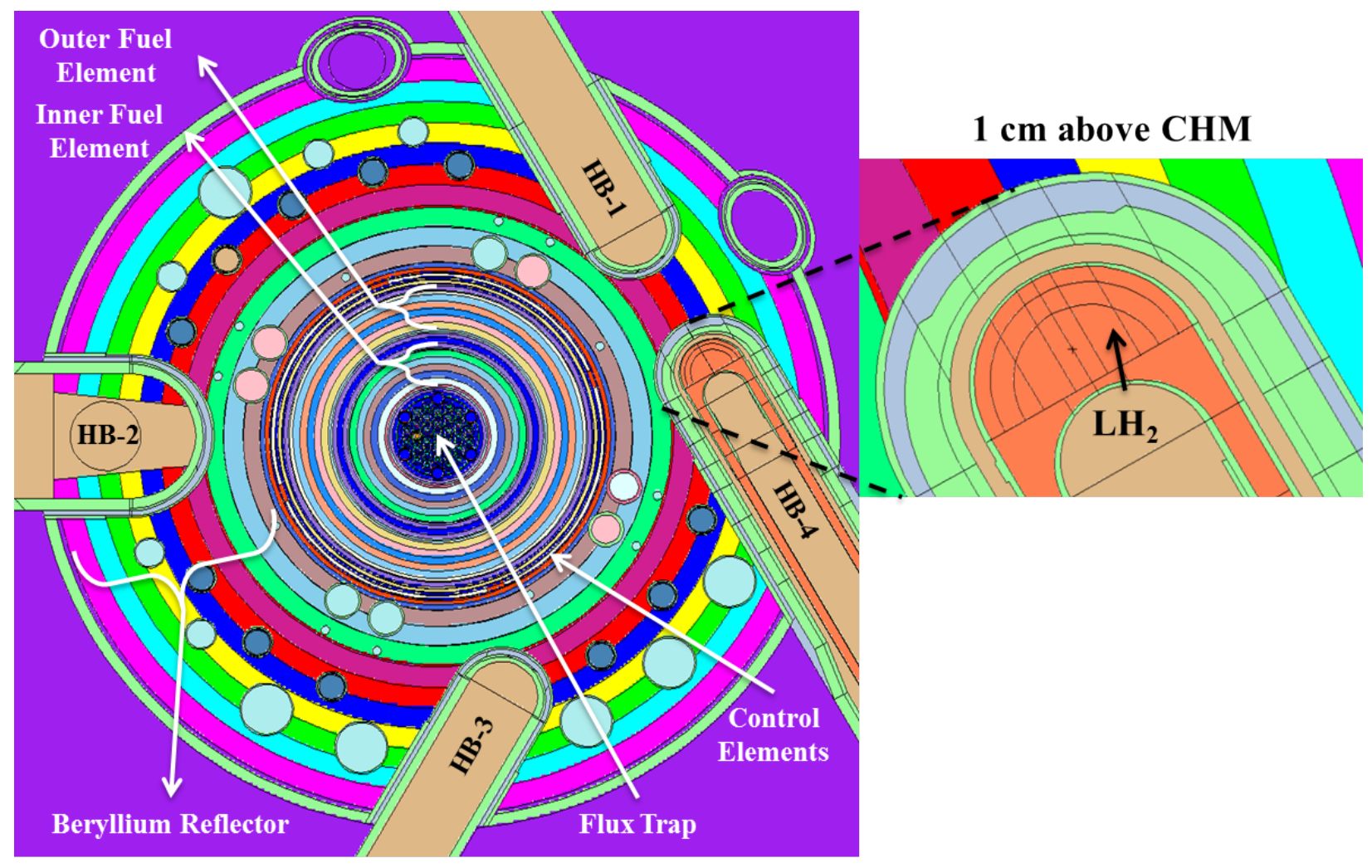

Fig. 2. Cross section of MCNP as-modeled geometry.

The hemispherical portion of the cold source moderator and the adjoining $0.12446 \mathrm{~cm}$ thick cylindrical disk were previously described by two cells (numbered 86011 and 86012 in the MCNP model). These cells were replaced by 36 cells numbered 95001 through 95036. The hemisphere was subdivided into three equal-volume regions, and these radii also subdivided the adjoining $0.12446 \mathrm{~cm}$ thick cylindrical disk. Each of the three subvolumes was subdivided into 12 azimuthal segments of equal volume within a given subvolume (because the cylinder was not subdivided into three equal subvolumes, the volumes of the cells comprising the union of the hemisphere and cylinder differed from one subvolume to the next).

The cells composing the hemispherical portion of the vessel (numbered 86021 and 86022) were partitioned into 12 azimuthal segments (numbered 86021-86032). The vessel cells numbered 86041 and 86042 were further subdivided into eight cells (numbered 86041-86048) having unequal volumes. Likewise, the cells numbered 86061 and 86062 were further subdivided into eight cells (numbered 86061-86068). Moderator cells numbered 86051 and 86052 were further subdivided into eight cells (numbered 86051-86058) having unequal volumes. Cells 86101, 86102, 86111, and 86112 were renamed 86111 through 86114.

The cells numbered 86091 and 86092 were further subdivided into 16 subcells (numbered 86091-86106). The region extends from a point $15.09268 \mathrm{~cm}$ from the start of the beam tube to a point $22.86 \mathrm{~cm}$ from the start of the beam tube. The first eight subcells cover the region from $15.09268 \mathrm{~cm}$ to $19.05 \mathrm{~cm}$, and the last eight cover the region from $19.05 \mathrm{~cm}$ to $22.86 \mathrm{~cm}$. Of the last eight, only four have nonzero volumes because, as seen in Fig. 3c, upper and lower segments are not present at this location. As seen in Fig. 2, the azimuthal angle is measured from a vector parallel to the radius vector from the core center to 
the origin of HB-4. Thus, the first azimuth is away from the core and above the tube midplane, and the last azimuth is away from the core and below the tube midplane. Volumes of the subdivided regions were stochastically computed, and averaged values were used when the volumes could not be easily computed analytically.

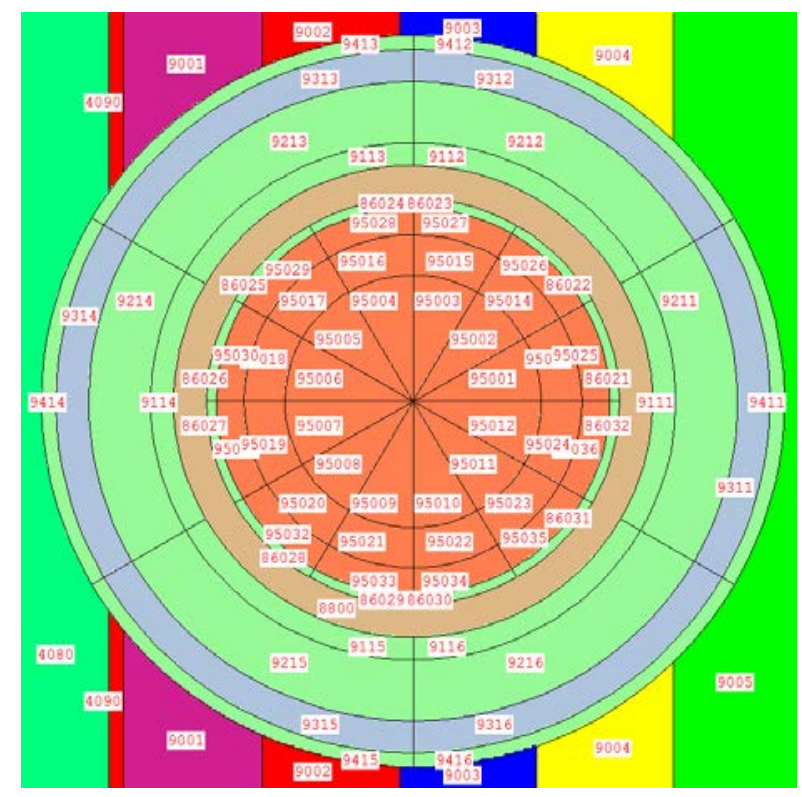

(a)

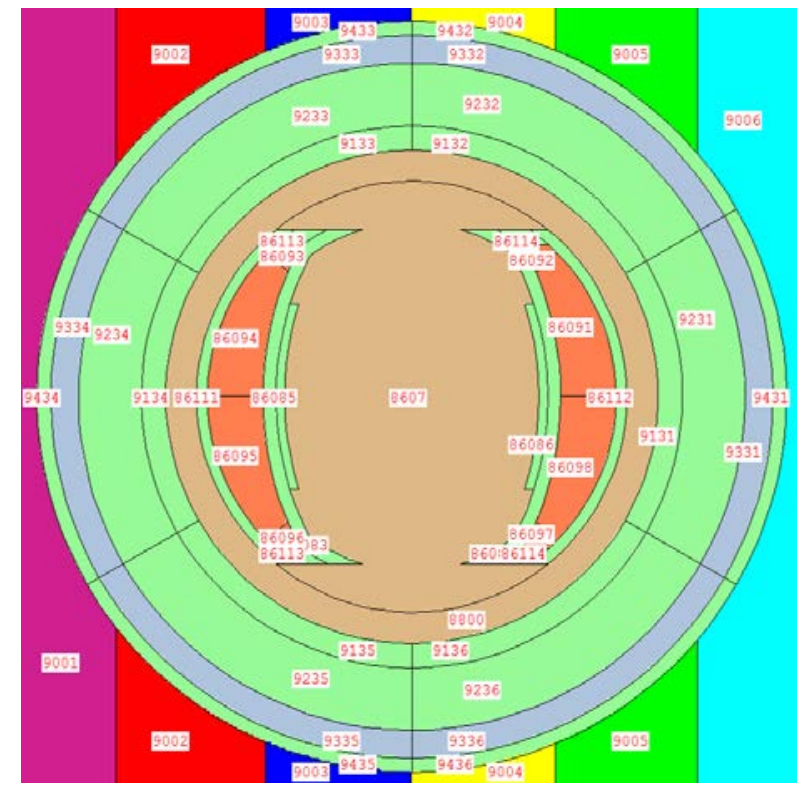

(c)

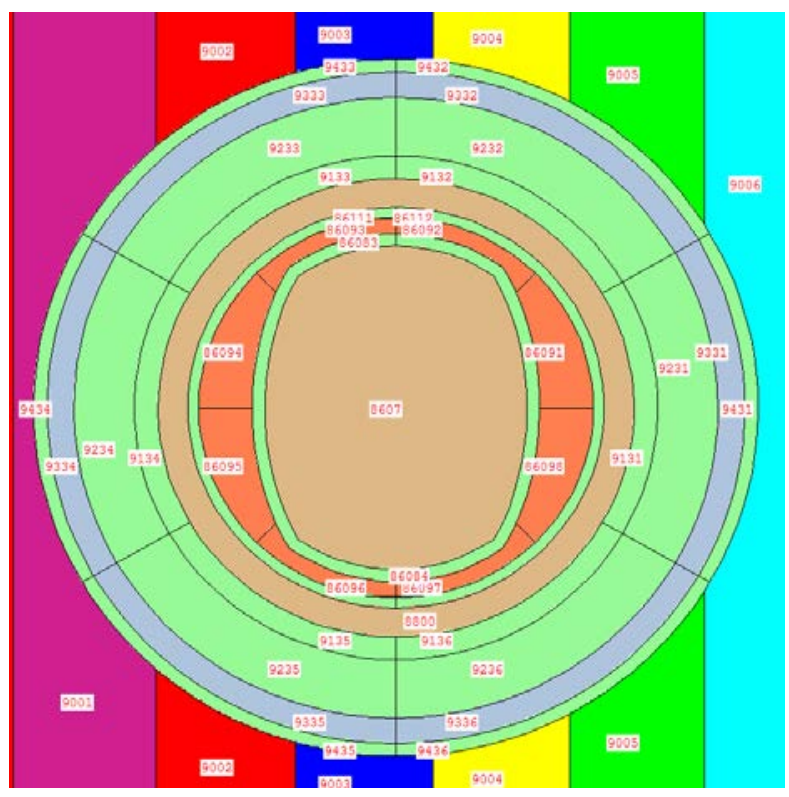

(b)

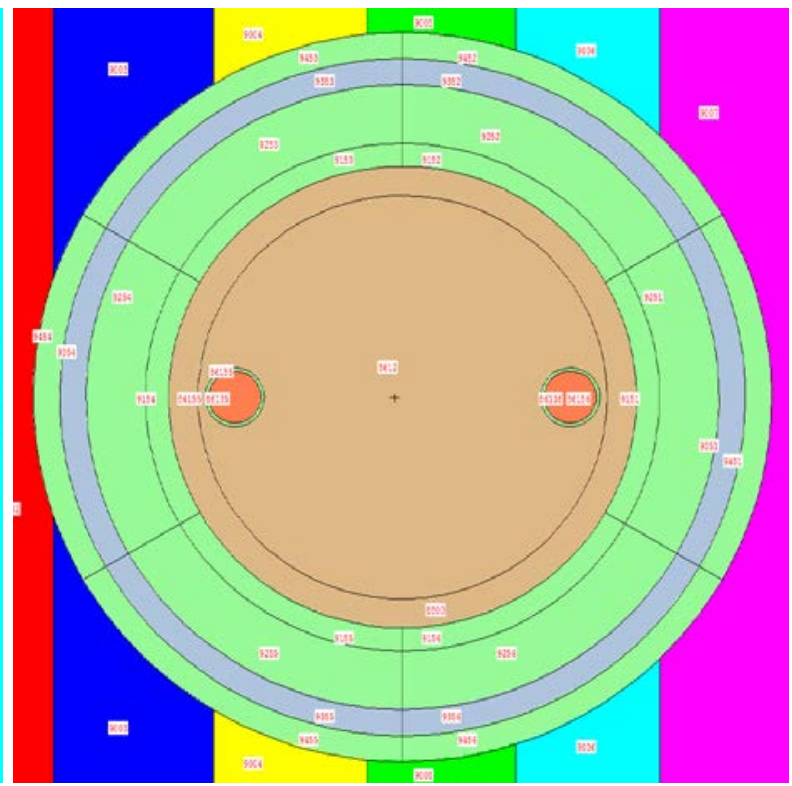

(d)

Fig. 3. Elevation view of horizontal beam tube 4 about 10 (a), 18 (b), 20 (c), and 25 (d) cm from the midpoint between horizontal beam tube 1 and horizontal beam tube 4 .

The beam tube origin is defined as being the intersection of the plane midway between HB- 1 and HB-4 and on the centerline for HB-4. The $r=0$ point lies on the centerline of HB-4 and is located $11.43 \mathrm{~cm}$ from the beam tube origin. The maximum value of $\mathrm{r}$ for the $\mathrm{LH}_{2}$ moderator is $4.6736 \mathrm{~cm}$. The azimuthal angle, $\theta$, is measured from a vector parallel to the radius vector from the core center to the beam tube 
origin. Thus, for a given distance along the beam tube, the zero-degree value will be a coordinate of the point farthest from the core, and the 180-degree value will be a coordinate of the point closest to the core. Refer to Fig. 3 for two-dimensional slices through HB-4 illustrating the subdivided cold source moderator and vessel regions. Data including the volumes of the cells are provided for the various regions in Table 1-Table 4. Note that the identifiers in these tables are used to identify the cells in the plots in Section 4. 
Table 1. Hemispherical region of cold source $\mathrm{LH}_{2}$ subdivided cell descriptions

\begin{tabular}{|c|c|c|c|c|c|}
\hline Identifier & Cell & $\begin{array}{c}\text { Volume } \\
\left(\mathrm{cm}^{3}\right)\end{array}$ & $\begin{array}{l}\text { Mass } \\
\text { (g) }\end{array}$ & $\begin{array}{c}\text { Radius } \\
\text { (cm) }\end{array}$ & $\begin{array}{l}\text { Angle } \\
\text { (deg.) }\end{array}$ \\
\hline 1 & 95001 & 6.28112 & 0.45601 & 2.57198 & 15 \\
\hline 2 & 95002 & 6.28112 & 0.45601 & 2.57198 & 45 \\
\hline 3 & 95003 & 6.28112 & 0.45601 & 2.57198 & 75 \\
\hline 4 & 95004 & 6.28112 & 0.45601 & 2.57198 & 105 \\
\hline 5 & 95005 & 6.28112 & 0.45601 & 2.57198 & 135 \\
\hline 6 & 95006 & 6.28112 & 0.45601 & 2.57198 & 165 \\
\hline 7 & 95007 & 6.28112 & 0.45601 & 2.57198 & 195 \\
\hline 8 & 95008 & 6.28112 & 0.45601 & 2.57198 & 225 \\
\hline 9 & 95009 & 6.28112 & 0.45601 & 2.57198 & 255 \\
\hline 10 & 95010 & 6.28112 & 0.45601 & 2.57198 & 285 \\
\hline 11 & 95011 & 6.28112 & 0.45601 & 2.57198 & 315 \\
\hline 12 & 95012 & 6.28112 & 0.45601 & 2.57198 & 345 \\
\hline 13 & 95013 & 6.13995 & 0.44576 & 3.70944 & 15 \\
\hline 14 & 95014 & 6.13995 & 0.44576 & 3.70944 & 45 \\
\hline 15 & 95015 & 6.13995 & 0.44576 & 3.70944 & 75 \\
\hline 16 & 95016 & 6.13995 & 0.44576 & 3.70944 & 105 \\
\hline 17 & 95017 & 6.13995 & 0.44576 & 3.70944 & 135 \\
\hline 18 & 95018 & 6.13995 & 0.44576 & 3.70944 & 165 \\
\hline 19 & 95019 & 6.13995 & 0.44576 & 3.70944 & 195 \\
\hline 20 & 95020 & 6.13995 & 0.44576 & 3.70944 & 225 \\
\hline 21 & 95021 & 6.13995 & 0.44576 & 3.70944 & 255 \\
\hline 22 & 95022 & 6.13995 & 0.44576 & 3.70944 & 285 \\
\hline 23 & 95023 & 6.13995 & 0.44576 & 3.70944 & 315 \\
\hline 24 & 95024 & 6.13995 & 0.44576 & 3.70944 & 345 \\
\hline 25 & 95025 & 6.10754 & 0.44341 & 4.39803 & 15 \\
\hline 26 & 95026 & 6.10754 & 0.44341 & 4.39803 & 45 \\
\hline 27 & 95027 & 6.10754 & 0.44341 & 4.39803 & 75 \\
\hline 28 & 95028 & 6.10754 & 0.44341 & 4.39803 & 105 \\
\hline 29 & 95029 & 6.10754 & 0.44341 & 4.39803 & 135 \\
\hline 30 & 95030 & 6.10754 & 0.44341 & 4.39803 & 165 \\
\hline 31 & 95031 & 6.10754 & 0.44341 & 4.39803 & 195 \\
\hline 32 & 95032 & 6.10754 & 0.44341 & 4.39803 & 225 \\
\hline 33 & 95033 & 6.10754 & 0.44341 & 4.39803 & 255 \\
\hline 34 & 95034 & 6.10754 & 0.44341 & 4.39803 & 285 \\
\hline 35 & 95035 & 6.10754 & 0.44341 & 4.39803 & 315 \\
\hline 36 & 95036 & 6.10754 & 0.44341 & 4.39803 & 345 \\
\hline
\end{tabular}


Table 2. Sections 2-6 of cold source $\mathrm{LH}_{2}$ subdivided cell descriptions

\begin{tabular}{|c|c|c|c|c|}
\hline Identifier & Cell & $\begin{array}{c}\text { Volume } \\
\left(\mathrm{cm}^{3}\right)\end{array}$ & $\begin{array}{c}\text { Mass } \\
\text { (g) }\end{array}$ & $\begin{array}{l}\text { Angle } \\
\text { (deg.) }\end{array}$ \\
\hline \multicolumn{5}{|c|}{ Section 2} \\
\hline 1 & 86051 & 19.51130 & 1.41652 & 22.5 \\
\hline 2 & 86052 & 14.12620 & 1.02556 & 67.5 \\
\hline 3 & 86053 & 14.12620 & 1.02556 & 112.5 \\
\hline 4 & 86054 & 19.51130 & 1.41652 & 157.5 \\
\hline 5 & 86055 & 19.51130 & 1.41652 & 202.5 \\
\hline 6 & 86056 & 14.12620 & 1.02556 & 247.5 \\
\hline 7 & 86057 & 14.12620 & 1.02556 & 292.5 \\
\hline 8 & 86058 & 19.51130 & 1.41652 & 337.5 \\
\hline \multicolumn{5}{|c|}{ Section 3} \\
\hline 9 & 86091 & 13.64330 & 0.99050 & 22.5 \\
\hline 10 & 86092 & 2.91403 & 0.21156 & 67.5 \\
\hline 11 & 86093 & 2.91403 & 0.21156 & 112.5 \\
\hline 12 & 86094 & 13.64330 & 0.99050 & 157.5 \\
\hline 13 & 86095 & 13.64330 & 0.99050 & 202.5 \\
\hline 14 & 86096 & 2.91403 & 0.21156 & 247.5 \\
\hline 15 & 86097 & 2.91403 & 0.21156 & 292.5 \\
\hline 16 & 86098 & 13.64330 & 0.99050 & 337.5 \\
\hline \multicolumn{5}{|c|}{ Section 4} \\
\hline 17 & 86099 & 7.96407 & 0.57819 & - \\
\hline 18 & 86106 & 7.96407 & 0.57819 & - \\
\hline 19 & 86102 & 7.96407 & 0.57819 & - \\
\hline 20 & 86103 & 7.96407 & 0.57819 & - \\
\hline \multicolumn{5}{|c|}{ Section 5} \\
\hline 21 & 86135 & 4.82639 & 0.35040 & - \\
\hline 22 & 86136 & 4.82639 & 0.35040 & - \\
\hline \multicolumn{5}{|c|}{ Section 6} \\
\hline 23 & 86137 & 217.18700 & 15.76778 & - \\
\hline 24 & 86138 & 217.18700 & 15.76778 & - \\
\hline
\end{tabular}


Table 3. Hemispherical region and sections $2-3$ of cold source aluminum subdivided cell descriptions

\begin{tabular}{|c|c|c|c|c|}
\hline Identifier & Cell & $\begin{array}{c}\text { Volume } \\
\left(\mathrm{cm}^{3}\right)\end{array}$ & $\begin{array}{l}\text { Mass } \\
\text { (g) }\end{array}$ & $\begin{array}{l}\text { Angle } \\
\text { (deg.) }\end{array}$ \\
\hline \multicolumn{5}{|c|}{ Hemisphere } \\
\hline 1 & 86021 & 2.27333 & 6.13799 & 15.0 \\
\hline 2 & 86022 & 2.27333 & 6.13799 & 45.0 \\
\hline 3 & 86023 & 2.27333 & 6.13799 & 75.0 \\
\hline 4 & 86024 & 2.27333 & 6.13799 & 105.0 \\
\hline 5 & 86025 & 2.27333 & 6.13799 & 135.0 \\
\hline 6 & 86026 & 2.27333 & 6.13799 & 165.0 \\
\hline 7 & 86027 & 2.27333 & 6.13799 & 195.0 \\
\hline 8 & 86028 & 2.27333 & 6.13799 & 225.0 \\
\hline 9 & 86029 & 2.27333 & 6.13799 & 255.0 \\
\hline 10 & 86030 & 2.27333 & 6.13799 & 285.0 \\
\hline 11 & 86031 & 2.27333 & 6.13799 & 315.0 \\
\hline 12 & 86032 & 2.27333 & 6.13799 & 345.0 \\
\hline \multicolumn{5}{|c|}{ Section 2} \\
\hline 13 & 86041 & 1.99551 & 5.38788 & 22.5 \\
\hline 14 & 86042 & 2.58831 & 6.98844 & 67.5 \\
\hline 15 & 86043 & 2.58831 & 6.98844 & 112.5 \\
\hline 16 & 86044 & 1.99551 & 5.38788 & 157.5 \\
\hline 17 & 86045 & 1.99551 & 5.38788 & 202.5 \\
\hline 18 & 86046 & 2.58831 & 6.98844 & 247.5 \\
\hline 19 & 86047 & 2.58831 & 6.98844 & 292.5 \\
\hline 20 & 86048 & 1.99551 & 5.38788 & 337.5 \\
\hline \multicolumn{5}{|c|}{ Section 3} \\
\hline 21 & 86061 & 3.66475 & 9.89483 & 22.5 \\
\hline 22 & 86062 & 3.66475 & 9.89483 & 67.5 \\
\hline 23 & 86063 & 3.66475 & 9.89483 & 112.5 \\
\hline 24 & 86064 & 3.66475 & 9.89483 & 157.5 \\
\hline 25 & 86065 & 3.66475 & 9.89483 & 202.5 \\
\hline 26 & 86066 & 3.66475 & 9.89483 & 247.5 \\
\hline 27 & 86067 & 3.66475 & 9.89483 & 292.5 \\
\hline 28 & 86068 & 3.66475 & 9.89483 & 337.5 \\
\hline
\end{tabular}


Table 4. Cold source aluminum regions beyond section 3 cell descriptions

\begin{tabular}{cccc}
\hline Identifier & Cell & $\begin{array}{c}\text { Volume } \\
\left.\mathbf{( c m}^{3}\right)\end{array}$ & $\begin{array}{c}\text { Mass } \\
\mathbf{( g )}\end{array}$ \\
\hline 29 & 86083 & 17.30090 & 46.71243 \\
30 & 86084 & 17.30090 & 46.71243 \\
31 & 86085 & 3.13850 & 8.47395 \\
32 & 86086 & 3.13850 & 8.47395 \\
33 & 86111 & 15.17320 & 40.96764 \\
34 & 86112 & 15.17320 & 40.96764 \\
35 & 86113 & 4.69875 & 12.68663 \\
36 & 86114 & 4.69875 & 12.68663 \\
37 & 86145 & 2.53774 & 6.85190 \\
38 & 86146 & 2.53774 & 6.85190 \\
39 & 86155 & 0.43096 & 1.16359 \\
40 & 86156 & 0.43096 & 1.16359 \\
41 & 86157 & 58.17930 & 157.08411 \\
42 & 86158 & 58.17930 & 157.08411 \\
\hline
\end{tabular}





\section{METHODS}

\subsection{NUCLEAR DATA}

The MCNP calculations made use of the ENDF/B-VII.0 cross sections. A modified version of the ENDF/B-VII.0 cross section library for ${ }^{27} \mathrm{Al}$, which is documented in [15], was created for these studies to include the $1.779 \mathrm{MeV}$ photon associated with the decay of ${ }^{28} \mathrm{Al}$ atoms that are created by neutron absorption in ${ }^{27} \mathrm{Al}$. Previous calculations [2-4] made use of a modified ${ }^{27} \mathrm{Al}$ cross section library based on ENDF/B-V data. The newly constructed library (based on ENDF/B-VII.0) was created and tested in a manner similar to that used for the previous library (based on ENDF/B-V) [16].

When the stable ${ }^{27} \mathrm{Al}$ isotope captures a neutron, an ${ }^{28} \mathrm{Al}$ nucleus is produced. Aluminum-28 has a half-life of about 2.24 minutes [17] and undergoes beta decay, creating an excited ${ }^{28} \mathrm{Si}$ nucleus that emits a photon as it decays to a stable state:

$$
{ }_{0}^{1} n+{ }_{13}^{27} A l \rightarrow{ }_{13}^{28} A l \rightarrow{ }_{14}^{28} S i+\beta^{-}+\gamma
$$

Because every ${ }^{27} \mathrm{Al}(\mathrm{n}, \gamma){ }^{28} \mathrm{Al}$ reaction produces a photon, the original ${ }^{27} \mathrm{Al}$ photon production cross sections were modified by adding the ${ }^{27} \mathrm{Al}(\mathrm{n}, \gamma)^{28} \mathrm{Al}$ cross section to the original photon production cross section:

$$
\sigma_{p p}^{\text {modified }}=\sigma_{p p}^{\text {original }}+\sigma_{(n, \gamma)}
$$

An additional photon production reaction was added to the ENDF/B-VII.0 library and was defined such that a $1.7791 \mathrm{MeV}$ photon would be emitted from the location of neutron capture in ${ }^{27} \mathrm{Al}$. Thus, the delayed photons are treated as regular secondary photons and are transported in the MCNP runs to determine where in the system their energy will be deposited. Using this cross section library eliminates the need to perform activation calculations in a code like the SCALE Oak Ridge Isotope Generation code (ORIGEN) [12] to generate a photon source distribution for use in a follow-on MCNP fixed source photon run.

According to the National Nuclear Data Center [17], the energy of the emitted photon is $1.77885 \pm$ $0.00003 \mathrm{MeV}$, and a value of $1.7791 \mathrm{MeV}$ was used here. This difference of $0.014 \%$ in energy has negligible impact on the results. Verification calculations and more details on the construction of this library are provided in [15].

Under standard temperature and pressure conditions, hydrogen gas is $75 \%$ orthohydrogen and $25 \%$ parahydrogen. However at lower temperatures, the equilibrium state is composed of more parahydrogen. The cold source $\mathrm{LH}_{2}$ is specified as a mixture of $65 \%$ orthohydrogen and $35 \%$ parahydrogen with a density of $0.0726 \mathrm{~g} / \mathrm{cm}^{3}$, which is consistent with previous cold source heat generation rate calculations [2-4]. In these previous calculations, unreleased (at the time) cross sections for the $\mathrm{LH}_{2}$ based on the LANL evaluation of the Institut für Kernenergetik und Energiesysteme (IKE) data from Germany were used. The calculations performed and documented here used the ENDF/B-VII.0 cross sections.

Parametric studies were performed to compare the average nuclear heat generation rates in the $\mathrm{LH}_{2}$ for a calculation using the IKE cross sections to one using the ENDF/B-VII.0 cross sections. Differences of $0.37 \%$ and $0.14 \%$, respectively, were calculated for neutron and photon heating. This and other method development calculations are described in more detail in the Appendix. 


\subsection{NEUTRON FLUX}

For each of the MCNP runs, the neutron fluxes were tabulated in a three-energy group structure with the upper energy boundaries being $6.25 \times 10^{-07}, 0.100$, and $20.0 \mathrm{MeV}$ and calculated with track length estimate of neutron cell flux tallies (F4:N). The units of a cell flux tally result are particles per $\mathrm{cm}^{2}$ per starting particle, and the physical quantity calculated by MCNP is given by [9]

$$
\bar{\phi}_{V}=\frac{1}{V} \int d E \int d t \int d V \int d \Omega \psi(\vec{r}, \widehat{\Omega}, E, t)
$$

where

$$
\begin{aligned}
& \bar{\phi}_{V} \quad=\text { volume averaged flux in the cell }\left(\text { particles } / \mathrm{cm}^{2}\right) \text {, } \\
& V \quad=\text { volume of the cell }\left(\mathrm{cm}^{3}\right) \text {, } \\
& \psi(\vec{r}, \widehat{\Omega}, E, t)=\text { angular flux (particles } / \mathrm{cm}^{2} / \mathrm{sh} / \mathrm{MeV} / \text { steradian), } \\
& \vec{r}=\text { position vector }(\mathrm{cm}) \text {, } \\
& \widehat{\Omega} \quad=\text { direction vector, } \\
& \text { E } \quad \text { energy }(\mathrm{MeV}) \text {, } \\
& t \quad=\text { time }\left(\mathrm{sh} ; 1 \mathrm{sh}=10^{-8} \mathrm{~s}\right) \text {. }
\end{aligned}
$$

MCNP tallies are normalized per starting particle (i.e., per source fission neutron), and therefore, the tally results must be multiplied by the fission neutron source strength. The fission neutron source strength is defined by

$$
\operatorname{Sn}\left(\frac{\text { fission neutrons }}{\text { second }}\right)=\frac{P(W) \times \bar{v}(n / \text { fission })}{e(J / M e V) \times Q(M e V / f i s s i o n) \times k_{e f f}} .
$$

In the source strength equation, $P$ is the reactor power in watts, $\bar{v}$ is the average number of neutrons produced per fission reaction, $e$ is a unit conversion factor $\left(1.602177 \times 10^{-13} \mathrm{~J} / \mathrm{MeV}\right)$, and $Q$ is the average recoverable energy. A value of $200.7 \mathrm{MeV} /$ fission was used here as the average recoverable energy. Values of 2.440 and 2.456, respectively, were used for the average number of neutrons produced per fission for the HEU and LEU cores. Thus, source strengths of $6.44987 \times 10^{18}$ and $7.63784 \times 10^{18} \mathrm{~s}^{-1}$, respectively, were used for the 85 MW HEU and 100 MW LEU cases.

\subsection{PROMPT RADIATION HEAT DEPOSITION}

Track length estimate of energy deposition tallies (type 6) are used to calculate the neutron, (F6:N), photon (F6:P), or combined neutron plus photon (F6:N,P) energy deposition. For these studies, the neutron and photon tallying were performed separately to assess the importance of each with respect to the total energy deposition.

The units corresponding to the F6 tally are megaelectron volts per gram and the desired units are watts per gram, so the tally multiplier required for these tallies is the product of the source strength $\left(\mathrm{s}^{-1}\right)$ and the unit conversion factor $1.602177 \times 10^{-13} \mathrm{~W}$-s/MeV. The physical quantity calculated by MCNP for the track length estimate of energy deposition tally is given as [9]

$$
H_{t}=\frac{\rho_{a}}{m} \int d E \int d t \int d V \int d \Omega \sigma_{t}(E) H(E) \psi(\vec{r}, \widehat{\Omega}, E, t)
$$


where

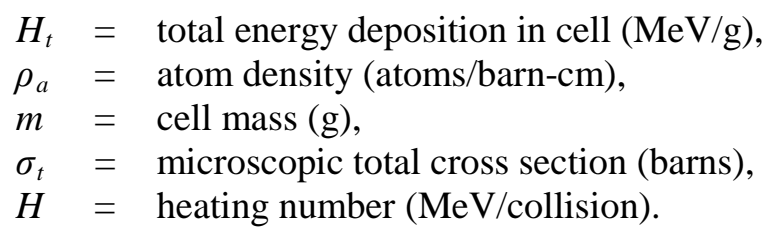

Energy deposition as calculated with the F6: $\mathrm{N}$ tally accounts for the kinetic energy of neutrons and fission products deposited in the cell being tallied on. Fission products are not transported and thus deposit their energy in the fuel regions. Neutrons are transported and deposit their kinetic energy throughout the system. Energy deposition due to prompt photons released following a fission event and capture photons emitted following a neutron capture event (if photon production data are available for the isotope) are tallied when using the F6:P tally. As previously described, the $1.779 \mathrm{MeV}^{28} \mathrm{Si}$ photon is treated as a regular secondary photon and is thus also accounted for in the F6:P tally.

\subsection{DELAYED PHOTON HEAT DEPOSITION}

Delayed fission product photons from the decay of fission products are not included in MCNP photon production cross sections, so the delayed photon source is typically determined from a separate calculation with a code like ORIGEN. Then a second MCNP calculation is run in photon transport only mode with the delayed source specified. Previous cold source calculations [2-4] used a specialized ${ }^{235} U$ cross section library based on ENDF/B-V data which was modified to include the energy dependent delayed fission product photons as regular secondary photons. Although this cross section library is very useful, it underestimates the heat generation rates due to decay photons, and it is based on the older ENDF/B-V data. Also, it only accounts for delayed ${ }^{235} \mathrm{U}$ fissions, which is sufficient for the HEU calculations but not for the LEU calculations.

The approach used to calculate the delayed photon heat generation rates in the calculations documented in this report was first adopted in [15] and [18] for HFIR analysis and is based on [19] and [20]. The photon heating tallies previously described (F6:P) were used to calculate the photon heat generation rates due to the prompt photons. The ENDF Q-values for delayed photons and prompt photons are 6.33 and $6.97 \mathrm{MeV} /$ fission, respectively. Assuming the delayed photon energy spectrum is the same as that of the prompt photon energy spectrum, then the spatially dependent energy deposition will be the same. Therefore, the delayed photon energy deposition can be calculated by multiplying the prompt photon energy deposition by the ratio of the delayed Q-value to the prompt Q-value:

$$
H_{d \gamma}=H_{p \gamma}\left(\frac{Q_{d \gamma}}{Q_{p \gamma}}\right)=H_{p \gamma}\left(\frac{6.33}{6.97}\right)
$$

The pikmt photon-production bias card is used to observe the heat deposition due to fission reactions only with biasing the neutron-induced photons. The following pikmt card was used for the HEU calculations.

pikmt 92235.701180011

For this particular example, the photon from ZAID $92235.70\left({ }^{235} \mathrm{U}\right.$ ENDF/B-VII.0 cross section library) will be produced from fission only (the MT reaction identifier 18001). No photons are produced from any other isotopes in the problem. It is valid to only use the ${ }^{235} \mathrm{U}$ isotope for the HEU core pikmt inputs because ${ }^{235} \mathrm{U}$ dominates the fission process in the HEU core, the ${ }^{238} \mathrm{U}$ content is very small, and the plutonium build-in is very low (see Table 18 in [1]). 
Due to the increased loading of ${ }^{238} \mathrm{U}$ in the LEU core and the increased build-in of the plutonium isotopes, additional isotopes were added to the pikmt card used for the LEU calculations. The following pikmt card was used for the LEU calculations.

$\begin{array}{ccccc}\text { pikmt } & 92234.70 & 1 & 18001 & 1 \\ 92235.70 & 1 & 18001 & 1 \\ 92236.70 & 1 & 18001 & 1 \\ 92238.70 & 1 & 18001 & 1 \\ 92237.70 & 1 & 18001 & 1 \\ 93237.70 & 1 & 18001 & 1 \\ 94239.70 & 1 & 18001 & 1 \\ 94240.70 & 1 & 18001 & 1 \\ 94241.70 & 1 & 18001 & 1\end{array}$

The pikmt method requires two MCNP runs to calculate the heat deposition in the cold source regions: a standard run to calculate the heat deposition due to neutrons, beta particles, prompt photons, and capture photons and a pikmt run to calculate the heat deposition due to delayed photons (with inference of the prompt photon heat deposition).

\subsection{DELAYED BETA HEAT DEPOSITION}

As previously described, neutron capture in ${ }^{27} \mathrm{Al}$ results in the formation of an ${ }^{28} \mathrm{Al}$ nucleus (2.24 min half-life), which undergoes beta decay, creating an excited ${ }^{28} \mathrm{Si}$ nucleus that gives off a photon as it relaxes to the ground state. The average beta energy is $1.247 \mathrm{MeV}$, and because beta radiation has very little penetrating power and can be stopped by a few millimeters of aluminum, it is assumed that all of its energy is deposited at the site of interaction (i.e., locally deposited). Beta heating rates in the aluminum regions were calculated with track length estimate of neutron cell flux tallies (F4:N) that were described previously.

For the 85 MW HEU and 100 MW LEU cases, tally multipliers of $2.87610 \times 10^{4}$ and $3.40584 \times 10^{4}$ $\left(\mathrm{W}-\mathrm{cm}^{2}\right) /\left(\right.$ barn-gram), respectively, were used with the ${ }^{27} \mathrm{Al}(\mathrm{n}, \gamma){ }^{28} \mathrm{Al}$ ENDF/B-VII.0 capture cross sections (MT 102). The tally multipliers were calculated as follows:

$\beta$ heating in Al tally multiplier

$$
\begin{aligned}
& =\operatorname{Sn}\left(\frac{1}{S}\right)\left(\frac{1.602177 \times 10^{-13} W-s}{M e V}\right)\left(\frac{0.602214 \mathrm{~cm}^{2}}{\text { barn }- \text { mole }}\right)\left(\frac{\text { mole }}{26.982 g}\right)\left(\frac{1.247 \mathrm{MeV}}{\beta \text { decay }}\right) \\
& =4.45917 \times 10^{-15}(\mathrm{Sn})\left(\frac{W-\mathrm{cm}^{2}}{\text { barn }-\mathrm{g}}\right) .
\end{aligned}
$$

Therefore, the beta heating in aluminum was estimated as follows:

$$
H_{\beta}=4.45917 \times 10^{-15}(S n)\left[\int \sigma_{n, \gamma}(E) \phi(E) d E\right](W / g) .
$$

\subsection{SILICON PRODUCTION RATES}

Silicon production rates [1/(g-s)] were calculated in the aluminum regions using type 4 tallies and the ${ }^{27} \mathrm{Al}(\mathrm{n}, \gamma){ }^{28} \mathrm{Al}$ ENDF/B-VII.0 cross sections (MT 102). The silicon production rates were calculated similarly to the beta energy deposition rates, but a different multiplier was used. The tally multipliers used to calculate the silicon production rates were calculated as follows: 


$$
\begin{aligned}
& \text { Si production in Al tally multiplier }=\operatorname{Sn}\left(\frac{1}{S}\right)\left(\frac{0.602214 \mathrm{~cm}^{2}}{\text { barn }- \text { mole }}\right)\left(\frac{\text { mole }}{26.982 \mathrm{~g}}\right) \\
& =2.23191 \times 10^{-02}(\mathrm{Sn})\left(\frac{\mathrm{cm}^{2}}{\text { barn }-\mathrm{g}}\right) .
\end{aligned}
$$

Therefore, the silicon production rate was estimated as follows:

$$
S i=2.23191 \times 10^{-02}(S n)\left[\int \sigma_{n, \gamma}(E) \phi(E) d E\right]\left(\frac{1}{g-s}\right) .
$$

\subsection{MATHEMATICAL FITS}

The spatially dependent specific heat generation rates were fit with the various mathematical functions as described in [4] for use in follow-on heat transfer and thermal hydraulics calculations. A mathematical function was generated for the first three $\mathrm{LH}_{2}$ zones. The first zone is the hemispherical shell plus the cylindrical shell between 11.43 and $11.55446 \mathrm{~cm}$ from the beam tube origin. The second zone is the annular region between 11.55446 and $15.09268 \mathrm{~cm}$ from the beam tube origin, and the third zone is the annular region between 15.09268 and $19.05 \mathrm{~cm}$ from the beam tube origin. Similarly, functions were generated for the first three cold source aluminum zones.

For the $\mathrm{LH}_{2}$ hemispherical region, the heat generation rate is defined as a function of both radial and angular position. The spatially dependent heat generation rates for the other $\mathrm{LH}_{2}$ zones and all of the cold source aluminum zones are defined as a function of angle only. Linear least square methods were used with the MATLAB programming language to solve for the coefficients in the equations describing the various regions as listed below.

\section{$\mathrm{LH}_{2}$ Hemisphere}

$$
\begin{aligned}
\mathrm{H}_{\mathrm{x}}(\mathrm{W} / \mathrm{g})= & \mathrm{C}_{1, \mathrm{x}}+\mathrm{C}_{2, \mathrm{x}} \mathrm{r} \cos (\theta)+\mathrm{C}_{3, \mathrm{x}} \mathrm{r} \sin (\theta)+\mathrm{C}_{4, \mathrm{x}} \mathrm{r} \sin (\theta) \cos (\theta)+\mathrm{C}_{5, \mathrm{x}} \mathrm{r}^{2} \cos (2 \theta)+\mathrm{C}_{6, \mathrm{x}} \mathrm{r}^{2} \sin (2 \theta)+ \\
& \mathrm{C}_{7, \mathrm{x}} \mathrm{r}^{2} \sin (2 \theta) \cos (2 \theta)+\mathrm{C}_{8, \mathrm{x}} \mathrm{r}+\mathrm{C}_{9, \mathrm{x}} \mathrm{r}^{2}+\mathrm{C}_{10, \mathrm{x}} \mathrm{r} \cos (2 \theta)+\mathrm{C}_{11, \mathrm{x}} \mathrm{r}^{3} \cos (\theta) \cos (2 \theta)+ \\
& \mathrm{C}_{12, \mathrm{x}} \mathrm{r}^{3} \cos (\theta) \sin (2 \theta)+\mathrm{C}_{13, \mathrm{x}} \mathrm{r}^{3} \sin (\theta) \cos (2 \theta)+\mathrm{C}_{14, \mathrm{x}} \mathrm{r}^{3} \sin (\theta) \sin (2 \theta)
\end{aligned}
$$

\section{Other Fitted Regions}

$\mathrm{H}_{\mathrm{x}}(\mathrm{W} / \mathrm{g})=\mathrm{C}_{1, \mathrm{x}}+\mathrm{C}_{2, \mathrm{x}} \cos (\theta)+\mathrm{C}_{3, \mathrm{x}} \sin (\theta)+\mathrm{C}_{4, \mathrm{x}} \cos (2 \theta)+\mathrm{C}_{5, \mathrm{x}} \sin (2 \theta)$

where

$\mathrm{x}$ denotes the heating type (neutron, beta, photon, or total),

$\mathrm{C}_{1}-\mathrm{C}_{\mathrm{i}}$ are the fitting coefficients,

$r$ is the radius ( $r=0$ is $11.43 \mathrm{~cm}$ from the HB-4 origin),

$\theta$ is the angle measured from a vector parallel to the radius vector from the core center to the beam tube origin. 



\section{RESULTS}

\subsection{SUMMARY OF MCNP RUNS}

A total of eight MCNP calculations were run to determine the specific nuclear heat generation rates for BOC and EOC 85 MW HEU and 100 MW LEU cores. Two MCNP runs were required for each combination (4 combinations): a standard run to determine the energy deposition due to neutrons, betas, prompt photons, and capture photons and a pikmt run to determine the delayed photon energy deposition.

For all calculations except the two EOC pikmt cases, 1.0 billion active histories were run (5,050 cycles, 200,000 source particles per cycle, and 50 cycles to be skipped before tally accumulation). The two EOC pikmt cases used 750 million active histories (3,800 cycles, 200,000 source particles per cycle, and 50 cycles to be skipped before tally accumulation). Fewer histories were used for the EOC pikmt cases because EOC calculations take longer than BOC calculations and pikmt calculations take longer than standard calculations. Therefore, the EOC pikmt calculations require the most computational time. Also, it was determined that 750 million histories yielded satisfactory statistics for the delayed photon energy deposition calculations. A summary of the eight calculations is provided in Table 5.

Table 5. Summary of MCNP calculations

\begin{tabular}{ccccccccc}
\hline $\begin{array}{c}\text { FP } \\
\text { (MW) }\end{array}$ & Core & Condition & Case & CPUs & $\begin{array}{c}\text { Clock } \\
\text { time (d) }\end{array}$ & $\begin{array}{c}\text { Active } \\
\text { histories }\end{array}$ & $\mathbf{k}_{\text {eff }}$ & $\boldsymbol{\sigma}_{\text {keff }}$ \\
\hline 85 & HEU & BOC & standard & 24 & 1.63 & $1.00 \mathrm{E}+09$ & 0.99716 & 0.00003 \\
85 & HEU & BOC & pikmt & 28 & 2.08 & $1.00 \mathrm{E}+09$ & 0.99720 & 0.00003 \\
85 & HEU & EOC & standard & 32 & 2.53 & $1.00 \mathrm{E}+09$ & 1.00132 & 0.00003 \\
85 & HEU & EOC & pikmt & 24 & 3.85 & $7.50 \mathrm{E}+08$ & 1.00129 & 0.00003 \\
100 & LEU & BOC & standard & 24 & 1.70 & $1.00 \mathrm{E}+09$ & 0.99978 & 0.00003 \\
100 & LEU & BOC & pikmt & 32 & 1.76 & $1.00 \mathrm{E}+09$ & 0.99980 & 0.00003 \\
100 & LEU & EOC & standard & 32 & 2.65 & $1.00 \mathrm{E}+09$ & 0.99819 & 0.00003 \\
100 & LEU & EOC & pikmt & 32 & 2.63 & $7.50 \mathrm{E}+08$ & 0.99817 & 0.00003 \\
\hline
\end{tabular}

\subsection{BEGINNING-OF-CYCLE HEAT GENERATION RESULTS}

As previously mentioned, the specific nuclear heat generation rates have been calculated for BOC and EOC conditions to bound typical cycle conditions. The specific heat generation rates in the cold source $\mathrm{LH}_{2}$ and aluminum regions have been calculated for the HEU core operating at an FP of $85 \mathrm{MW}$ and for the reference LEU core operating at an FP of $100 \mathrm{MW}$ in units of watts per gram. For all of the regions of interest, line plots are provided for each of the heat deposition constituents (i.e., neutron heating, photon heating, and beta heating) and for the total heating rates:

$$
\mathrm{H}_{\text {total }}(\mathrm{W} / \mathrm{g})=\mathrm{H}_{\beta}+\mathrm{H}_{\mathrm{n}}+\mathrm{H}_{\gamma} \text {, }
$$

where

$\mathrm{H}_{\beta}$ is the heat deposition due to beta radiation (only for the aluminum regions),

$\mathrm{H}_{\mathrm{n}}$ is the heat deposition due to neutrons,

$\mathrm{H}_{\gamma}$ is the heat deposition due to photons (prompt + capture + delayed),

$\mathrm{H}_{\gamma}=\mathrm{H}_{\gamma(\mathrm{p}+\mathrm{c})}+\mathrm{H}_{\gamma \mathrm{d}}$. 
The BOC total heat generation rates and the heat generation rates by the various radiation types in the cold source $\mathrm{LH}_{2}$ hemispherical region are shown in Fig. 4. (Refer to Table 1 for brief descriptions of the 36 cells composing the cold source $\mathrm{LH}_{2}$ hemispherical region.) As shown in Fig. 4, the total heat generation rate in these cells varies from about 9 to about $19 \mathrm{~W} / \mathrm{g}$ for the two cores. Heat generation rates in sections $2-6$ of the cold source $\mathrm{LH}_{2}$ are illustrated in Fig. 5.

Both Fig. 4 and Fig. 5 show that neutron energy deposition is greater than photon energy deposition in the cold source $\mathrm{LH}_{2}$ regions for both fuel types. For the BOC configuration, the neutron energy deposition rates are greater for the LEU core and the photon energy deposition rates are greater for the HEU core. The total heat generation rates for the $\mathrm{LH}_{2}$ regions due to each fuel type are comparable, but on average, they are slightly greater for the LEU core.

It is also important to note the critical CE positions differ for the HEU core and the LEU core. The startup critical CE position for the LEU core is $19.5 \mathrm{in}$. in comparison to $18.0 \mathrm{in}$. for the HEU core. This difference in position increases the distance between the CHM and the absorbing regions of the CEs, thus increasing the probability of neutrons leaking from the core into the reflector and cold source regions.

As shown in Table 6, the average BOC heat generation rates in the hemispherical region of the cold source $\mathrm{LH}_{2}$ for the HEU and LEU cores are 12.76 and $12.92 \mathrm{~W} / \mathrm{g}$, respectively. A comparison of the $\mathrm{LH}_{2}$ radiation-dependent heat generation rates for the HEU core and the LEU core is provided in Table 7. On average, the BOC heat generation rates in the cold source $\mathrm{LH}_{2}$ regions for the $100 \mathrm{MW}$ LEU core are about $1 \%$ greater than those for the 85 MW HEU core.

The BOC total heat generation rates and the heat generation rates by the various radiation types in the cold source aluminum regions are shown in Fig. 6. (Refer to Table 3 and Table 4 for brief descriptions of cells composing the cold source aluminum regions addressed in this figure.) As shown in Fig. 6, the maximum total heat generation rates in these cells are about $3.9 \mathrm{~W} / \mathrm{g}$ and $3.4 \mathrm{~W} / \mathrm{g}$, respectively, for the HEU and LEU cores.

As shown in Fig. 6, neutron energy deposition is essentially a negligible contributor to the total heat generation rates in aluminum, and most of the energy deposition is due to photon radiation. Beta radiation is a small contributor to the total energy deposition. The beta energy deposition rates are greater for the LEU core, the photon energy deposition rates are greater for the HEU core, and the total heat generation rates for the cold source aluminum regions are greater for the HEU core.

As shown in Table 8, the average BOC heat generation rates in the hemispherical region of the cold source aluminum for the $85 \mathrm{MW} \mathrm{HEU}$ and the $100 \mathrm{MW}$ LEU cores are 3.12 and $2.79 \mathrm{~W} / \mathrm{g}$, respectively. A comparison of the radiation-dependent nuclear heat generation rates in the aluminum regions for the HEU and LEU cores is provided in Table 9. Photon energy deposition contributes about $85 \%$ of the total aluminum heating for the HEU core and $80 \%$ for the LEU core, and beta heating contributes to the majority of the remaining percentage in each case. 


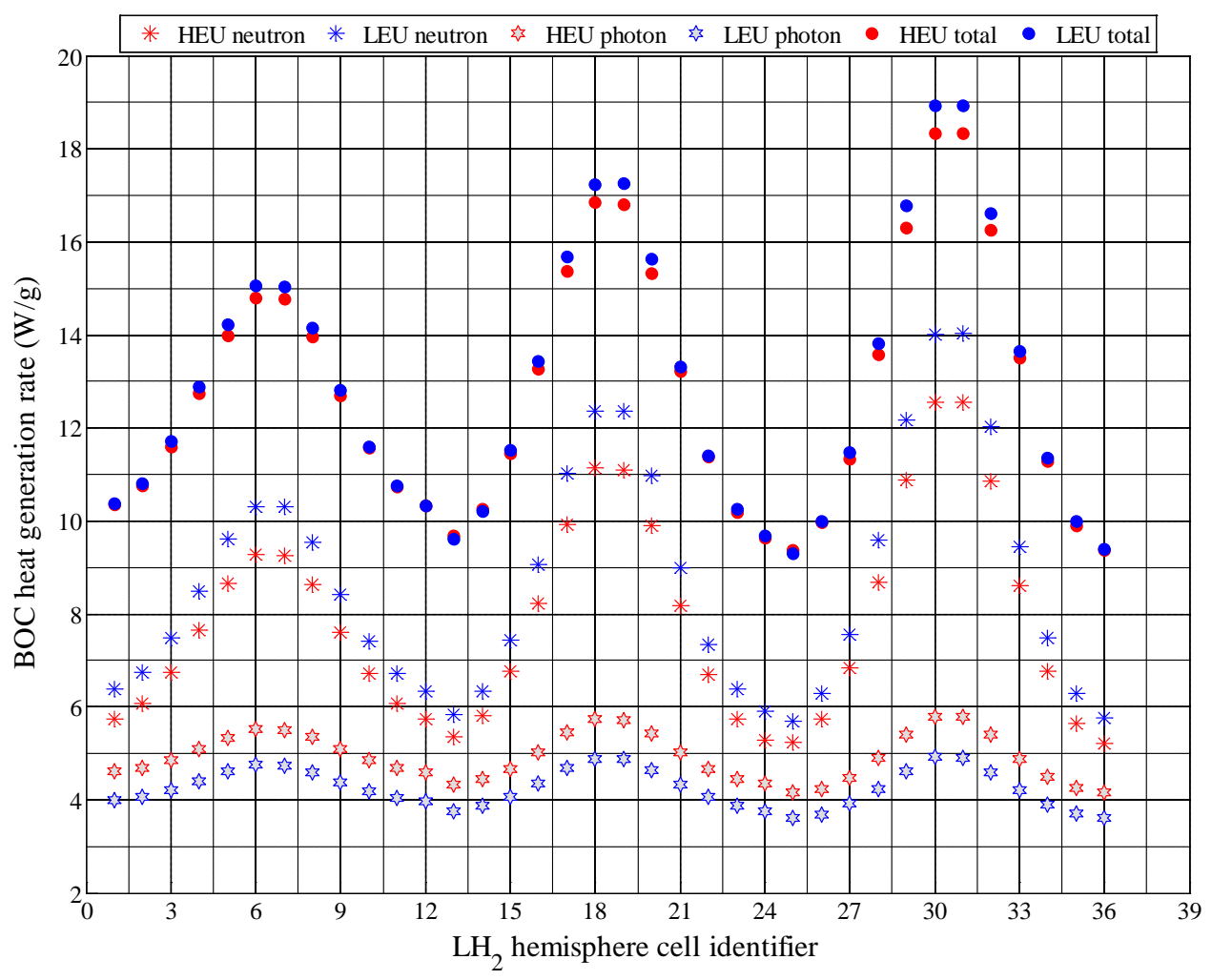

Fig. 4. Beginning-of-cycle heat generation rates in $\mathrm{LH}_{2}$ hemisphere.

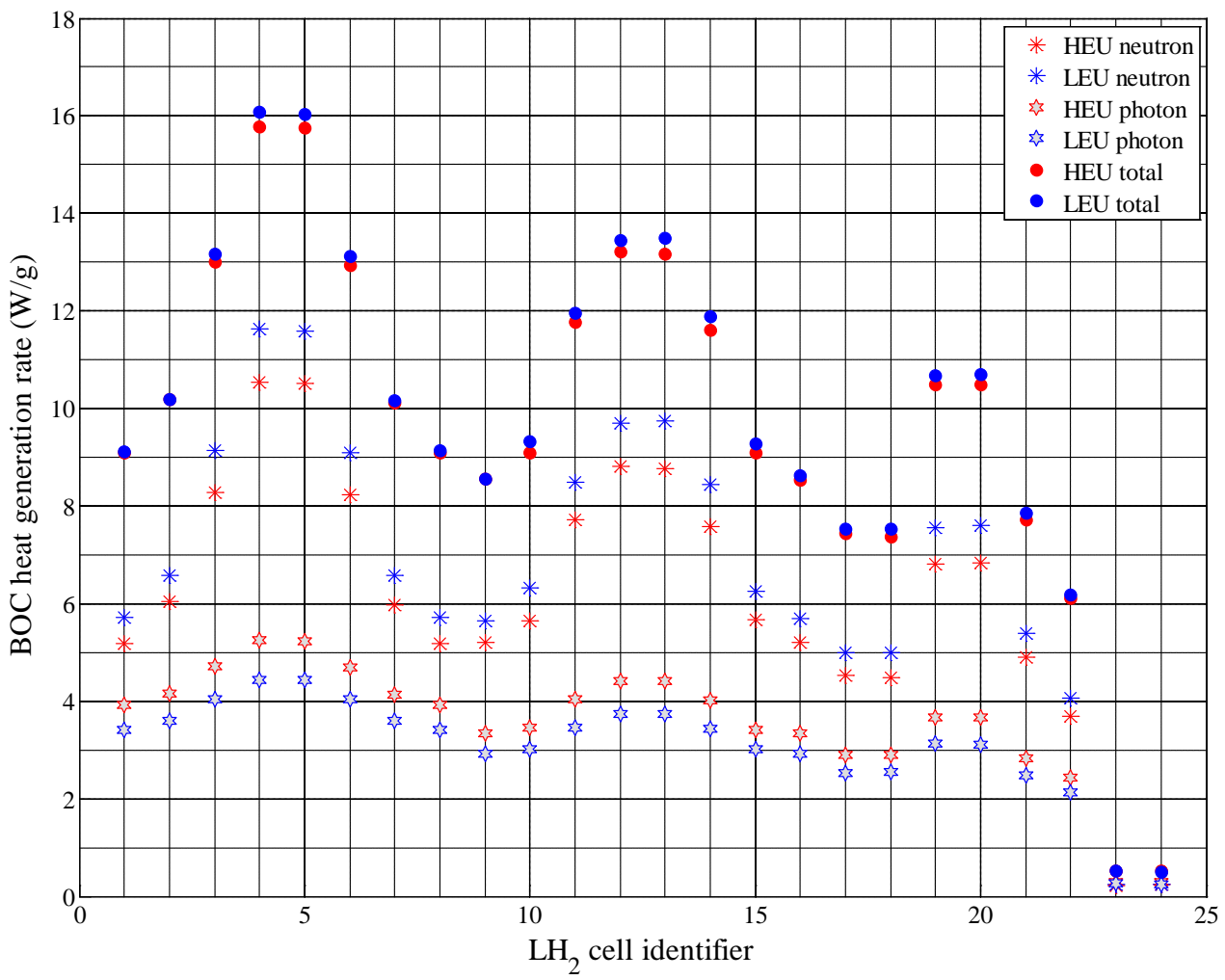

Fig. 5. Beginning-of-cycle heat generation rates in $\mathrm{LH}_{2}$ sections 2-6. 
Table 6. Beginning-of-cycle total heat generation rate summary for the cold source $\mathrm{LH}_{2}$ regions

\begin{tabular}{|c|c|c|c|c|c|c|}
\hline \multirow{2}{*}{ Cold source $\mathrm{LH}_{2}$ region } & \multirow{2}{*}{$\begin{array}{l}\text { Mass } \\
\text { (g) }\end{array}$} & \multicolumn{2}{|c|}{85 MW HEU } & \multicolumn{2}{|c|}{100 MW LEU } & \multirow{2}{*}{$\begin{array}{c}(\mathrm{LEU}-\mathrm{HEU}) / \mathrm{HEU} \\
(\%)\end{array}$} \\
\hline & & $\mathbf{W}^{a}$ & avg. $W / g^{b}$ & $\mathbf{W}$ & avg. W/g & \\
\hline hemispherical part & 16.14 & 205.94 & 12.76 & 208.55 & 12.92 & 1.27 \\
\hline section 2 & 9.77 & 117.81 & 12.06 & 119.17 & 12.20 & 1.15 \\
\hline section 3 & 4.81 & 51.86 & 10.79 & 52.68 & 10.96 & 1.58 \\
\hline section 4 & 2.31 & 20.68 & 8.94 & 21.08 & 9.12 & 1.94 \\
\hline sections 5 \& 6 & 32.24 & 21.13 & 0.66 & 21.02 & 0.65 & -0.52 \\
\hline sum of above & 65.27 & 417.43 & 6.40 & 422.50 & 6.47 & 1.21 \\
\hline
\end{tabular}

${ }^{a} \mathrm{~W}=\sum \mathrm{H}_{\mathrm{i}} \mathrm{M}_{\mathrm{i}}$, where $\mathrm{H}$ is heating rate $(\mathrm{W} / \mathrm{g}), \mathrm{M}$ is mass $(\mathrm{g})$, and $\mathrm{i}=1: \mathrm{N}$ ( $\mathrm{N}$ is the number of cells in the region of interest)

${ }^{b}$ avg. W/g is mass weighted: $\mathrm{H}_{\mathrm{avg}}=\left(\sum \mathrm{H}_{\mathrm{i}} \mathrm{M}_{\mathrm{i}}\right) /\left(\sum \mathrm{M}_{\mathrm{i}}\right)$

Table 7. Beginning-of-cycle radiation-dependent heat generation rate summary for the cold source $\mathrm{LH}_{2}$ regions

\begin{tabular}{lcccc||cc}
\hline \multirow{2}{*}{ Cold source LH } & \multicolumn{2}{c|}{$\mathbf{8 5}$ MW HEU } & \multicolumn{2}{c||}{$\mathbf{1 0 0}$ MW LEU } & \multicolumn{2}{c}{ (LEU-HEU)/HEU } \\
\cline { 2 - 6 } & neutron & photon & neutron & photon & $\begin{array}{c}\text { neutron } \\
\text { (\%) }\end{array}$ & $\begin{array}{c}\text { photon } \\
\text { (\%) }\end{array}$ \\
\hline hemispherical part $\left(\mathrm{W}^{\boldsymbol{a}}\right.$ ) & 126.34 & 79.60 & 139.90 & 68.64 & 10.73 & -13.76 \\
section 2 (W) & 73.72 & 44.10 & 81.27 & 37.89 & 10.25 & -14.07 \\
section 3 (W) & 33.33 & 18.53 & 36.76 & 15.92 & 10.28 & -14.07 \\
section 4 (W) & 13.10 & 7.59 & 14.54 & 6.54 & 11.01 & -13.72 \\
sections 5 \& 6 (W) & 10.36 & 10.78 & 11.31 & 9.71 & 9.20 & -9.87 \\
sum of above (W) & 256.84 & 160.59 & 283.78 & 138.72 & 10.49 & -13.62 \\
percent of total & $61.53 \%$ & $38.47 \%$ & $67.26 \%$ & $32.83 \%$ & 9.16 & -14.66 \\
avg. W/g & 3.94 & 2.46 & 4.35 & 2.13 & 10.49 & -13.62 \\
\hline
\end{tabular}

${ }^{a} \mathrm{~W}=\sum \mathrm{H}_{\mathrm{i}} \mathrm{M}_{\mathrm{i}}$, where $\mathrm{H}$ is heating rate $(\mathrm{W} / \mathrm{g}), \mathrm{M}$ is mass $(\mathrm{g})$, and $\mathrm{i}=1: \mathrm{N}$ ( $\mathrm{N}$ is the number of cells in the region of interest)

${ }^{b}$ avg. W/g is mass weighted: $\mathrm{H}_{\text {avg }}=\left(\sum \mathrm{H}_{\mathrm{i}} \mathrm{M}_{\mathrm{i}}\right) /\left(\sum \mathrm{M}_{\mathrm{i}}\right)$ 


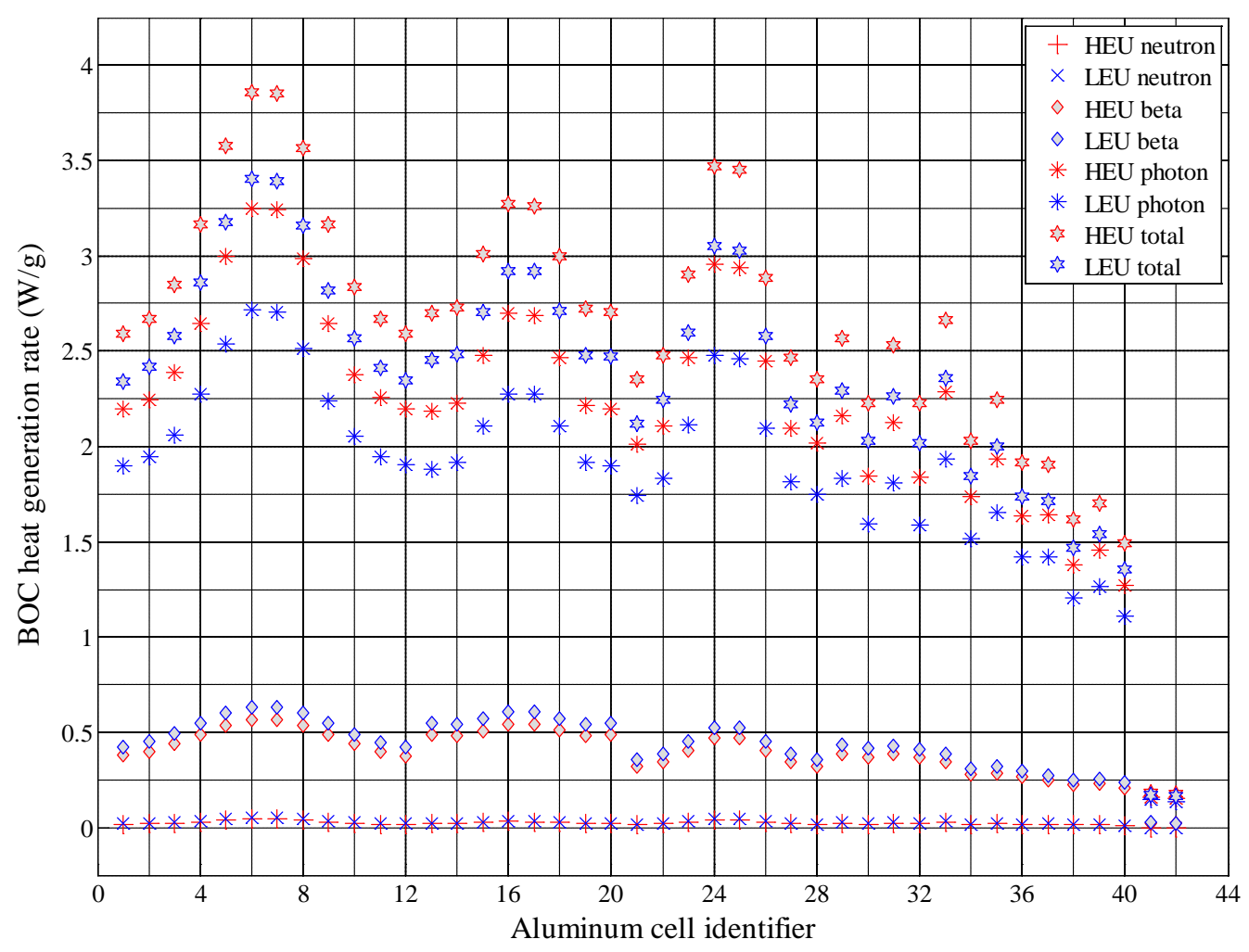

Fig. 6. Beginning-of-cycle heat generation rates in aluminum sections.

Table 8. Beginning-of-cycle total heat generation rate summary for the cold source aluminum regions

\begin{tabular}{|c|c|c|c|c|c|c|}
\hline \multirow{2}{*}{$\begin{array}{l}\text { Cold source } \\
\text { aluminum region }\end{array}$} & \multirow{2}{*}{$\begin{array}{c}\text { Mass } \\
\text { (g) }\end{array}$} & \multicolumn{2}{|c|}{85 MW HEU } & \multicolumn{2}{|c|}{100 MW LEU } & \multirow{2}{*}{$\begin{array}{c}(\text { LEU-HEU)/HEU } \\
(\%)\end{array}$} \\
\hline & & $\mathbf{W}^{a}$ & avg. W/g $\mathbf{g}^{b}$ & $\mathbf{W}$ & avg. W/g & \\
\hline hemispherical part & 73.66 & 229.48 & 3.12 & 205.50 & 2.79 & -10.45 \\
\hline section 2 & 49.51 & 144.43 & 2.92 & 130.54 & 2.64 & -9.62 \\
\hline section 3 & 79.16 & 221.09 & 2.79 & 197.62 & 2.50 & -10.62 \\
\hline beyond section 3 & 547.88 & 593.75 & 1.08 & 535.66 & 0.98 & -9.78 \\
\hline sum of above & 750.20 & 1188.75 & 1.58 & 1069.32 & 1.43 & -10.05 \\
\hline
\end{tabular}

${ }^{a} \mathrm{~W}=\sum \mathrm{H}_{\mathrm{i}} \mathrm{M}_{\mathrm{i}}$, where $\mathrm{H}$ is heating rate $(\mathrm{W} / \mathrm{g}), \mathrm{M}$ is mass $(\mathrm{g})$, and $\mathrm{i}=1: \mathrm{N}$ ( $\mathrm{N}$ is the number of cells in the region of interest)

${ }^{b}$ avg. W/g is mass weighted: $\mathrm{H}_{\text {avg }}=\left(\sum \mathrm{H}_{\mathrm{i}} \mathrm{M}_{\mathrm{i}}\right) /\left(\sum \mathrm{M}_{\mathrm{i}}\right)$ 
Table 9. Beginning-of-cycle radiation-dependent heat generation rate summary for the cold source aluminum regions

\begin{tabular}{lcccccc||ccc}
\hline \multirow{2}{*}{$\begin{array}{l}\text { Cold source aluminum } \\
\text { region }\end{array}$} & \multicolumn{3}{c}{$\mathbf{8 5}$ MW HEU } & \multicolumn{3}{c||}{$\mathbf{1 0 0}$ MW LEU } & \multicolumn{3}{c}{ (LEU-HEU)/HEU } \\
\cline { 2 - 10 } & neutron & photon & beta & neutron & photon & beta & $\begin{array}{c}\text { neutron } \\
\text { (\%) }\end{array}$ & $\begin{array}{c}\text { photon } \\
\text { (\%) }\end{array}$ & $\begin{array}{c}\text { beta } \\
\text { (\%) }\end{array}$ \\
\hline hemispherical part $\left(\mathrm{W}^{\boldsymbol{a}}\right.$ ) & 2.14 & 192.92 & 34.42 & 2.38 & 164.48 & 38.64 & 11.13 & -14.74 & 12.27 \\
section 2 (W) & 1.22 & 118.20 & 25.01 & 1.35 & 101.15 & 28.04 & 10.13 & -14.42 & 12.11 \\
section 3 (W) & 2.11 & 188.47 & 30.52 & 2.32 & 161.14 & 34.16 & 10.05 & -14.50 & 11.95 \\
beyond section 3 (W) & 5.19 & 503.59 & 84.97 & 5.74 & 434.81 & 95.11 & 10.45 & -13.66 & 11.94 \\
sum of above (W) & 10.67 & 1003.17 & 174.91 & 11.79 & 861.59 & 195.95 & 10.47 & -14.11 & 12.03 \\
percent of total & $0.90 \%$ & $84.39 \%$ & $14.71 \%$ & $1.10 \%$ & $80.57 \%$ & $18.32 \%$ & 22.81 & -4.52 & 24.54 \\
avg. W/g & 0.01 & 1.34 & 0.23 & 0.02 & 1.15 & 0.26 & 10.47 & -14.11 & 12.03 \\
\hline
\end{tabular}

${ }^{a} \mathrm{~W}=\sum \mathrm{H}_{\mathrm{i}} \mathrm{M}_{\mathrm{i}}$, where $\mathrm{H}$ is heating rate $(\mathrm{W} / \mathrm{g}), \mathrm{M}$ is mass (g), and $\mathrm{i}=1: \mathrm{N}$ ( $\mathrm{N}$ is the number of cells in the region of interest)

${ }^{b}$ avg. W/g is mass weighted: $\mathrm{H}_{\mathrm{avg}}=\left(\sum \mathrm{H}_{\mathrm{i}} \mathrm{M}_{\mathrm{i}}\right) /\left(\sum \mathrm{M}_{\mathrm{i}}\right)$

\subsection{END-OF-CYCLE HEAT GENERATION RESULTS}

EOC specific nuclear heat generation rates are presented in this section. For both the HEU and LEU cases, the CEs are fully withdrawn. Thus, the aluminum only sections of the CEs are surrounding the fueled section of the core, and the neutron absorbing regions in the outer and inner control elements are respectively situated above and below the fueled section of the core.

The EOC neutron-induced, photon-induced, and total heat generation rates are illustrated in Fig. 7 for the cold source $\mathrm{LH}_{2}$ hemispherical region and in Fig. 8 for sections 2-6 of the cold source $\mathrm{LH}_{2}$. Both figures again show that neutron energy deposition is greater than photon energy deposition in the cold source $\mathrm{LH}_{2}$ regions for both fuel types. For the EOC configuration, the neutron energy deposition rates are still greater for the LEU core and the photon energy deposition rates are still greater for the HEU core, but the total heat generation rates for the $\mathrm{LH}_{2}$ regions are now slightly greater for the HEU core.

As shown in Table 10, the average EOC total heat generation rates in the hemispherical region of the cold source $\mathrm{LH}_{2}$ for the HEU and LEU cores are 13.25 and $12.86 \mathrm{~W} / \mathrm{g}$, respectively. Thus, the EOC heat generation rate in the cold source hemisphere $\mathrm{LH}_{2}$ is about $3.0 \%$ greater for the HEU core compared to the LEU core. The total estimated energy deposition in the 65.27 grams of $\mathrm{LH}_{2}$ in the regions tallied on is 432.8 and 420.3 watts, respectively, for the HEU and LEU cores at EOC.

From BOC to EOC, the total heat generation rate in the cold source hemisphere $\mathrm{LH}_{2}$ increased about $3.8 \%$ for the HEU core and decreased about $0.4 \%$ for the LEU core. The total energy deposition in the $\mathrm{LH}_{2}$ regions increased about $3.7 \%$ for the HEU core and decreased about $0.5 \%$ for the LEU core from BOC to EOC.

A comparison of the radiation-dependent $\mathrm{LH}_{2}$ heat generation rates for the HEU core and the LEU core is provided in Table 11. As shown in this table, the neutron-induced heat generation rates contribute about $58.3 \%$ and $65.4 \%$, respectively, to the total heat generation rate in the $\mathrm{LH}_{2}$ regions for the HEU and LEU cores, and thus photon-induced heat generation rates contribute about $41.7 \%$ and $34.6 \%$, respectively, to the total heat generation rate in the $\mathrm{LH}_{2}$ regions for the $\mathrm{HEU}$ and $\mathrm{LEU}$ cores. The neutron-induced heat generation rates in the cold source $\mathrm{LH}_{2}$ regions for both cores decreased a small amount from BOC to EOC (about 2\% and 3\%, respectively, for the HEU and LEU cores); however, the photon-induced heat generation rates in the $\mathrm{LH}_{2}$ regions for the HEU and LEU cores increased about 5\% and $12 \%$, 
respectively. This large increase in the photon energy deposition rates in the HEU core causes the $\mathrm{LH}_{2}$ total energy deposition to be slightly greater for the HEU core compared to the LEU core at EOC.

As shown in Fig. 9, the EOC total heat generation rates in the cold source aluminum regions are greater when the HEU core is operating than when the reference LEU core is. As described in Section 4.2, photon energy deposition is the dominant heating mechanism in aluminum and neutron energy deposition is a negligible factor.

Table 12 provides a summary of heat generation rates in the cold source aluminum regions, and Table 13 provides a summary of the radiation-dependent heat generation rates. As shown in these tables, the total heat generation rates in the cold source aluminum regions are about 17\% lower for the LEU core in comparison to the HEU core under EOC conditions. The total heat generation rates in these regions increased by about 14\% and 5\%, respectively, for the HEU and LEU cores from BOC to EOC. At EOC, beta-induced energy deposition rates due to the LEU core are estimated to be about $2 \%-3 \%$ greater than those due to the HEU core, but the photon-induced energy deposition rates due to the LEU core are estimated to be about $20 \%-21 \%$ lower than those due to the HEU core.

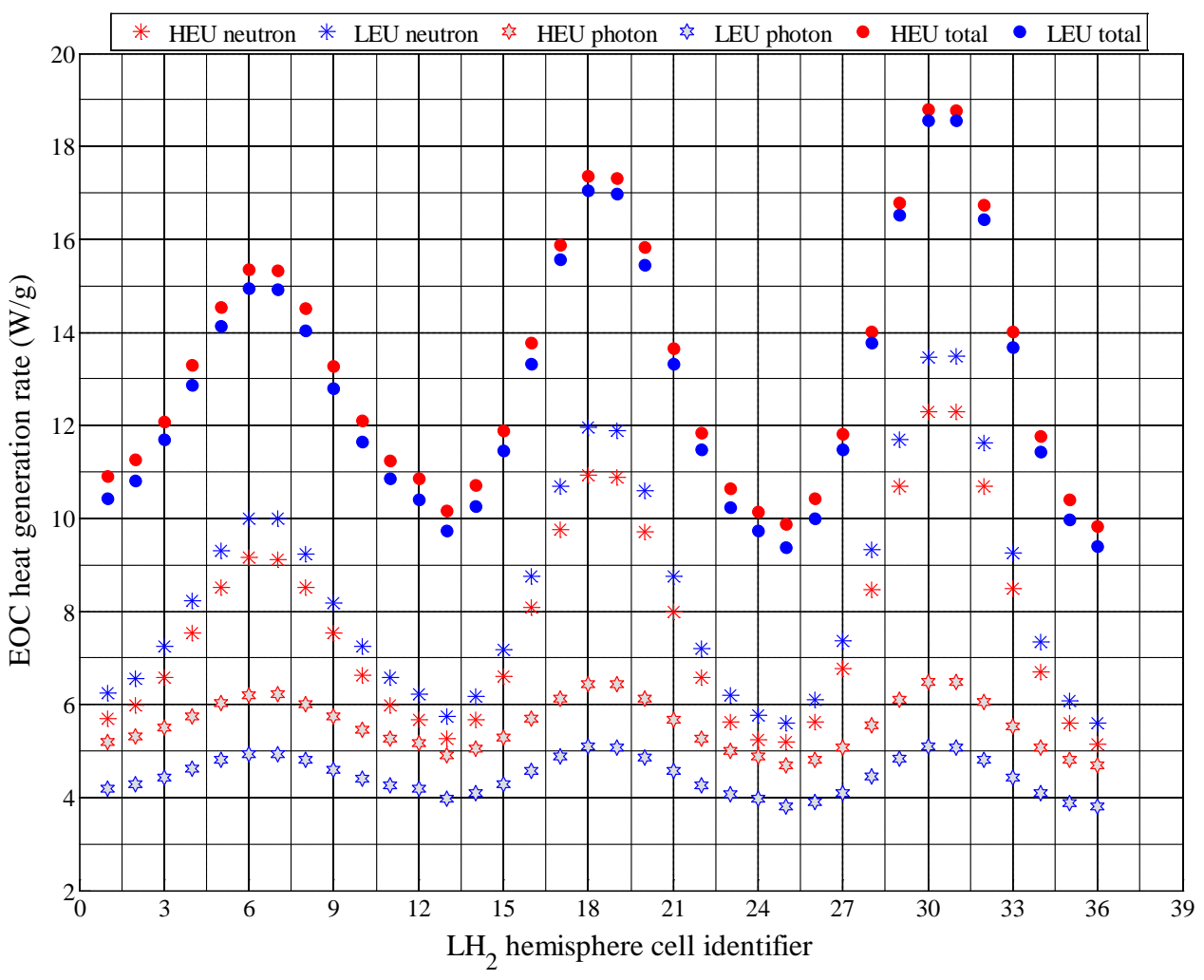

Fig. 7. End-of-cycle heat generation rates in $\mathrm{LH}_{2}$ hemisphere. 


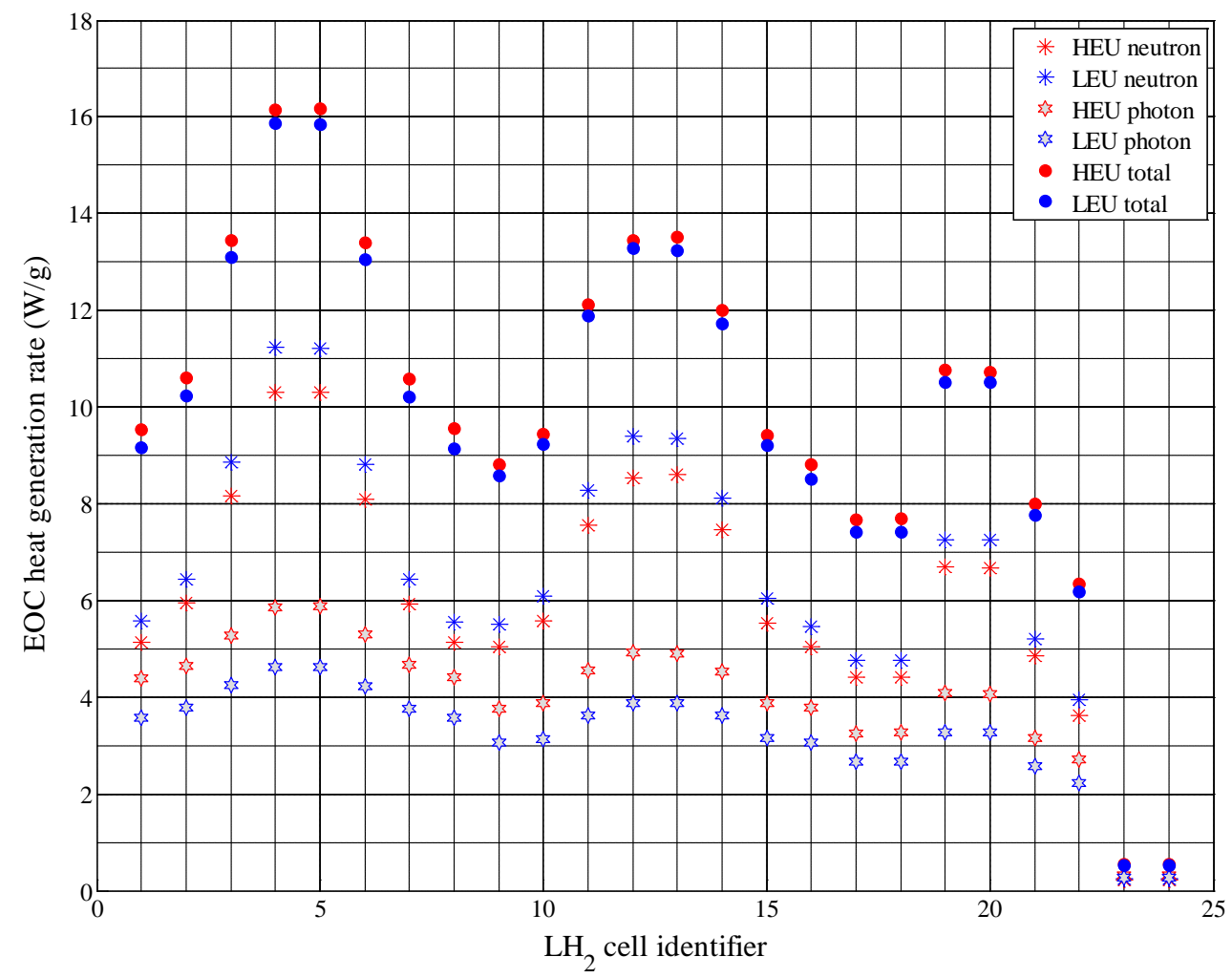

Fig. 8. End-of-cycle heat generation rates in $\mathrm{LH}_{2}$ sections $2-6$.

Table 10. End-of-cycle total heat generation rate summary for the cold source $\mathrm{LH}_{2}$ regions

\begin{tabular}{|c|c|c|c|c|c|c|}
\hline \multirow{2}{*}{ Cold source $\mathrm{LH}_{2}$ region } & \multirow{2}{*}{$\begin{array}{c}\text { Mass } \\
\text { (g) }\end{array}$} & \multicolumn{2}{|c|}{85 MW HEU } & \multicolumn{2}{|c|}{$100 \mathrm{MW}$ LEU } & \multirow{2}{*}{$\begin{array}{c}(\mathrm{LEU}-\mathrm{HEU}) / \mathrm{HEU} \\
(\%)\end{array}$} \\
\hline & & $\mathbf{W}^{a}$ & avg. $W / g^{b}$ & $\mathbf{W}$ & avg. W/g & \\
\hline hemispherical part & 16.14 & 213.86 & 13.25 & 207.63 & 12.86 & -2.91 \\
\hline section 2 & 9.77 & 122.07 & 12.50 & 118.59 & 12.14 & -2.84 \\
\hline section 3 & 4.81 & 53.27 & 11.08 & 52.09 & 10.83 & -2.21 \\
\hline section 4 & 2.31 & 21.31 & 9.22 & 20.75 & 8.97 & -2.66 \\
\hline sections $5 \& 6$ & 32.24 & 22.29 & 0.69 & 21.29 & 0.66 & -4.50 \\
\hline sum of above & 65.27 & 432.79 & 6.63 & 420.35 & 6.44 & -2.87 \\
\hline
\end{tabular}

${ }^{a} \mathrm{~W}=\sum \mathrm{H}_{\mathrm{i}} \mathrm{M}_{\mathrm{i}}$, where $\mathrm{H}$ is heating rate $(\mathrm{W} / \mathrm{g}), \mathrm{M}$ is mass $(\mathrm{g})$, and $\mathrm{i}=1: \mathrm{N}$ ( $\mathrm{N}$ is the number of cells in the region of interest)

${ }^{b}$ avg. W/g is mass weighted: $\mathrm{H}_{\mathrm{avg}}=\left(\sum \mathrm{H}_{\mathrm{i}} \mathrm{M}_{\mathrm{i}}\right) /\left(\sum \mathrm{M}_{\mathrm{i}}\right)$ 
Table 11. End-of-cycle radiation-dependent heat generation rate summary for the cold source $\mathrm{LH}_{2}$ regions

\begin{tabular}{lcccc||cc}
\hline \multirow{2}{*}{ Cold source LH } & \multicolumn{2}{c|}{$\mathbf{8 5}$ MW region } & \multicolumn{2}{c||}{$\mathbf{1 0 0}$ MW LEU } & \multicolumn{2}{c}{ (LEU-HEU)/HEU } \\
\cline { 2 - 5 } & neutron & photon & neutron & photon & $\begin{array}{c}\text { neutron } \\
\text { (\%) }\end{array}$ & $\begin{array}{c}\text { photon } \\
\text { (\%) }\end{array}$ \\
\hline hemispherical part $\left(\mathrm{W}^{\boldsymbol{a}}\right)$ & 124.18 & 89.68 & 135.70 & 71.93 & 9.28 & -19.78 \\
section 2 (W) & 72.58 & 49.49 & 78.91 & 39.68 & 8.73 & -19.82 \\
section 3 (W) & 32.51 & 20.76 & 35.46 & 16.63 & 9.09 & -19.91 \\
section 4 (W) & 12.83 & 8.49 & 13.89 & 6.86 & 8.29 & -19.21 \\
sections 5 \& 6 (W) & 10.13 & 12.16 & 11.00 & 10.29 & 8.54 & -15.37 \\
sum of above (W) & 252.22 & 180.57 & 274.96 & 145.39 & 9.02 & -19.48 \\
percent of total & $58.28 \%$ & $41.72 \%$ & $65.41 \%$ & $34.59 \%$ & 12.24 & -17.10 \\
avg. W/g & 3.86 & 2.77 & 4.21 & 2.23 & 9.02 & -19.48 \\
\hline
\end{tabular}

${ }^{a} \mathrm{~W}=\sum \mathrm{H}_{\mathrm{i}} \mathrm{M}_{\mathrm{i}}$, where $\mathrm{H}$ is heating rate $(\mathrm{W} / \mathrm{g}), \mathrm{M}$ is mass $(\mathrm{g})$, and $\mathrm{i}=1: \mathrm{N}$ ( $\mathrm{N}$ is the number of cells in the region of interest)

${ }^{b}$ avg. W/g is mass weighted: $\mathrm{H}_{\mathrm{avg}}=\left(\sum \mathrm{H}_{\mathrm{i}} \mathrm{M}_{\mathrm{i}}\right) /\left(\sum \mathrm{M}_{\mathrm{i}}\right)$

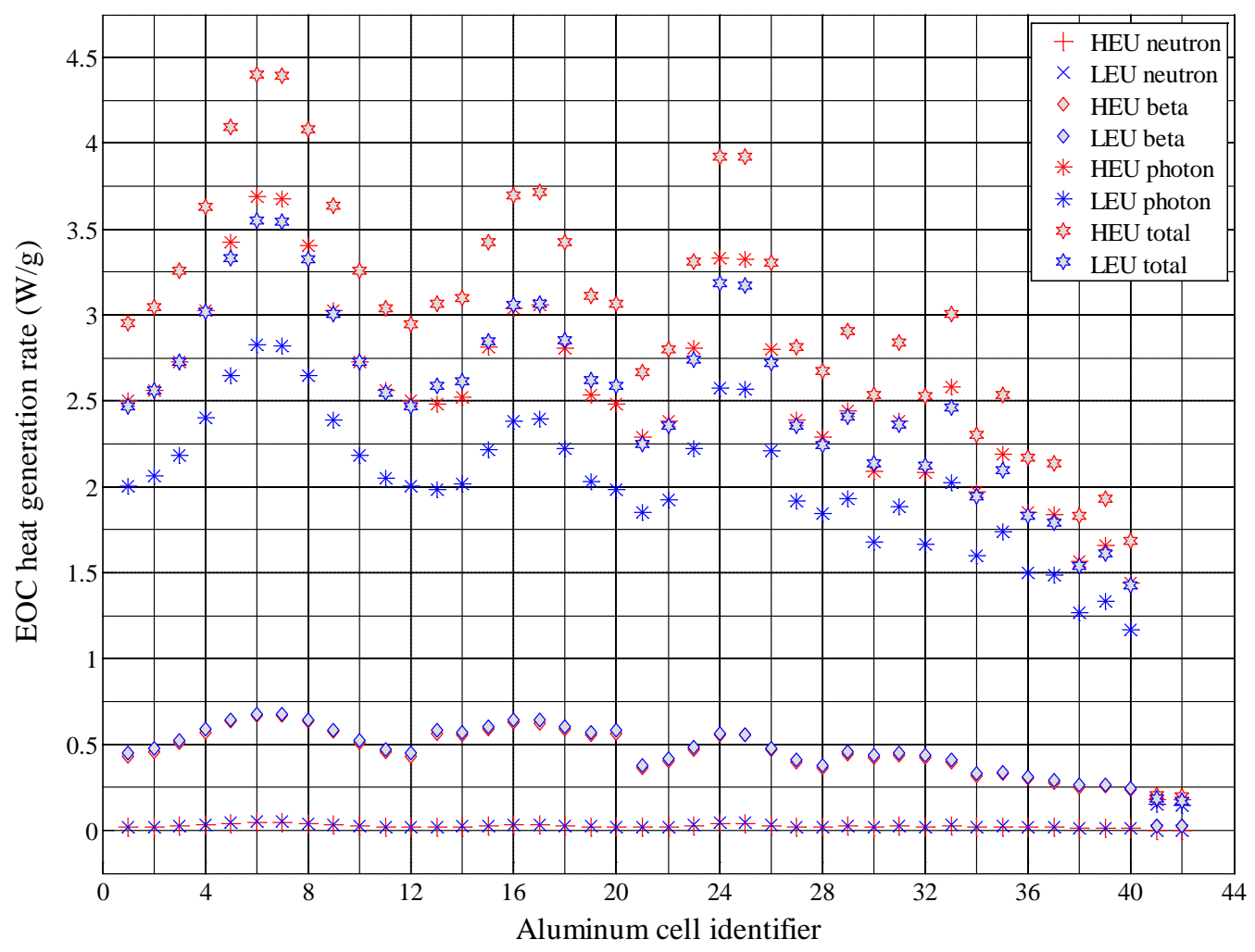

Fig. 9. End-of-cycle heat generation rates in aluminum sections. 
Table 12. End-of-cycle total heat generation rate summary for the cold source aluminum regions

\begin{tabular}{lccccc||c}
\hline \multirow{2}{*}{$\begin{array}{l}\text { Cold source } \\
\text { aluminum region }\end{array}$} & $\begin{array}{c}\text { Mass } \\
\mathbf{( g )}\end{array}$ & \multicolumn{2}{c|}{$\mathbf{8 5} \mathbf{~ M W ~ H E U}$} & \multicolumn{2}{c||}{$\mathbf{1 0 0} \mathbf{M W} \mathbf{~ L E U}$} & \multirow{2}{*}{$\begin{array}{c}\text { (LEU-HEU)/HEU } \\
\text { (\%) }\end{array}$} \\
\cline { 3 - 6 } hemispherical part & 73.66 & 262.44 & 3.56 & 216.68 & 2.94 & -17.44 \\
section 2 & 49.51 & 164.24 & 3.32 & 137.39 & 2.78 & -16.35 \\
section 3 & 79.16 & 251.56 & 3.18 & 208.00 & 2.63 & -17.32 \\
beyond section 3 & 547.88 & 672.50 & 1.23 & 563.05 & 1.03 & -16.27 \\
sum & 750.20 & 1350.74 & 1.80 & 1125.12 & 1.50 & -16.70 \\
\hline
\end{tabular}

${ }^{a} \mathrm{~W}=\sum \mathrm{H}_{\mathrm{i}} \mathrm{M}_{\mathrm{i}}$, where $\mathrm{H}$ is heating rate $(\mathrm{W} / \mathrm{g}), \mathrm{M}$ is mass (g), and $\mathrm{i}=1: \mathrm{N}$ ( $\mathrm{N}$ is the number of cells in the region of interest)

${ }^{b}$ avg. W/g is mass weighted: $\mathrm{H}_{\text {avg }}=\left(\sum \mathrm{H}_{\mathrm{i}} \mathrm{M}_{\mathrm{i}}\right) /\left(\sum \mathrm{M}_{\mathrm{i}}\right)$

Table 13. End-of-cycle radiation-dependent heat generation rate summary for the cold source aluminum regions

\begin{tabular}{lcccccc||ccc}
\hline \multirow{2}{*}{$\begin{array}{l}\text { Cold source aluminum } \\
\text { region }\end{array}$} & \multicolumn{3}{c}{ 85 MW HEU } & \multicolumn{3}{c||}{ 100 MW LEU } & \multicolumn{3}{c}{ (LEU-HEU)/HEU } \\
\cline { 2 - 9 } & neutron & photon & beta & neutron & photon & beta & $\begin{array}{c}\text { neutron } \\
\text { (\%) }\end{array}$ & $\begin{array}{c}\text { photon } \\
\text { (\%) }\end{array}$ & $\begin{array}{c}\text { beta } \\
\text { (\%) }\end{array}$ \\
\hline hemispherical part (W $\mathbf{W}^{\boldsymbol{a}}$ ) & 2.12 & 220.01 & 40.31 & 2.31 & 173.25 & 41.12 & 9.06 & -21.25 & 2.02 \\
section 2 (W) & 1.21 & 134.26 & 28.77 & 1.32 & 106.49 & 29.59 & 8.85 & -20.69 & 2.84 \\
section 3 (W) & 2.07 & 213.96 & 35.53 & 2.26 & 169.48 & 36.26 & 8.98 & -20.79 & 2.04 \\
beyond section 3 (W) & 5.07 & 570.18 & 97.24 & 5.54 & 457.22 & 100.29 & 9.26 & -19.81 & 3.14 \\
sum of above (W) & 10.47 & 1138.41 & 201.85 & 11.43 & 906.43 & 207.26 & 9.12 & -20.38 & 2.68 \\
percent of total & $0.78 \%$ & $84.28 \%$ & $14.94 \%$ & $1.02 \%$ & $80.56 \%$ & $18.42 \%$ & 31.00 & -4.41 & 23.27 \\
avg. W/g & 0.01 & 1.52 & 0.27 & 0.02 & 1.21 & 0.28 & 9.12 & -20.38 & 2.68 \\
\hline
\end{tabular}

${ }^{a} \mathrm{~W}=\sum \mathrm{H}_{\mathrm{i}} \mathrm{M}_{\mathrm{i}}$, where $\mathrm{H}$ is heating rate $(\mathrm{W} / \mathrm{g}), \mathrm{M}$ is mass (g), and $\mathrm{i}=1: \mathrm{N}$ ( $\mathrm{N}$ is the number of cells in the region of interest)

${ }^{b}$ avg. W/g is mass weighted: $\mathrm{H}_{\text {avg }}=\left(\sum \mathrm{H}_{\mathrm{i}} \mathrm{M}_{\mathrm{i}}\right) /\left(\sum \mathrm{M}_{\mathrm{i}}\right)$

\subsection{FITS TO HEAT GENERATION RATES}

Various mathematic functions were generated to fit the spatially dependent specific nuclear heat generation rates in the cold source $\mathrm{LH}_{2}$ moderator and vessel regions. The basis functions of the fitting functions are those generated in [2] and [4]. The coefficients are determined with linear least square methods and MATLAB scripts developed during this project. Fitting coefficients were generated for the neutron-induced, beta-induced (aluminum only), photon-induced, and total energy deposition in the regions described previously. The coefficients calculated for the total heat generation rates in the $\mathrm{LH}_{2}$ hemispherical region for both cores at BOC and EOC are listed in Table 14. The radiation-dependent fitting functions for the $\mathrm{LH}_{2}$ hemispherical region and the fitting functions for the other cold source $\mathrm{LH}_{2}$ regions can be found in [5].

The total calculated and fitted heat generation rates in the $\mathrm{LH}_{2}$ hemispherical region for both cores at BOC and EOC and the percent differences between the calculated and fitted values are provided in Table 15. As shown in this table, the fitted values are in good agreement with the calculated results; the differences range from $-0.5 \%$ to $+0.7 \%$. The fitted neutron, photon, and combined neutron + photon (i.e., total) heat generation rates in the $\mathrm{LH}_{2}$ hemispherical region for the BOC HEU and LEU cores are illustrated in Fig. 10-Fig. 12. Fig. 13-Fig. 15 show the EOC fitted neutron, photon, and total heat 
generation rates. For each set of surface plots, the color maps have the same axes to allow a visual comparison between the HEU and LEU results.

Table 14. Fitting coefficients to total heat generation rates in hemispherical part of cold source $\mathrm{LH}_{2}$

\begin{tabular}{cccccc}
\hline Coef. & Function $^{a}$ & BOC HEU & BOC LEU & EOC HEU & EOC LEU \\
\hline $\mathrm{C}_{1}$ & 1 & $1.20506 \mathrm{E}+01$ & $1.25040 \mathrm{E}+01$ & $1.29235 \mathrm{E}+01$ & $1.25343 \mathrm{E}+01$ \\
$\mathrm{C}_{2}$ & $\mathrm{r} \cos (\theta)$ & $-8.24578 \mathrm{E}-01$ & $-8.64197 \mathrm{E}-01$ & $-8.40474 \mathrm{E}-01$ & $-8.28626 \mathrm{E}-01$ \\
$\mathrm{C}_{3}$ & $\mathrm{r} \sin (\theta)$ & $7.67442 \mathrm{E}-03$ & $1.65974 \mathrm{E}-02$ & $9.35677 \mathrm{E}-03$ & $8.97120 \mathrm{E}-03$ \\
$\mathrm{C}_{4}$ & $\mathrm{r} \sin (\theta) \cos (\theta)$ & $-7.17075 \mathrm{E}-04$ & $2.39634 \mathrm{E}-02$ & $-9.13475 \mathrm{E}-03$ & $-2.85415 \mathrm{E}-02$ \\
$\mathrm{C}_{5}$ & $\mathrm{r}^{2} \cos (2 \theta)$ & $5.32530 \mathrm{E}-02$ & $5.86452 \mathrm{E}-02$ & $4.99830 \mathrm{E}-02$ & $4.59048 \mathrm{E}-02$ \\
$\mathrm{C}_{6}$ & $\mathrm{r}^{2} \sin (2 \theta)$ & $3.94907 \mathrm{E}-04$ & $-4.87006 \mathrm{E}-03$ & $1.24248 \mathrm{E}-03$ & $2.30816 \mathrm{E}-03$ \\
$\mathrm{C}_{7}$ & $\mathrm{r}^{2} \sin (2 \theta) \cos (2 \theta)$ & $3.99418 \mathrm{E}-04$ & $-3.76982 \mathrm{E}-04$ & $2.85073 \mathrm{E}-04$ & $1.38062 \mathrm{E}-04$ \\
$\mathrm{C}_{8}$ & $\mathrm{r}$ & $-5.19770 \mathrm{E}-02$ & $-2.94708 \mathrm{E}-01$ & $-2.44958 \mathrm{E}-01$ & $-3.03355 \mathrm{E}-01$ \\
$\mathrm{C}_{9}$ & $\mathrm{r}^{2}$ & $6.76885 \mathrm{E}-02$ & $1.10943 \mathrm{E}-01$ & $9.06477 \mathrm{E}-02$ & $1.06672 \mathrm{E}-01$ \\
$\mathrm{C}_{10}$ & $\mathrm{r} \cos (2 \theta)$ & $-4.82783 \mathrm{E}-02$ & $-5.38916 \mathrm{E}-02$ & $-3.49317 \mathrm{E}-02$ & $-1.93906 \mathrm{E}-02$ \\
$\mathrm{C}_{11}$ & $\mathrm{r}^{3} \cos (\theta) \cos (2 \theta)$ & $-1.23536 \mathrm{E}-02$ & $-1.41739 \mathrm{E}-02$ & $-1.13688 \mathrm{E}-02$ & $-1.34126 \mathrm{E}-02$ \\
$\mathrm{C}_{12}$ & $\mathrm{r}^{3} \cos (\theta) \sin (2 \theta)$ & $6.74187 \mathrm{E}-05$ & $-6.26712 \mathrm{E}-04$ & $-4.67653 \mathrm{E}-05$ & $-9.22994 \mathrm{E}-05$ \\
$\mathrm{C}_{13}$ & $\mathrm{r}^{3} \sin (\theta) \cos (2 \theta)$ & $-3.11552 \mathrm{E}-05$ & $-1.45394 \mathrm{E}-04$ & $2.52584 \mathrm{E}-04$ & $2.30219 \mathrm{E}-04$ \\
$\mathrm{C}_{14}$ & $\mathrm{r}^{3} \sin (\theta) \sin (2 \theta)$ & $-1.03066 \mathrm{E}-02$ & $-1.13080 \mathrm{E}-02$ & $-9.54375 \mathrm{E}-03$ & $-1.13191 \mathrm{E}-02$ \\
\hline
\end{tabular}

${ }^{a} \mathrm{r}$ is the radius (cm) and $\theta$ is the angle (radians) 
Table 15. Fits to total heat generation rates in hemispherical part of cold source $\mathrm{LH}_{2}$

\begin{tabular}{|c|c|c|c|c|c|c|c|c|c|c|c|c|c|}
\hline \multirow[b]{2}{*}{ Identifier } & \multirow[b]{2}{*}{ Cell } & \multicolumn{3}{|c|}{ BOC HEU } & \multicolumn{3}{|c|}{ BOC LEU } & \multicolumn{3}{|c|}{ EOC HEU } & \multicolumn{3}{|c|}{ EOC LEU } \\
\hline & & $\begin{array}{l}\text { input } \\
\text { (W/g) }\end{array}$ & $\begin{array}{c}\text { fit } \\
(W / g)\end{array}$ & $\begin{array}{l}\text { diff. } \\
\text { (\%) }\end{array}$ & $\begin{array}{l}\text { input } \\
\text { (W/g) }\end{array}$ & $\begin{array}{c}\text { fit } \\
\text { (W/g) }\end{array}$ & $\begin{array}{l}\text { diff. } \\
\text { (\%) }\end{array}$ & $\begin{array}{l}\text { input } \\
\text { (W/g) }\end{array}$ & $\begin{array}{c}\text { fit } \\
(W / g)\end{array}$ & $\begin{array}{l}\text { diff. } \\
(\%)\end{array}$ & $\begin{array}{l}\text { input } \\
\text { (W/g) }\end{array}$ & $\begin{array}{c}\text { fit } \\
(W / g)\end{array}$ & $\begin{array}{l}\text { diff. } \\
\text { (\%) }\end{array}$ \\
\hline 1 & 95001 & 10.36 & 10.32 & -0.36 & 10.38 & 10.33 & -0.48 & 10.89 & 10.84 & -0.52 & 10.44 & 10.40 & -0.35 \\
\hline 2 & 95002 & 10.77 & 10.76 & -0.12 & 10.81 & 10.79 & -0.19 & 11.27 & 11.26 & -0.10 & 10.82 & 10.81 & -0.08 \\
\hline 3 & 95003 & 11.61 & 11.60 & -0.07 & 11.71 & 11.69 & -0.11 & 12.08 & 12.11 & 0.20 & 11.69 & 11.65 & -0.33 \\
\hline 4 & 95004 & 12.74 & 12.77 & 0.29 & 12.90 & 12.92 & 0.15 & 13.29 & 13.30 & 0.10 & 12.85 & 12.86 & 0.07 \\
\hline 5 & 95005 & 13.99 & 14.00 & 0.06 & 14.23 & 14.21 & -0.11 & 14.54 & 14.56 & 0.10 & 14.12 & 14.14 & 0.12 \\
\hline 6 & 95006 & 14.80 & 14.81 & 0.09 & 15.05 & 15.08 & 0.16 & 15.35 & 15.38 & 0.16 & 14.94 & 14.97 & 0.17 \\
\hline 7 & 95007 & 14.78 & 14.81 & 0.18 & 15.04 & 15.06 & 0.18 & 15.32 & 15.36 & 0.32 & 14.93 & 14.94 & 0.07 \\
\hline 8 & 95008 & 13.97 & 13.98 & 0.02 & 14.15 & 14.16 & 0.08 & 14.52 & 14.52 & -0.01 & 14.03 & 14.07 & 0.27 \\
\hline 9 & 95009 & 12.70 & 12.73 & 0.24 & 12.81 & 12.84 & 0.23 & 13.27 & 13.26 & -0.08 & 12.79 & 12.80 & 0.09 \\
\hline 10 & 95010 & 11.57 & 11.56 & -0.11 & 11.59 & 11.61 & 0.12 & 12.09 & 12.07 & -0.13 & 11.64 & 11.64 & -0.02 \\
\hline 11 & 95011 & 10.75 & 10.72 & -0.21 & 10.77 & 10.75 & -0.16 & 11.24 & 11.24 & -0.04 & 10.85 & 10.82 & -0.24 \\
\hline 12 & 95012 & 10.33 & 10.31 & -0.23 & 10.33 & 10.32 & -0.07 & 10.85 & 10.82 & -0.22 & 10.41 & 10.41 & 0.02 \\
\hline 13 & 95013 & 9.69 & 9.73 & 0.40 & 9.61 & 9.67 & 0.68 & 10.16 & 10.20 & 0.36 & 9.72 & 9.74 & 0.23 \\
\hline 14 & 95014 & 10.25 & 10.28 & 0.28 & 10.21 & 10.26 & 0.53 & 10.71 & 10.74 & 0.29 & 10.25 & 10.29 & 0.38 \\
\hline 15 & 95015 & 11.44 & 11.43 & -0.09 & 11.52 & 11.52 & 0.02 & 11.88 & 11.89 & 0.09 & 11.45 & 11.48 & 0.28 \\
\hline 16 & 95016 & 13.26 & 13.24 & -0.16 & 13.43 & 13.43 & -0.02 & 13.76 & 13.71 & -0.34 & 13.32 & 13.35 & 0.23 \\
\hline 17 & 95017 & 15.38 & 15.34 & -0.23 & 15.69 & 15.66 & -0.23 & 15.88 & 15.83 & -0.29 & 15.56 & 15.50 & -0.36 \\
\hline 18 & 95018 & 16.86 & 16.82 & -0.23 & 17.24 & 17.25 & 0.10 & 17 & 17.31 & -0.27 & 17.04 & 17.00 & -0.25 \\
\hline 19 & 95019 & 16.82 & 16.81 & -0.02 & 17.26 & 17.23 & -0.19 & 17.31 & 17.30 & -0.10 & 16.97 & 16.96 & -0.09 \\
\hline 20 & 95020 & 15.34 & 15.31 & -0.20 & 15.63 & 15.57 & -0.39 & 15.83 & 15.79 & -0.24 & 15.46 & 15.42 & -0.26 \\
\hline 22 & 95021 & 13.21 & 13.18 & -0.22 & 13.32 & 13.29 & -0.27 & 13.65 & 13.67 & 0.15 & 13.31 & 13.28 & -0.23 \\
\hline 22 & 95022 & 11.37 & 11.38 & 0.01 & 11.41 & 11.41 & 0.06 & 11.85 & 11.85 & -0.01 & 11.47 & 11.46 & -0.08 \\
\hline 23 & 95023 & 10.20 & 10.23 & 0.31 & 10.26 & 10.26 & 0.01 & 10.63 & 10.69 & 0.53 & 10.24 & 10.30 & 0.51 \\
\hline 24 & 95024 & 9.64 & 9.71 & 0.69 & 9.68 & 9.70 & 0.22 & 10.13 & 10.17 & 0.40 & 9.73 & 9.75 & 0.17 \\
\hline 25 & 95025 & 9.39 & 9.36 & -0.26 & 9.31 & 9.29 & -0.19 & 9.87 & 9.84 & -0.31 & 9.38 & 9.36 & -0.21 \\
\hline 26 & 95026 & 9.98 & 9.98 & 0.03 & 9.99 & 9.96 & -0.28 & 10.42 & 10.44 & 0.17 & 9.99 & 10.01 & 0.20 \\
\hline 27 & 95027 & 11.33 & 11.33 & 0.01 & 11.47 & 11.45 & -0.11 & 11.82 & 11.78 & -0.34 & 11.47 & 11.43 & -0.40 \\
\hline 28 & 95028 & 13.59 & 13.59 & -0.04 & 13.82 & 13.85 & 0.17 & 14.01 & 14.05 & 0.26 & 13.77 & 13.75 & -0.11 \\
\hline 29 & 95029 & 16.30 & 16.34 & 0.25 & 16.78 & 16.78 & -0.04 & 16.78 & 16.81 & 0.18 & 16.52 & 16.56 & 0.26 \\
\hline 30 & 95030 & 18.34 & 18.34 & 0.02 & 18.93 & 18.95 & 0.08 & 18.78 & 18.80 & 0.08 & 18.56 & 18.58 & 0.10 \\
\hline 31 & 95031 & 18.33 & 18.33 & -0.01 & 18.93 & 18.92 & -0.05 & 18.78 & 18.78 & 0.02 & 18.56 & 18.54 & -0.09 \\
\hline 32 & 95032 & 16.27 & 16.29 & 0.14 & 16.62 & 16.67 & 0.27 & 16.74 & 16.77 & 0.13 & 16.44 & 16.48 & 0.28 \\
\hline 33 & 95033 & 13.50 & 13.51 & 0.11 & 13.64 & 13.66 & 0.14 & 14.01 & 14.01 & -0.02 & 13.67 & 13.69 & 0.11 \\
\hline 34 & 95034 & 11.28 & 11.26 & -0.13 & 11.36 & 11.34 & -0.19 & 11.76 & 11.74 & -0.11 & 11.44 & 11.41 & -0.30 \\
\hline 35 & 95035 & 9.91 & 9.91 & 0.08 & 9.99 & 10.01 & 0.24 & 10.40 & 10.38 & -0.14 & 9.97 & 10.00 & 0.30 \\
\hline 36 & 95036 & 9.37 & 9.33 & -0.50 & 9.39 & 9.36 & -0.34 & 9.82 & 9.80 & -0.23 & 9.40 & 9.36 & -0.45 \\
\hline
\end{tabular}




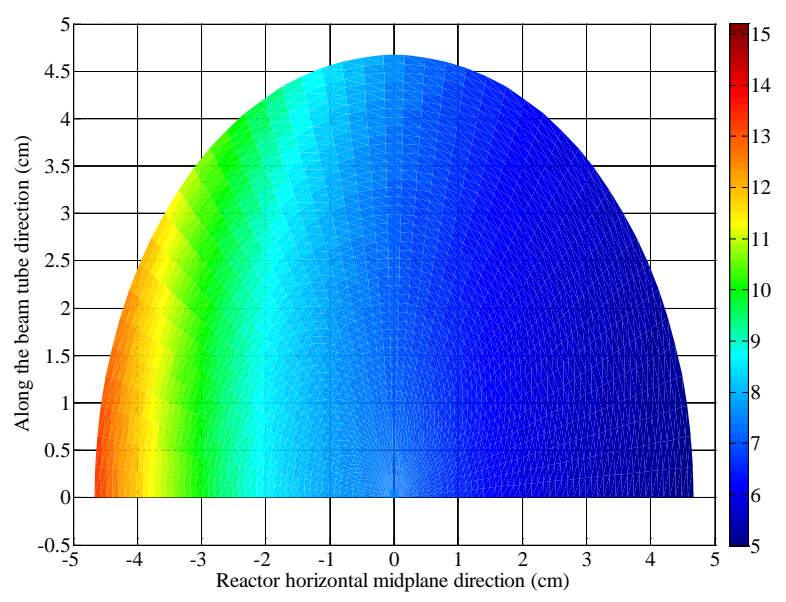

(a)

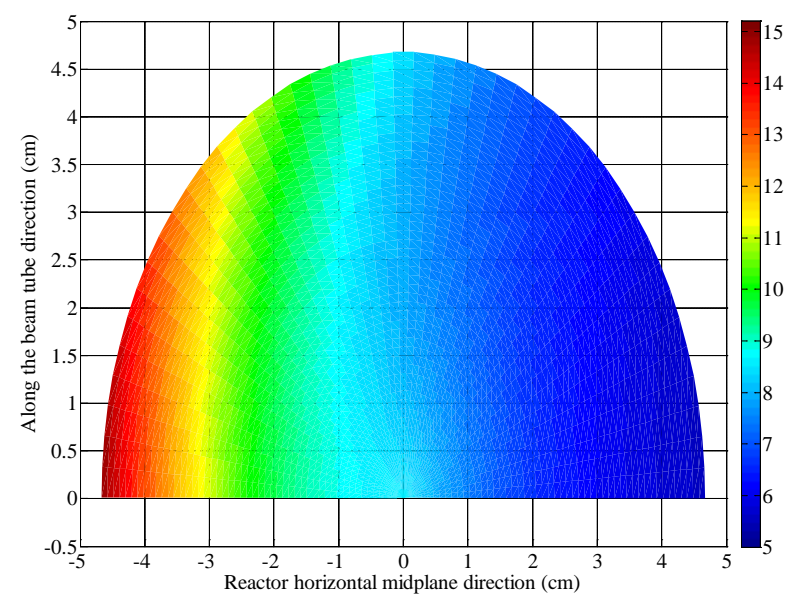

(b)

Fig. 10. Beginning-of-cycle $\mathrm{LH}_{2}$ hemisphere neutron energy deposition (W/g): HEU (a) and LEU (b).

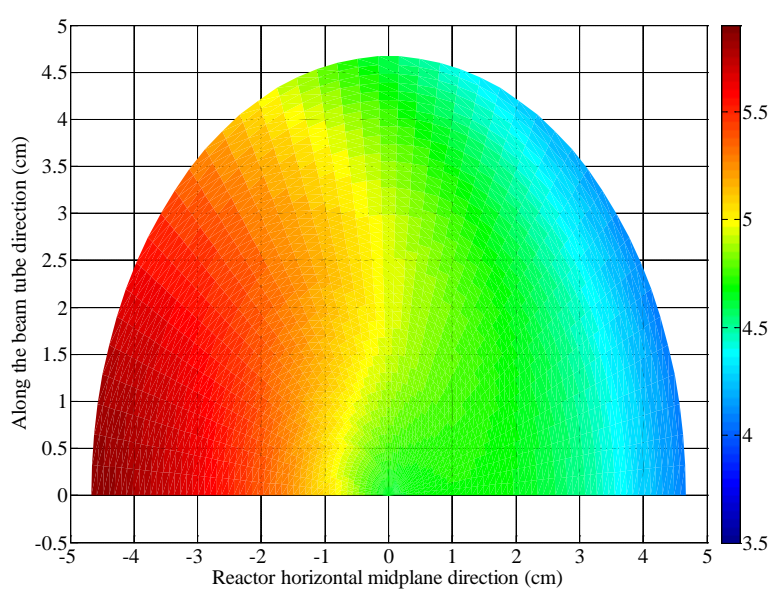

(a)

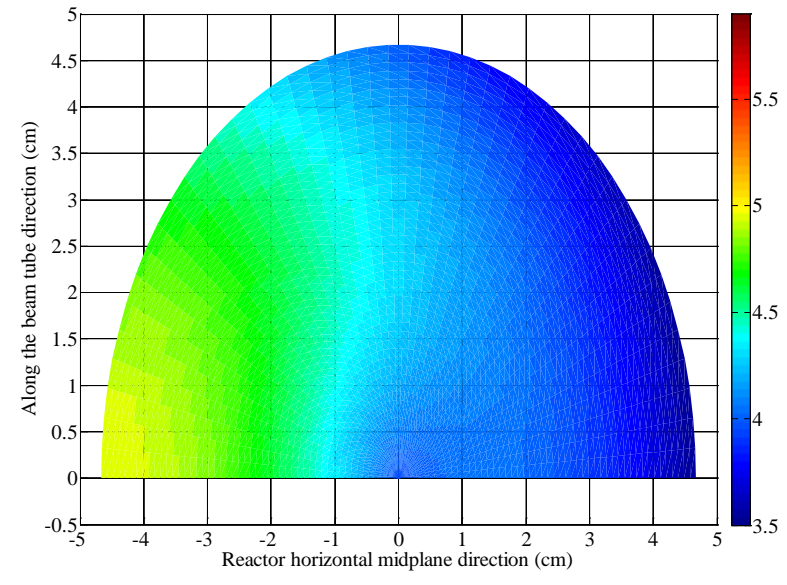

(b)

Fig. 11. Beginning-of-cycle $\mathrm{LH}_{2}$ hemisphere photon energy deposition (W/g): HEU (a) and LEU (b).

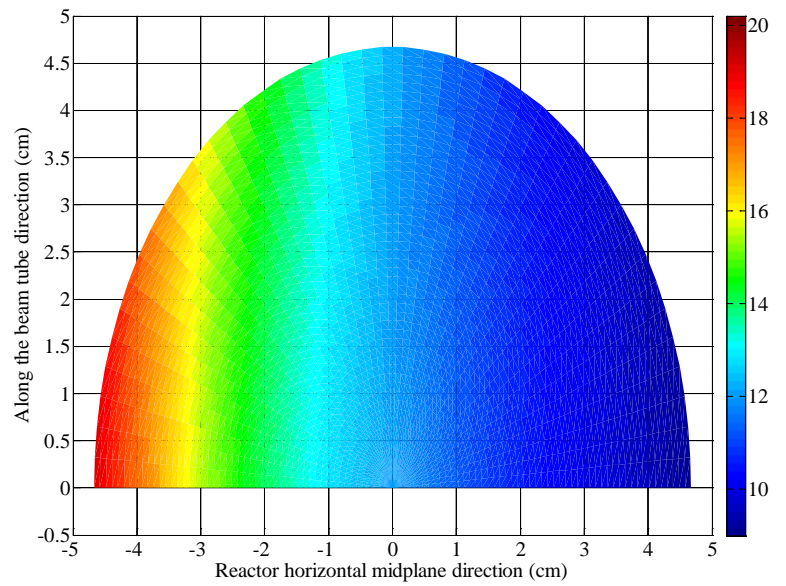

(a)

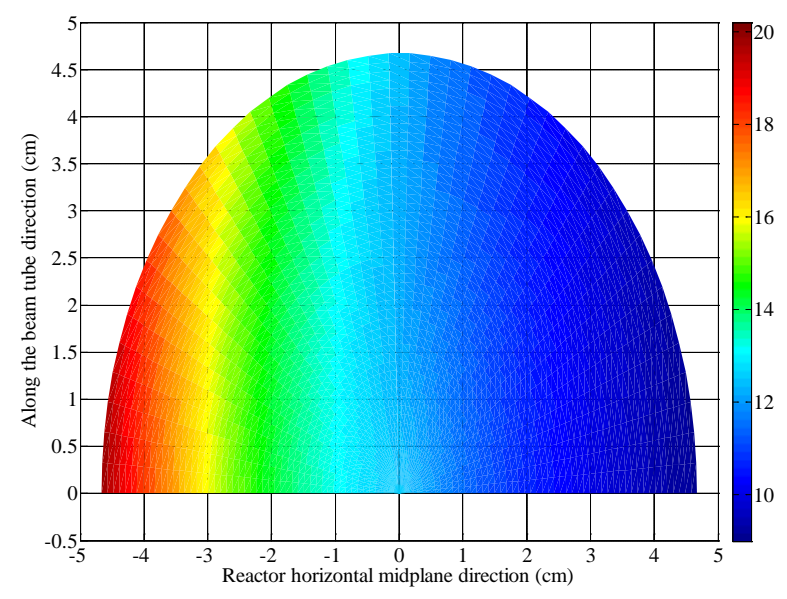

(b)

Fig. 12. Beginning-of-cycle $\mathrm{LH}_{2}$ hemisphere total energy deposition (W/g): HEU (a) and LEU (b). 


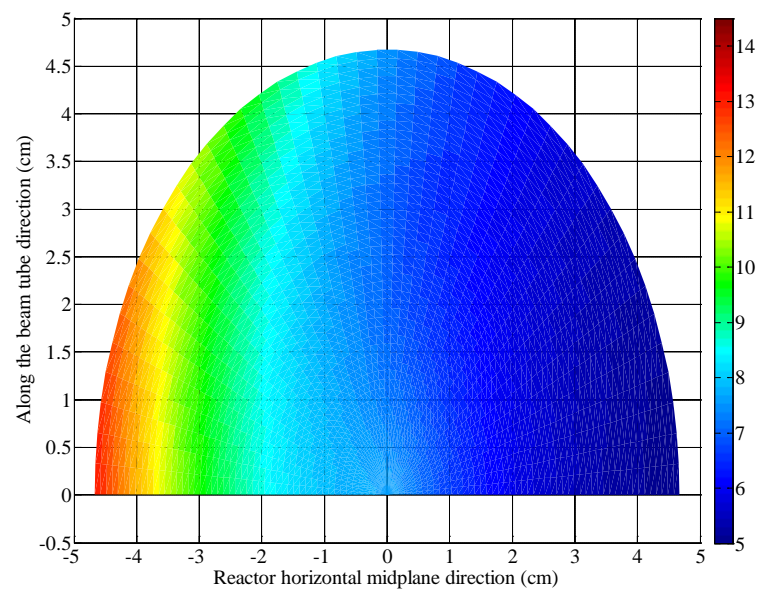

(a)

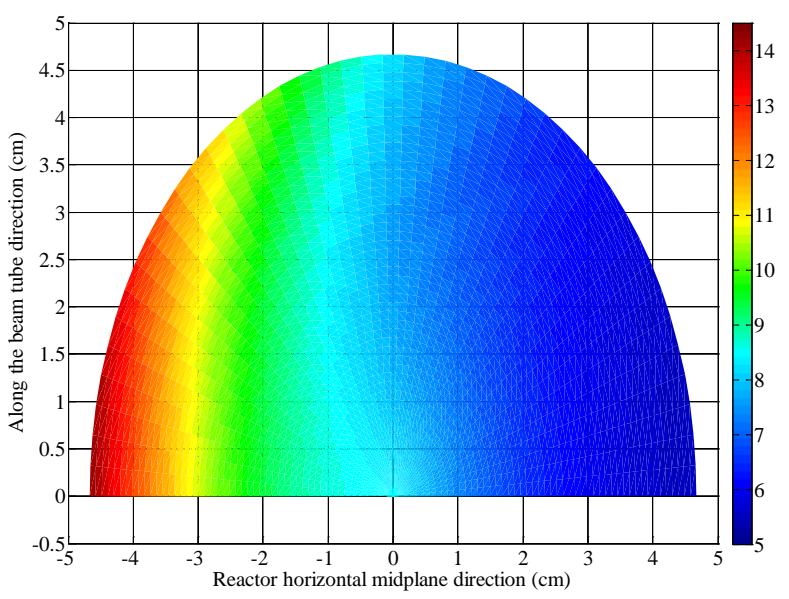

(b)

Fig. 13. End-of-cycle $\mathrm{LH}_{2}$ hemisphere neutron energy deposition (W/g): HEU (a) and LEU (b).

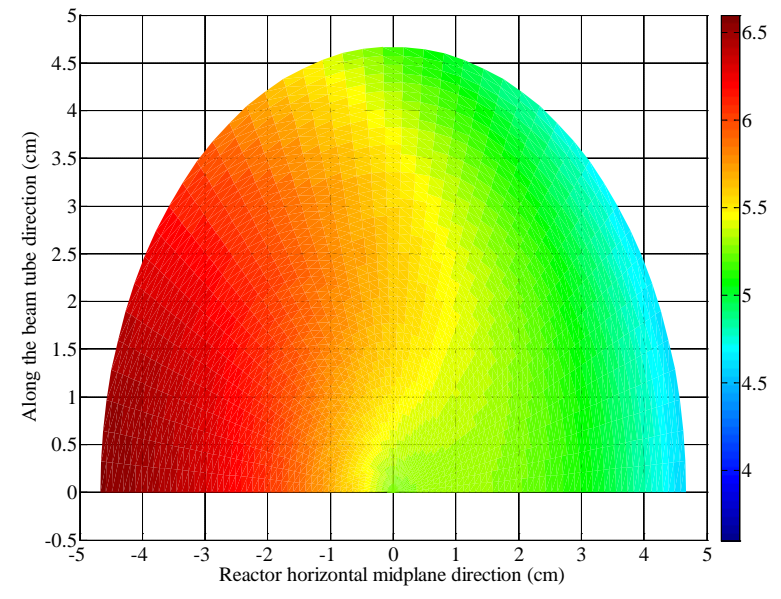

(a)

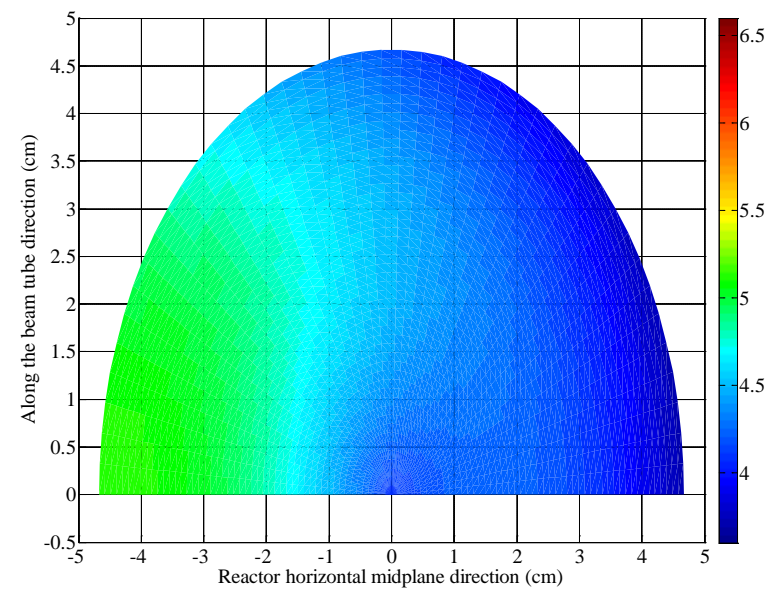

(b)

Fig. 14. End-of-cycle $\mathrm{LH}_{2}$ hemisphere photon energy deposition (W/g): HEU (a) and LEU (b).

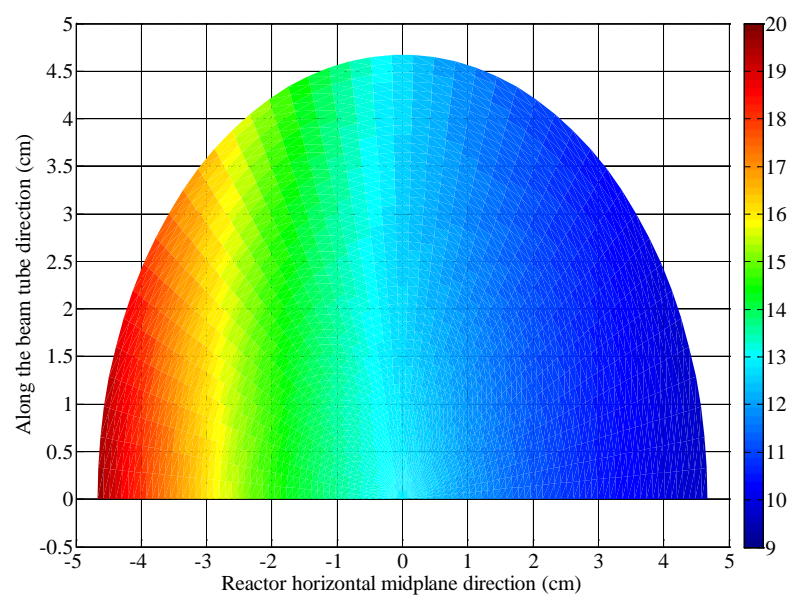

(a)

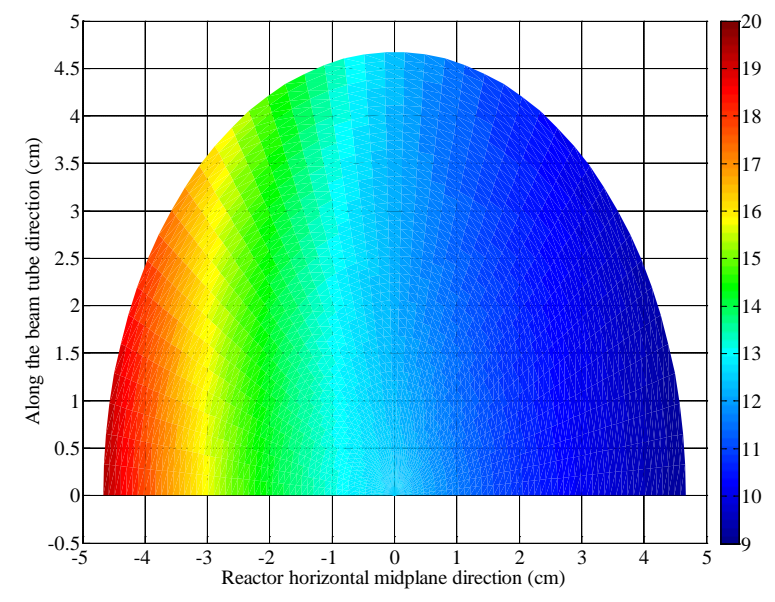

(b)

Fig. 15. End-of-cycle $\mathrm{LH}_{2}$ hemisphere total energy deposition (W/g): HEU (a) and LEU (b). 
Table 16 gives the coefficients calculated for the total heat generation rates in the aluminum hemispherical region (i.e., neutron + photon + beta) for both cores at BOC and EOC. The radiationdependent fitting functions for the aluminum hemispherical region and the fitting functions for the other cold source aluminum regions are provided in [5]. Table 17 provides the total calculated and fitted heat generation rates in the aluminum hemispherical region cells for both cores at BOC and EOC and the percent differences between the calculated and fitted values. As shown in this table, the fitted values are in good agreement with the calculated results; the differences range from $-0.5 \%$ to $+0.5 \%$.

The ratios of the $85 \mathrm{MW}$ HEU to the $100 \mathrm{MW}$ LEU fitted neutron, beta, photon, and total heat generation rates in the aluminum hemispherical regions for the BOC and EOC cores are illustrated in Fig. 16 and Fig. 17.

Table 16. Fitting coefficients to total heat generation rates in hemispherical part of cold source aluminum

\begin{tabular}{cccccc}
\hline Coef. & Function $^{\boldsymbol{a}}$ & BOC HEU & BOC LEU & EOC HEU & EOC LEU \\
\hline $\mathrm{C}_{1}$ & 1 & $3.11551 \mathrm{E}+00$ & $2.79000 \mathrm{E}+00$ & $3.56305 \mathrm{E}+00$ & $2.94182 \mathrm{E}+00$ \\
$\mathrm{C}_{2}$ & $\cos (\theta)$ & $-6.46324 \mathrm{E}-01$ & $-5.40767 \mathrm{E}-01$ & $-7.45061 \mathrm{E}-01$ & $-5.54808 \mathrm{E}-01$ \\
$\mathrm{C}_{3}$ & $\sin (\theta)$ & $3.26857 \mathrm{E}-03$ & $1.18782 \mathrm{E}-02$ & $2.43827 \mathrm{E}-03$ & $4.71038 \mathrm{E}-03$ \\
$\mathrm{C}_{4}$ & $\cos (2 \theta)$ & $1.27782 \mathrm{E}-01$ & $9.46634 \mathrm{E}-02$ & $1.32611 \mathrm{E}-01$ & $8.00474 \mathrm{E}-02$ \\
$\mathrm{C}_{5}$ & $\sin (2 \theta)$ & $-2.35996 \mathrm{E}-03$ & $-6.93006 \mathrm{E}-03$ & $-2.34234 \mathrm{E}-03$ & $-4.62251 \mathrm{E}-04$ \\
\hline
\end{tabular}

${ }^{a} \theta$ is the angle (radians)

Table 17. Fit to total heat generation rates in hemispherical part of cold source aluminum

\begin{tabular}{|c|c|c|c|c|c|c|c|c|c|c|c|c|c|}
\hline \multirow[b]{2}{*}{ Identifier } & \multirow[b]{2}{*}{ Cell } & \multicolumn{3}{|c|}{ BOC HEU } & \multicolumn{3}{|c|}{ BOC LEU } & \multicolumn{3}{|c|}{ EOC HEU } & \multicolumn{3}{|c|}{ EOC LEU } \\
\hline & & $\begin{array}{l}\text { input } \\
\text { (W/g) }\end{array}$ & $\begin{array}{c}\text { fit } \\
(W / g)\end{array}$ & $\begin{array}{l}\text { diff. } \\
\text { (\%) }\end{array}$ & $\begin{array}{l}\text { input } \\
\text { (W/g) }\end{array}$ & $\begin{array}{c}\text { fit } \\
\text { (W/g) }\end{array}$ & $\begin{array}{l}\text { diff. } \\
(\%)\end{array}$ & $\begin{array}{l}\text { input } \\
\text { (W/g) }\end{array}$ & $\begin{array}{c}\text { fit } \\
(\mathbf{W} / g)\end{array}$ & $\begin{array}{l}\text { diff. } \\
\text { (\%) }\end{array}$ & $\begin{array}{l}\text { input } \\
\text { (W/g) }\end{array}$ & $\begin{array}{c}\text { fit } \\
(W / g)\end{array}$ & $\begin{array}{l}\text { diff. } \\
(\%)\end{array}$ \\
\hline 1 & 86021 & 2.59 & 2.60 & 0.32 & 2.34 & 2.35 & 0.39 & 2.95 & 2.96 & 0.13 & 2.47 & 2.48 & 0.20 \\
\hline 2 & 86022 & 2.67 & 2.66 & -0.31 & 2.42 & 2.41 & -0.31 & 3.04 & 3.04 & -0.27 & 2.56 & 2.55 & -0.33 \\
\hline 3 & 86023 & 2.85 & 2.84 & -0.31 & 2.58 & 2.58 & -0.15 & 3.26 & 3.26 & -0.17 & 2.73 & 2.73 & 0.10 \\
\hline 4 & 86024 & 3.16 & 3.18 & 0.39 & 2.86 & 2.86 & 0.05 & 3.63 & 3.64 & 0.37 & 3.02 & 3.02 & 0.02 \\
\hline 5 & 86025 & 3.58 & 3.58 & 0.04 & 3.18 & 3.19 & 0.26 & 4.10 & 4.09 & -0.07 & 3.33 & 3.34 & 0.10 \\
\hline 6 & 86026 & 3.86 & 3.85 & -0.15 & 3.40 & 3.40 & -0.12 & 4.40 & 4.40 & -0.12 & 3.55 & 3.55 & -0.12 \\
\hline 7 & 86027 & 3.85 & 3.85 & -0.09 & 3.39 & 3.39 & -0.16 & 4.40 & 4.40 & -0.04 & 3.55 & 3.55 & -0.03 \\
\hline 8 & 86028 & 3.56 & 3.57 & 0.11 & 3.16 & 3.16 & -0.06 & 4.08 & 4.09 & 0.14 & 3.33 & 3.33 & 0.05 \\
\hline 9 & 86029 & 3.16 & 3.17 & 0.15 & 2.82 & 2.83 & 0.52 & 3.64 & 3.64 & 0.07 & 3.01 & 3.01 & 0.17 \\
\hline 10 & 86030 & 2.84 & 2.84 & -0.01 & 2.57 & 2.56 & -0.32 & 3.26 & 3.25 & -0.14 & 2.73 & 2.72 & -0.25 \\
\hline 11 & 86031 & 2.67 & 2.66 & -0.49 & 2.41 & 2.41 & -0.30 & 3.04 & 3.04 & -0.20 & 2.55 & 2.55 & 0.00 \\
\hline 12 & 86032 & 2.59 & 2.60 & 0.35 & 2.35 & 2.35 & 0.19 & 2.95 & 2.96 & 0.30 & 2.47 & 2.47 & 0.09 \\
\hline
\end{tabular}




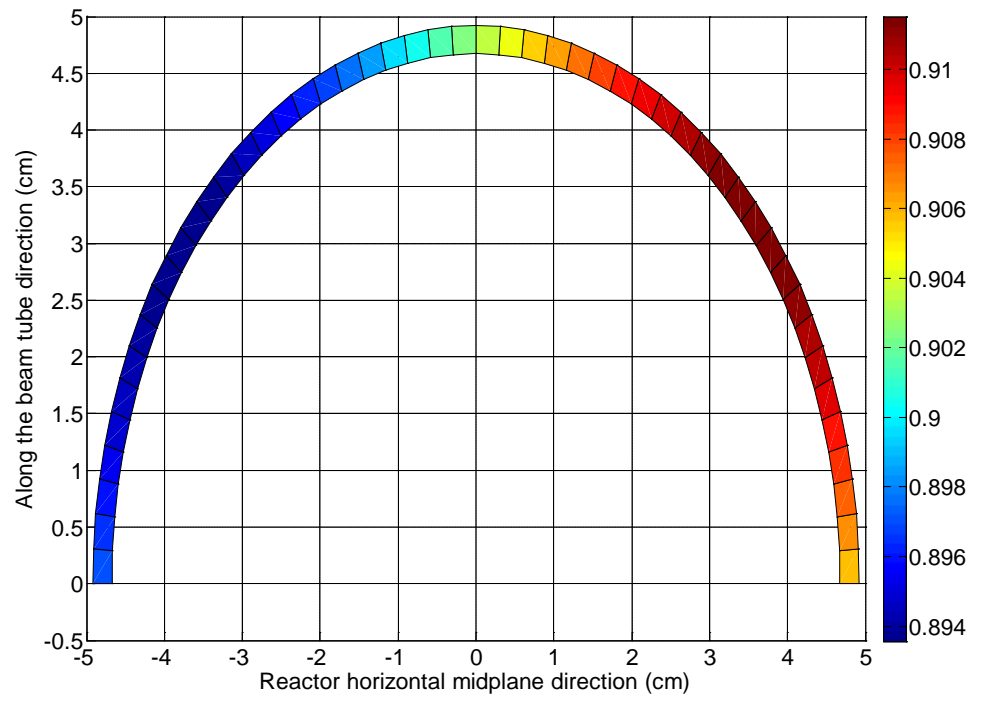

(a)

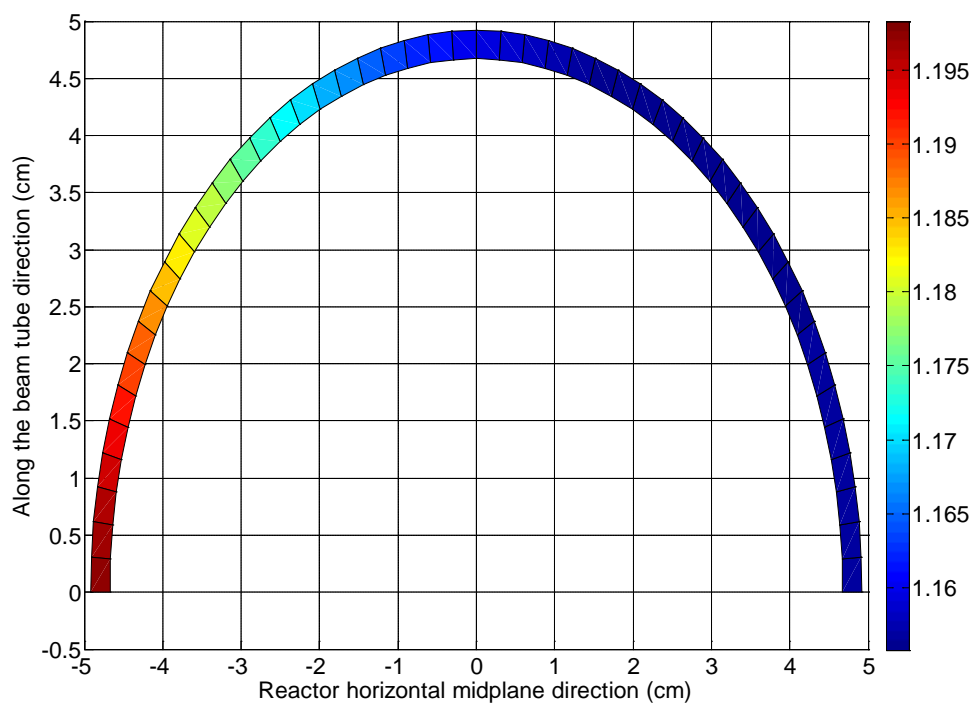

(c)

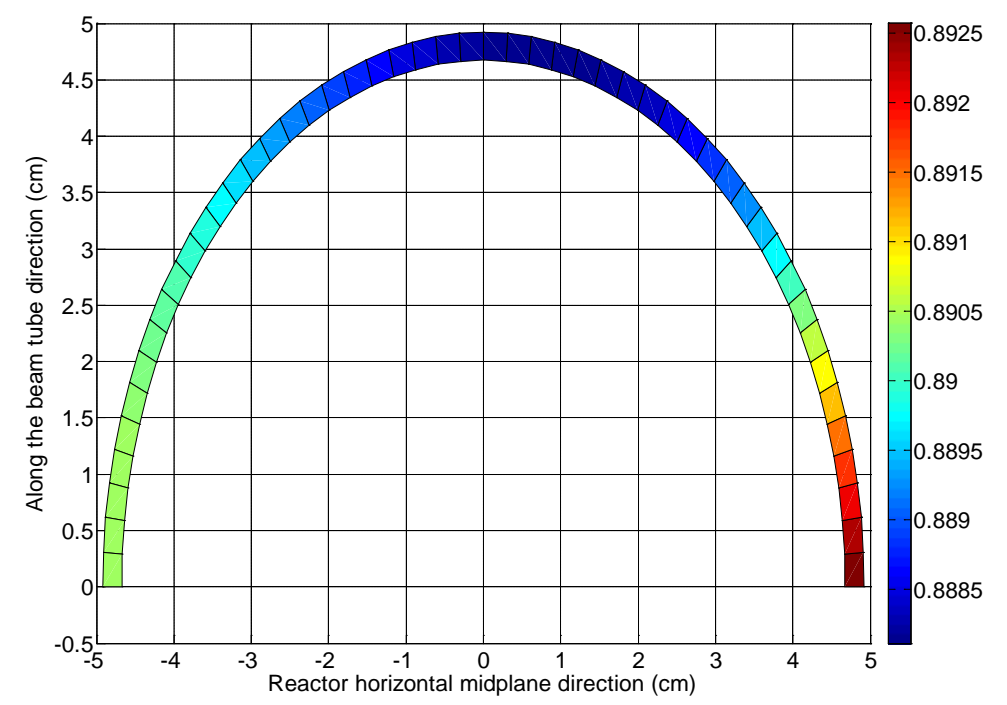

(b)

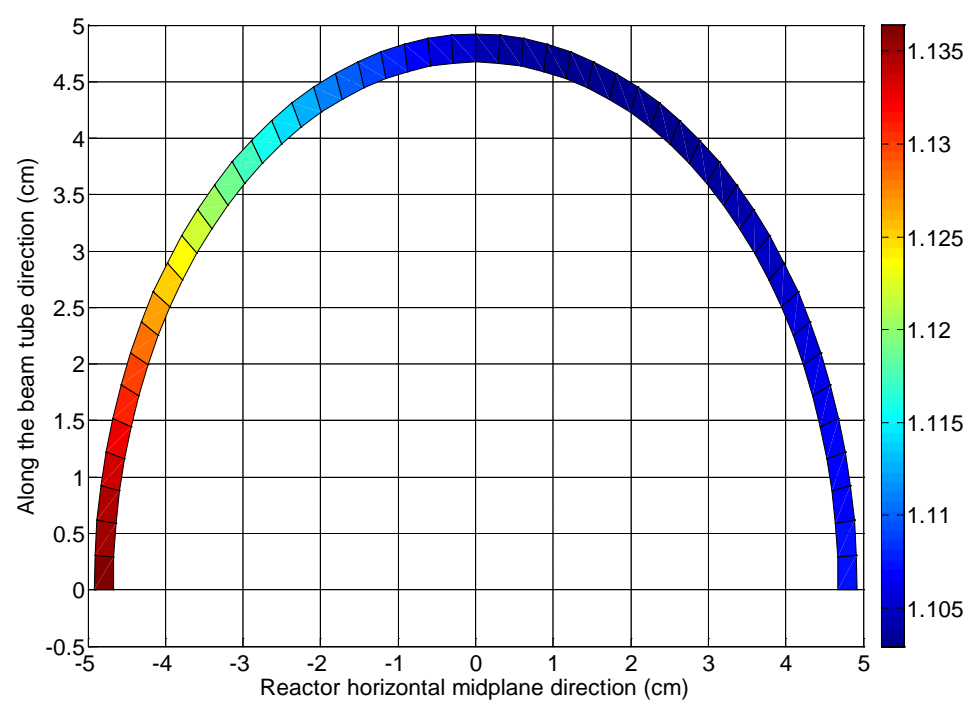

(d)

Fig. 16. Beginning-of-cycle aluminum hemisphere 85 HEU to 100 LEU ratio: neutron (a), beta (b), photon (c), and total (d). 


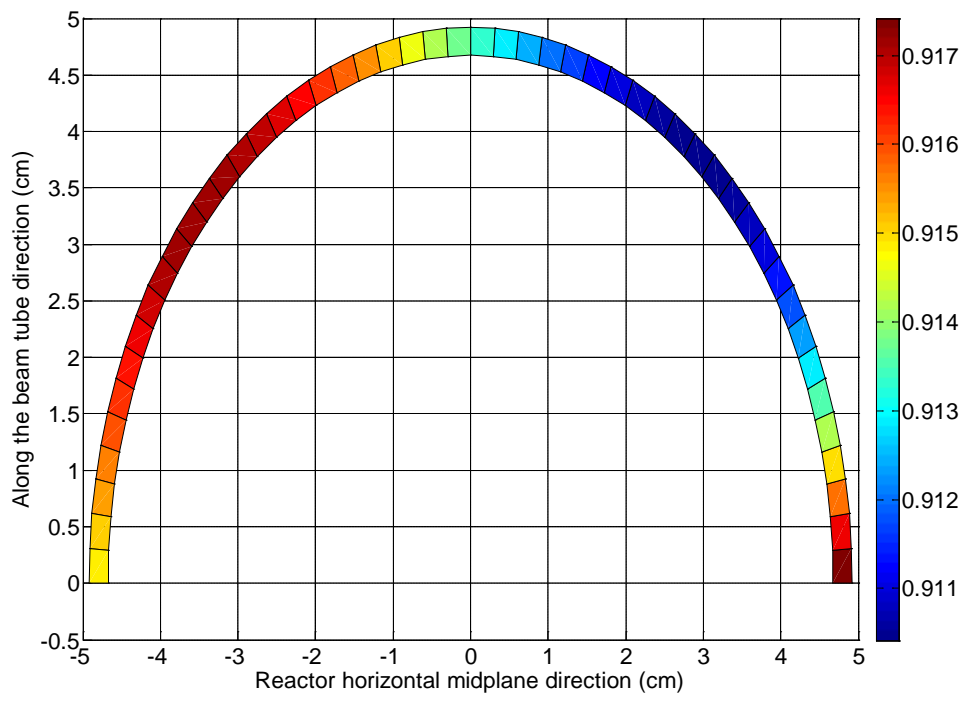

(a)

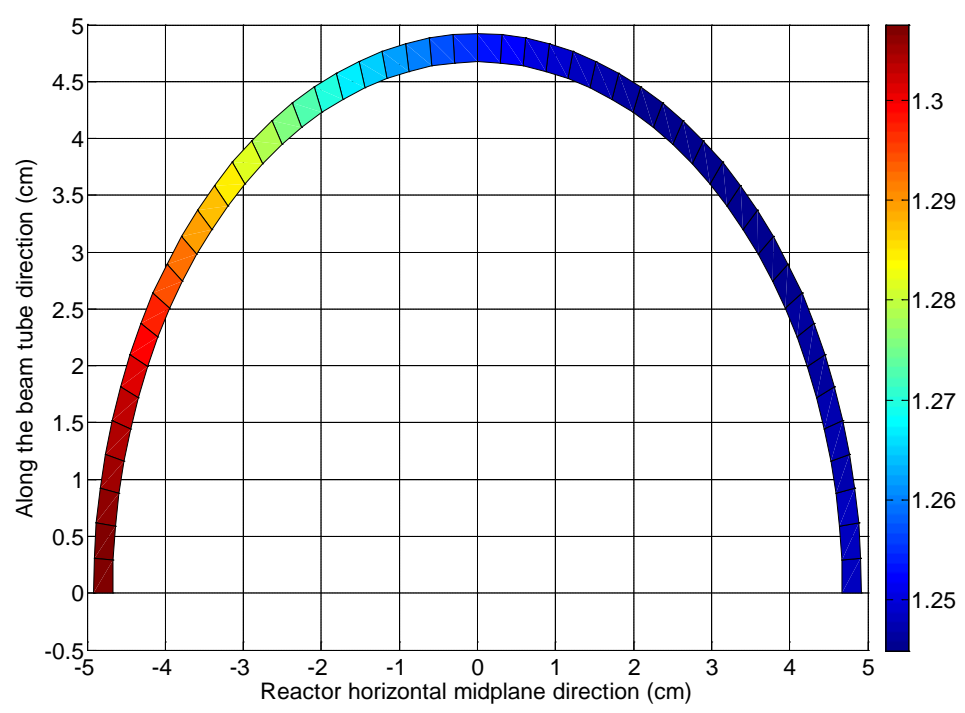

(c)

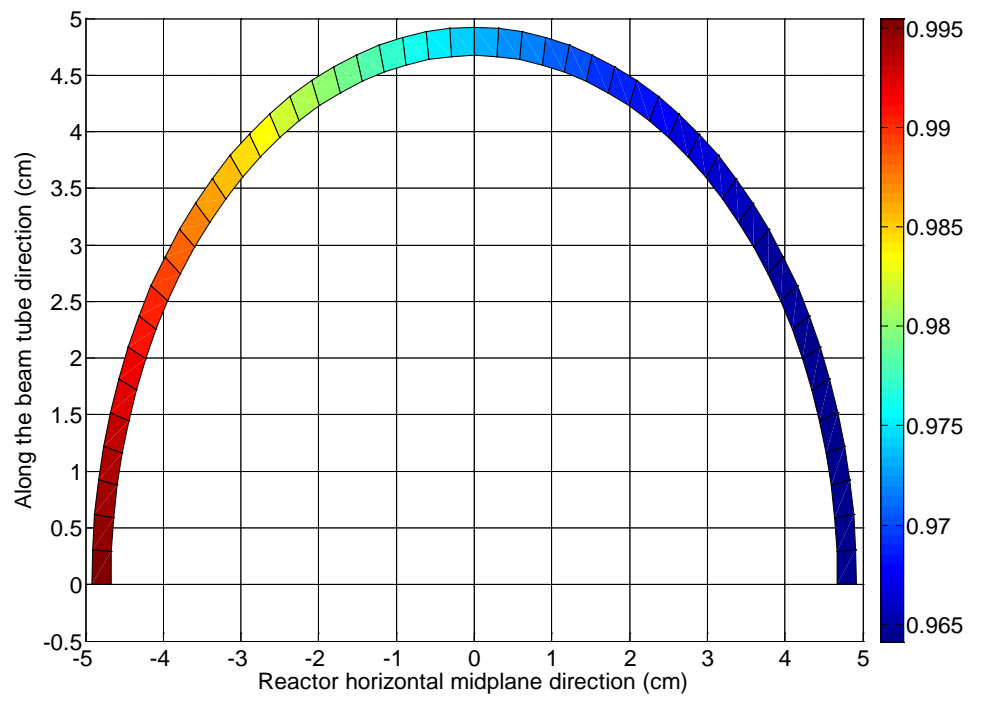

(b)

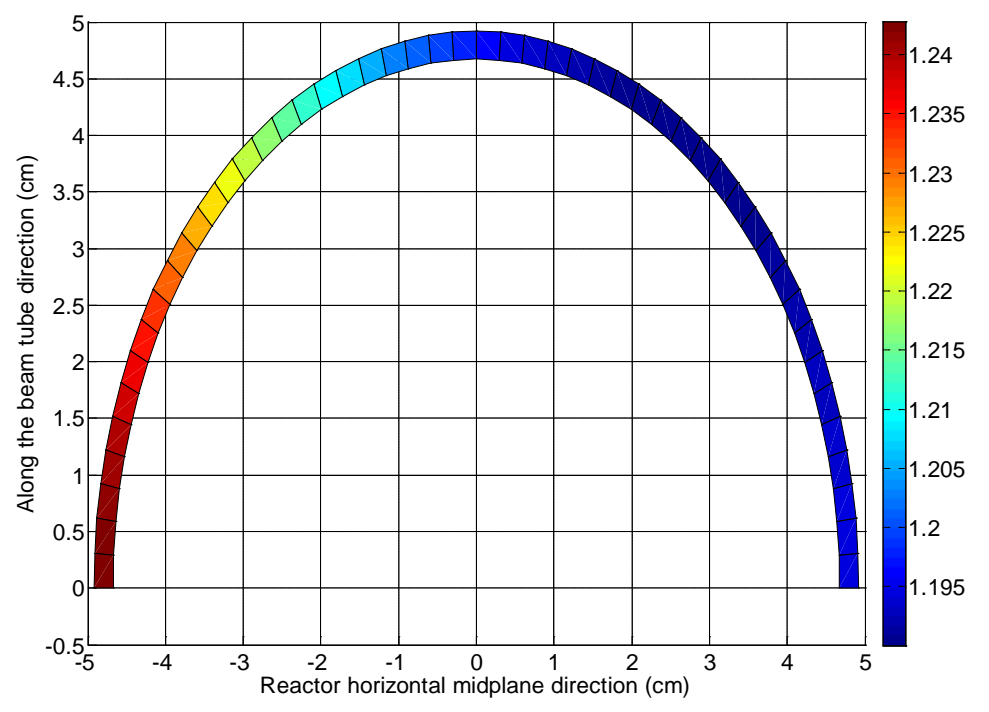

(d)

Fig. 17. End-of-cycle aluminum hemisphere 85 HEU to $100 \mathrm{LEU}$ ratio: neutron (a), beta (b), photon (c), and total (d). 


\subsection{SILICON PRODUCTION RATE RESULTS}

Silicon production rates in units of atoms of ${ }^{28} \mathrm{Si}$ per gram ${ }^{27} \mathrm{Al}$ per second were estimated for the cold source aluminum regions previously described (Table 3 and Table 4). Production rates at BOC and EOC are illustrated in Fig. 18 and Fig. 19. Production rates in cells 86157 and 86158 (i.e., identifiers 41 and 42) are not shown in these figures because their production rates are much lower than those of the other cells due to their location with respect to the fuel. For both BOC and EOC, the production rates for the reference LEU core are greater than those for the HEU core. The silicon production rate is dependent on the neutron flux (both magnitude and spectra), and because the thermal (and total) neutron flux in these aluminum regions increases over the course of the cycle for both core configurations, the EOC production rates are greater than those at BOC.

For the 40 cold source aluminum cells displayed in these figures, the HEU BOC production rates range from about $1.1 \times 10^{12}$ to about $2.8 \times 10^{12}(\mathrm{~g}-\mathrm{s})^{-1}$, and the LEU BOC rates range from about $1.2 \times 10^{12}$ to about $3.2 \times 10^{12}(\mathrm{~g}-\mathrm{s})^{-1}$. The BOC volume-averaged production rate for these regions is about $12.0 \%$ greater when the reactor is operating with the reference LEU core than when operating with the HEU core. However, the EOC volume-averaged production rate due to the LEU core is only about $2.7 \%$ greater than that due to the HEU core.

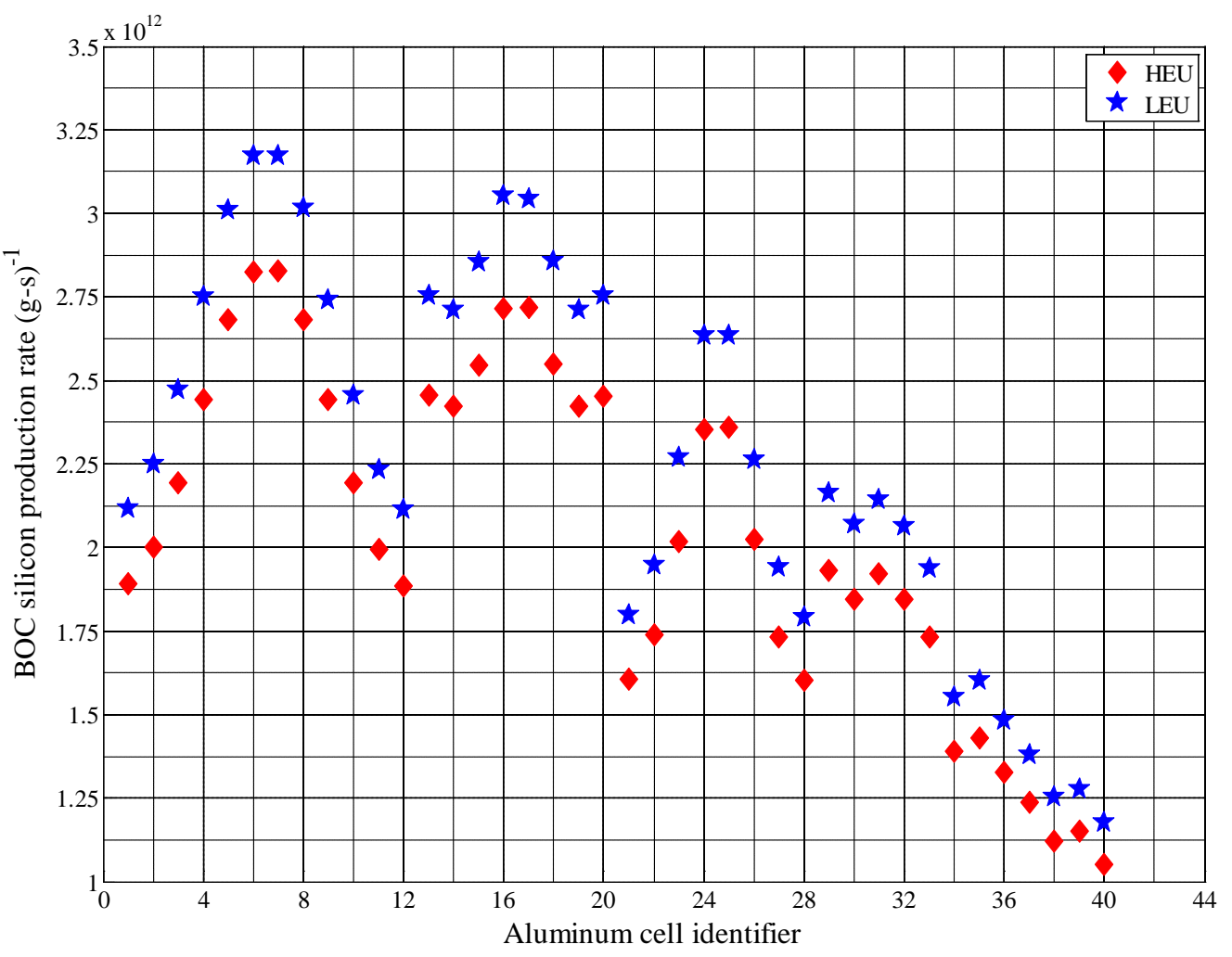

Fig. 18. Beginning-of-cycle silicon production rates in aluminum sections. 


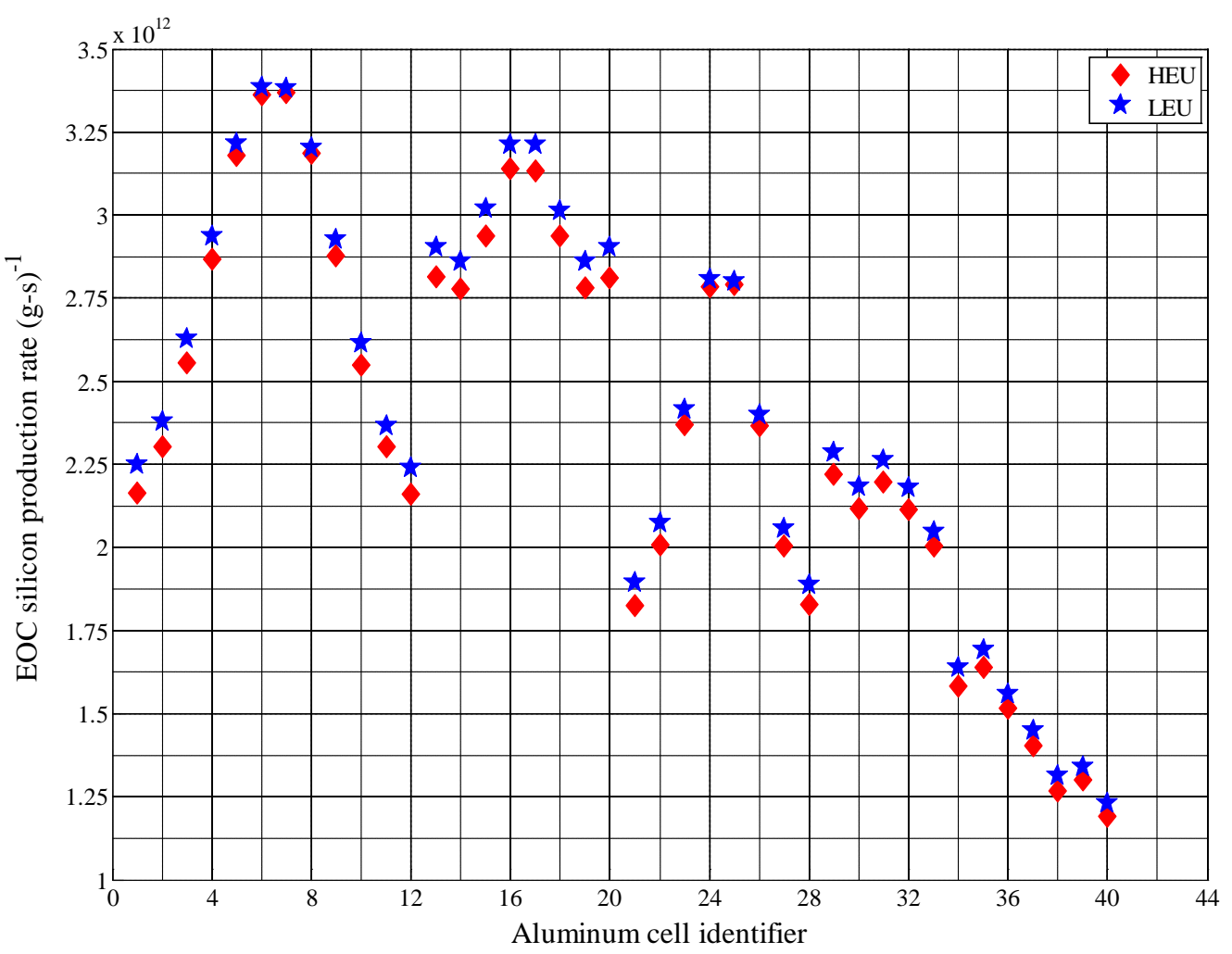

Fig. 19. End-of-cycle silicon production rates in aluminum sections.

\subsection{NEUTRON FLUX IN LH$_{2}$ HEMISPHERE RESULTS}

The impact of the HEU to LEU fuel conversion on the few-group neutron fluxes in the cold source $\mathrm{LH}_{2}$ hemispherical region is discussed in this section. A previous study [7] was performed to assess the impact of the conversion on neutron fluxes at relevant experiment locations in the flux trap, beryllium reflector, and horizontal beam tubes. The study concluded that the BOC thermal, epithermal, and fast fluxes in a tally sphere placed in the HB- $4 \mathrm{LH}_{2}$ region are about $12.21 \pm 0.19 \%, 13.32 \pm 0.37 \%$, and $10.93 \pm 0.53 \%$, respectively, greater for the LEU core. At EOC, [7] concluded the thermal, epithermal, and fast fluxes for the LEU core are about $4.31 \pm 0.17 \%, 13.28 \pm 0.37 \%$, and $11.26 \pm 0.55 \%$, respectively, greater than for the HEU core.

For the studies performed and documented in this report, the same three-group energy structure as that used in [7] was used to calculate the neutron fluxes on the spatial grid described in the previous sections for the cold source $\mathrm{LH}_{2}$ and aluminum regions. The neutron fluxes calculated in the cold source $\mathrm{LH}_{2}$ hemispherical region are documented here. Thermal, epithermal, fast, and total neutron fluxes in the 36 cells composing the $\mathrm{LH}_{2}$ hemispherical region in the MCNP input are illustrated for the HEU and LEU cores at BOC and EOC in Fig. 20-Fig. 23. Fractional standard deviations of 0.0010-0.0013, $0.0019-0.0030$, and $0.0032-0.0050$ (i.e., all less than or equal to $0.5 \%$ ) were obtained for the thermal, epithermal, and fast energy bins. 


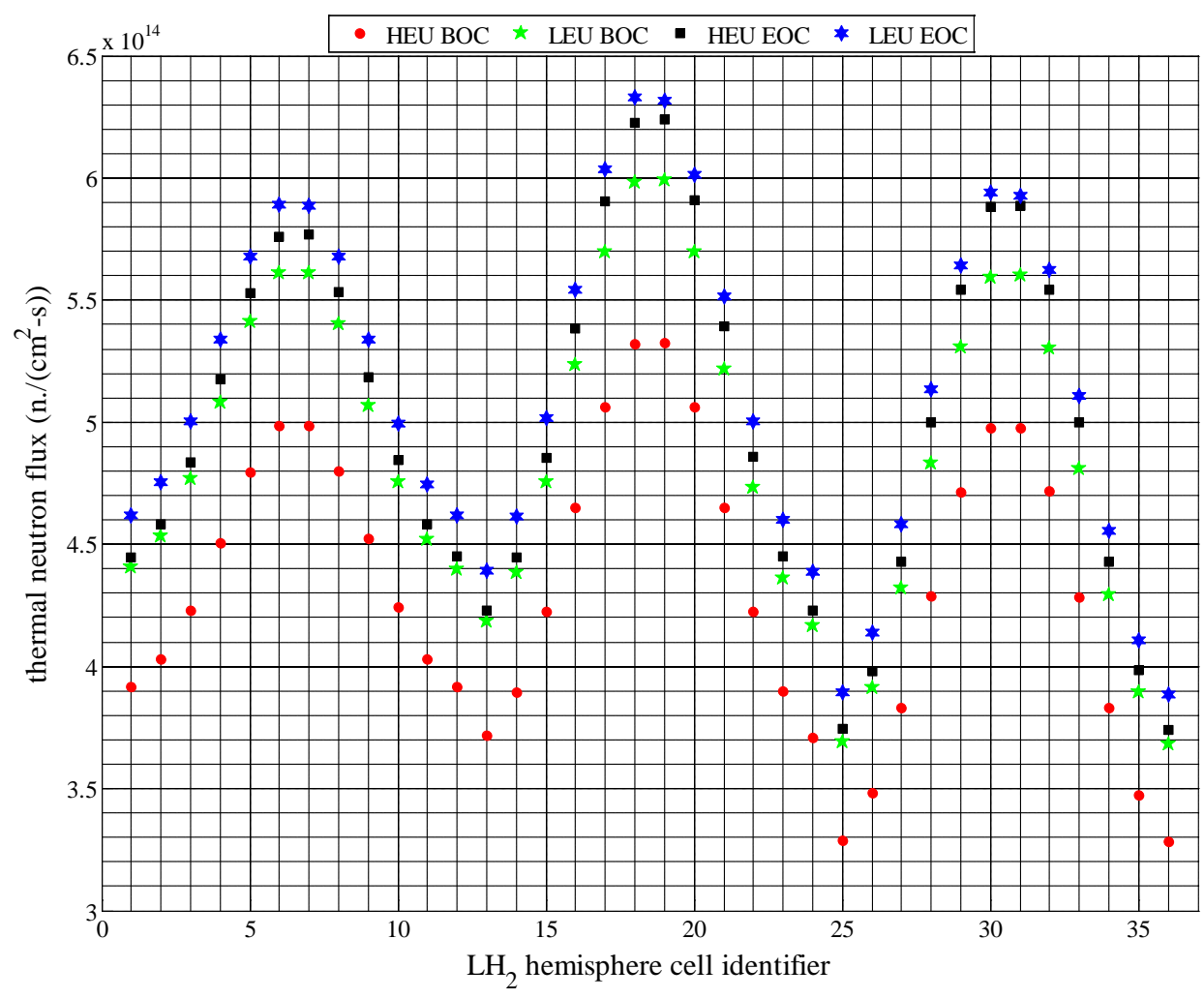

Fig. 20. Thermal $\left(E_{n}<0.625 \mathrm{eV}\right)$ neutron flux in $\mathrm{LH}_{2}$ hemisphere.

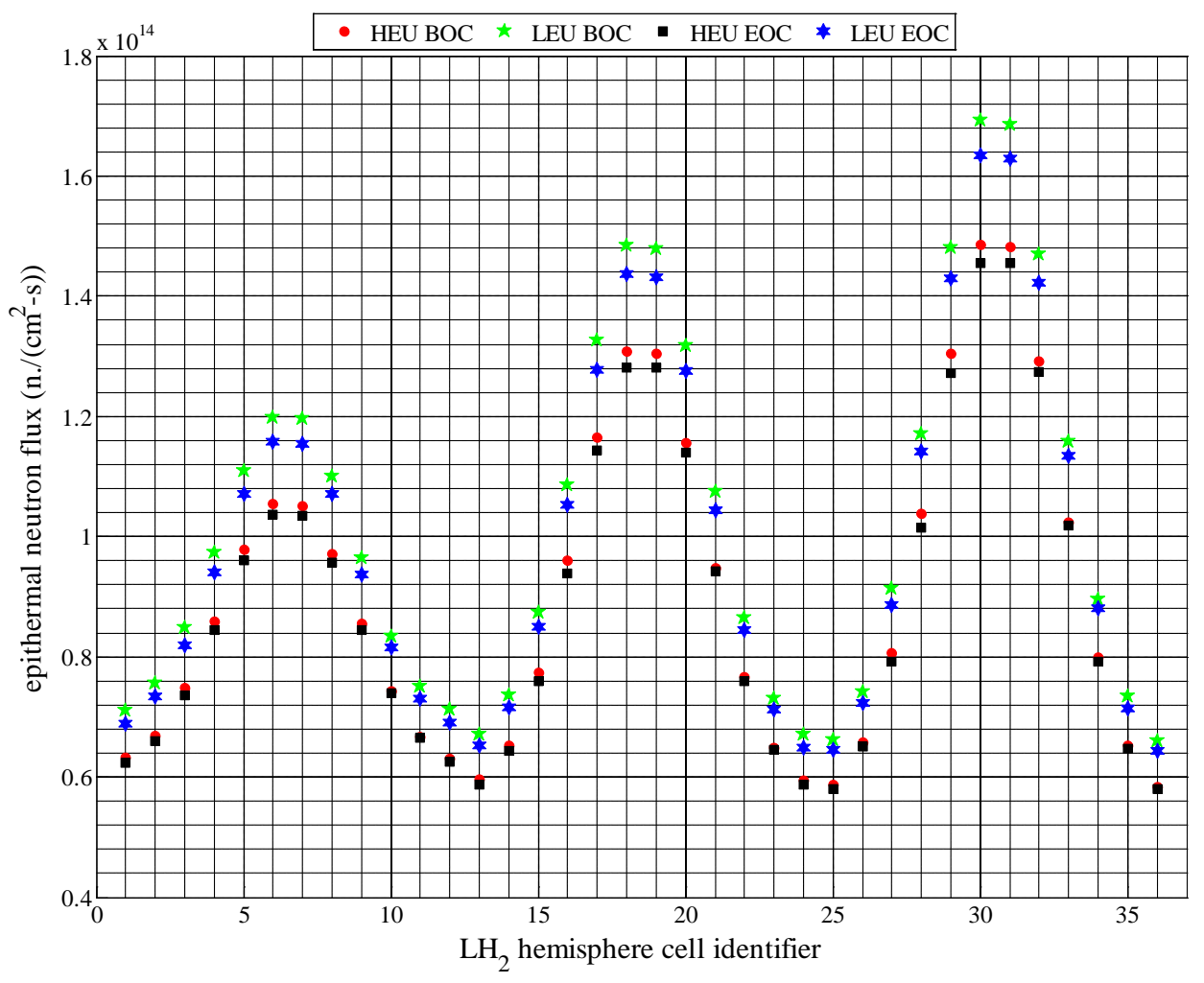

Fig. 21. Epithermal $\left(0.1 \mathrm{MeV}>\mathrm{E}_{\mathrm{n}}>0.625 \mathrm{eV}\right)$ neutron flux in $\mathrm{LH}_{2}$ hemisphere. 


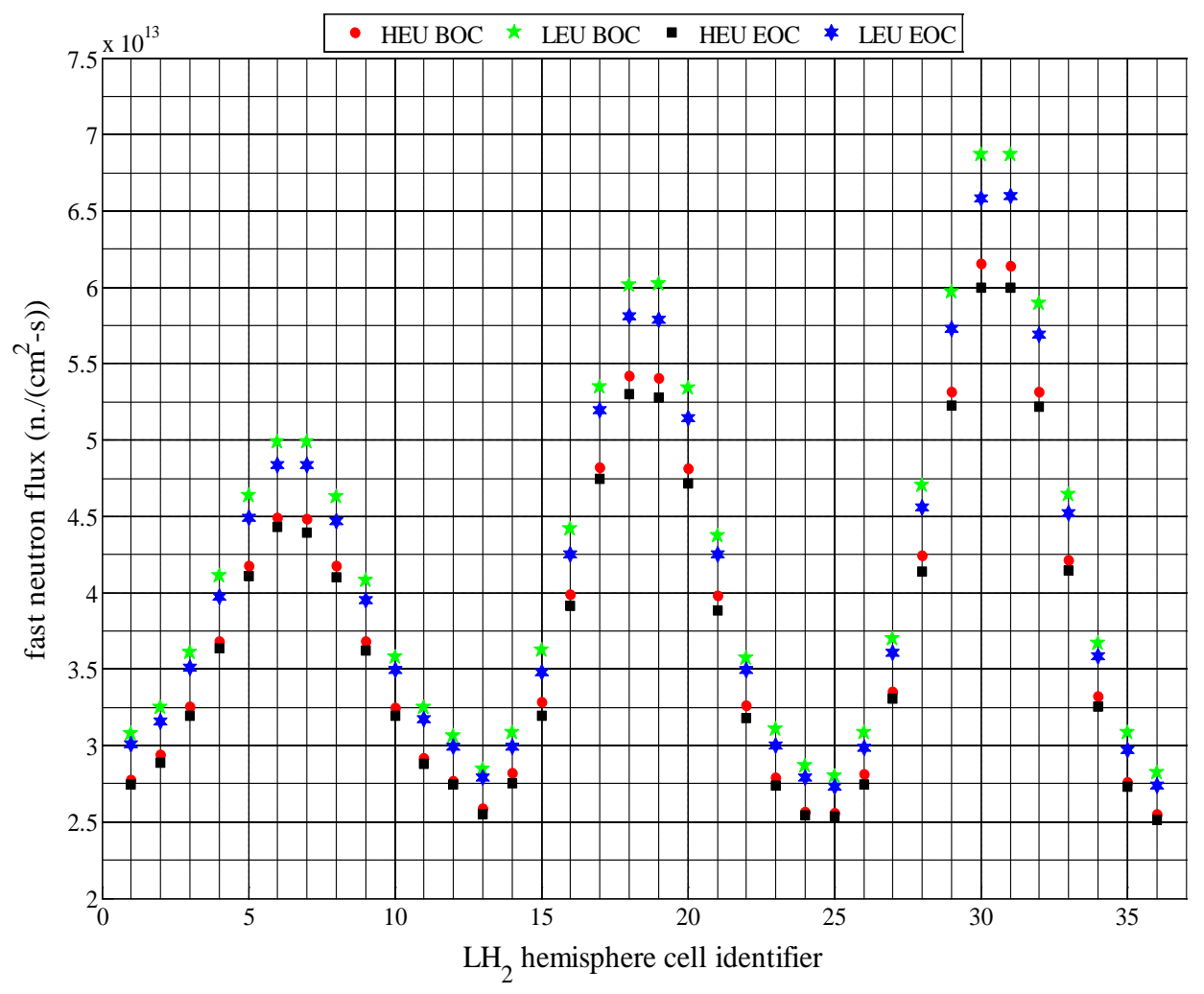

Fig. 22. Fast (20 MeV $\left.>E_{n}>0.1 \mathrm{MeV}\right)$ neutron flux in $\mathrm{LH}_{2}$ hemisphere.

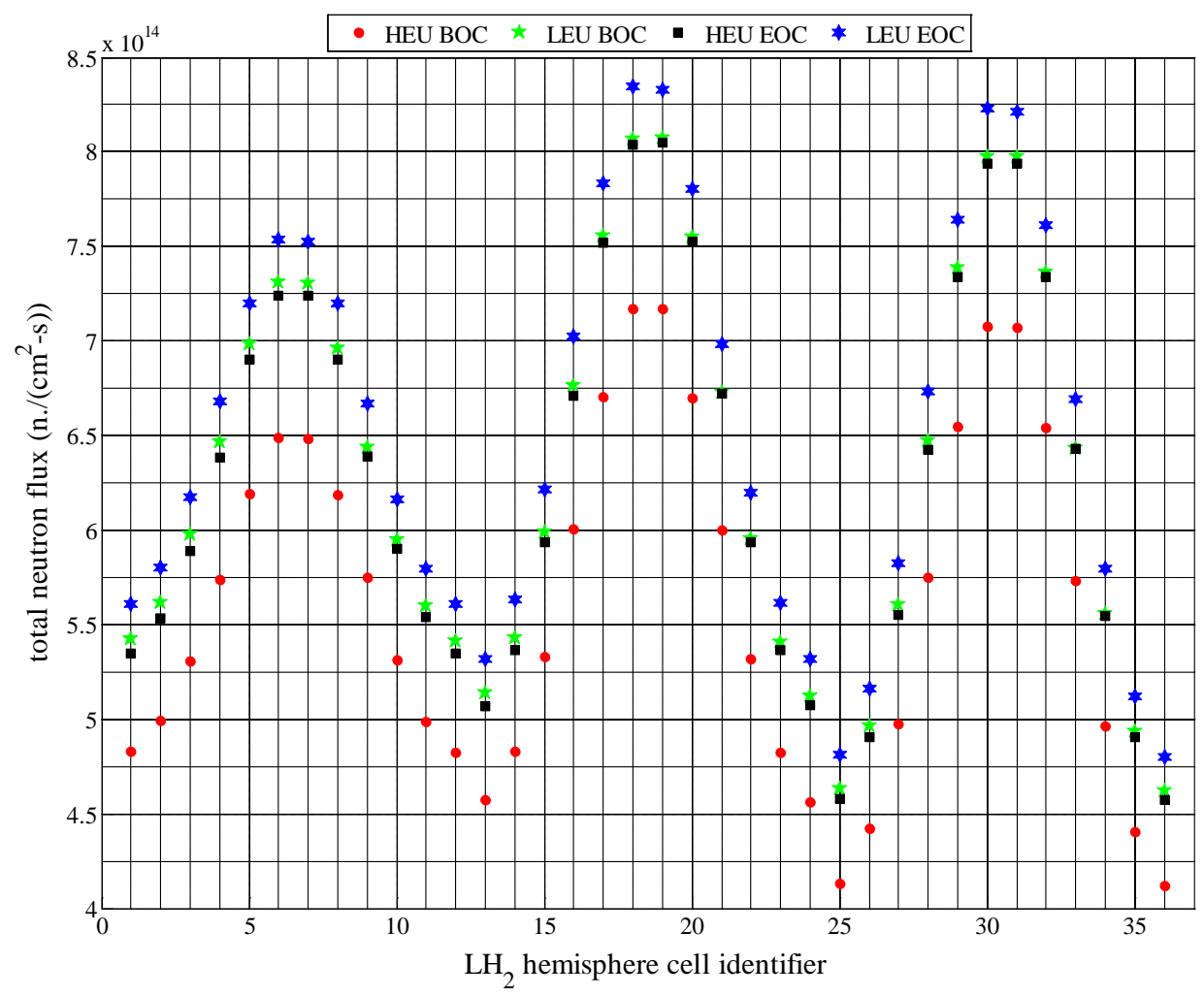

Fig. 23. Total neutron flux in $\mathrm{LH}_{2}$ hemisphere. 
As shown in Fig. 20, the thermal neutron flux is greatest for the LEU EOC core and increases from BOC to EOC for both the LEU and HEU cores. However, the percent increase from BOC to EOC is much greater for the HEU core, which is partly due to the CE positions described previously. The volumeaveraged thermal flux for the HEU and LEU cores increased $15.5 \%$ and 5.5\%, respectively, from BOC to EOC. At BOC, the volume-averaged thermal flux for the LEU core is about $12.4 \%$ greater than the HEU core, but at EOC, the thermal flux for the LEU core is only about $2.7 \%$ greater.

The epithermal and fast neutron fluxes actually decrease slightly from BOC to EOC for both the HEU and LEU cores. Under BOC conditions, the volume-averaged epithermal and fast fluxes were determined to be about $13.2 \%$ and $10.8 \%$ greater, respectively, for the LEU core. At EOC, the volume-averaged epithermal and fast fluxes in the $\mathrm{LH}_{2}$ hemispherical region were determined to be about $11.5 \%$ and $9.4 \%$ greater, respectively, for the LEU core. The results compare well to those calculated in [7] when considering the Monte Carlo statistical uncertainties and the modeling differences. 



\section{SUMMARY AND CONCLUSIONS}

As part of the HFIR HEU to LEU fuel conversion project, an assessment of the impact the conversion would have on nuclear heat generation rates, silicon production rates, and neutron fluxes in regions of the HFIR cold source has been performed. Neutronics calculations were performed with the MCNP5 computational tool and the HEU and reference LEU models documented in [1]. These models were modified as necessary to calculate detailed distributions of the heat generation rates, silicon production rates, and neutron fluxes. Calculations were performed with BOC and EOC conditions to bound typical irradiation conditions.

Volume-averaged BOC heat generation rates of 12.76 and $12.92 \mathrm{~W} / \mathrm{g}$, respectively, were calculated for the hemispherical region of the cold source $\mathrm{LH}_{2}$ region for the HEU and LEU cores, and EOC heat generation rates of 13.25 and $12.86 \mathrm{~W} / \mathrm{g}$, respectively, were calculated for the HEU and LEU cores. Thus, the heat generation rates are slightly greater in the cold source moderator for the LEU core at BOC, but they are greater for the HEU core at EOC. The greatest heat generation rates in both the cold source $\mathrm{LH}_{2}$ moderator and aluminum vessel were determined to occur at EOC for the HEU core. Therefore, the current heat removal system will retain its ability to remove the heat deposited in the cold source system.

As shown in Figure 3 of [2], the total heat deposition in the cold source moderator and vessel varies between about 2.0 and $2.2 \mathrm{~kW}$ during a typical cycle. The total heat depositions calculated in this report, based on the cycle 400 core configuration, for the 85 MW HEU core at BOC and EOC, are about 1.6 and $1.8 \mathrm{~kW}$, respectively. Thus, the calculations based on the cycle 400 input are underestimating the total heat deposited in the cold source moderator and vessel during a typical cycle. This underestimation is primarily due to the beryllium reflector experiment loading modeled in the cycle $400 \mathrm{MCNP}$ input (see Appendix). However, the purpose of this report is to assess the impact the conversion has on the heat generation rates, and because the beryllium reflector experiment loading is the same for both the HEU and LEU inputs, a fair comparison is made. Also, the BOC calculations are expected to be lower than measured results because a true BOC measurement is not possible due to the fuel composition changing in a shorter time span than that required for the measurements [2].

The thermal neutron flux $\left(\mathrm{E}_{\mathrm{n}}<0.625 \mathrm{eV}\right)$ in the cold source $\mathrm{LH}_{2}$ hemispherical region is greatest for the LEU EOC core and increases from BOC to EOC for both the LEU and HEU cores. The volume-averaged thermal flux in the hemisphere $\mathrm{LH}_{2}$ for the HEU and LEU cores increased about $15.5 \%$ and 5.5\%, respectively, from BOC to EOC. At BOC, the volume-averaged thermal flux for the LEU core is about $12.4 \%$ greater than that for the HEU core, but at EOC, the thermal flux for the LEU core is only about $2.7 \%$ greater. Because the thermal neutron flux in the cold source moderator is greater for the LEU core, the number of neutrons cooled by the $\mathrm{LH}_{2}$ and transported to the scattering instruments located in the cold guide hall will also be enhanced. Thus, cold neutron scattering will not be adversely affected by the HEU to LEU fuel conversion.

Similar trends to those observed in the thermal flux results were observed in the silicon production rate results since they are dependent on the neutron flux. Silicon is produced by neutron capture in aluminum, and its presence in structural aluminum can lead to effects on mechanical properties including radiation hardening, loss of ductility, and swelling. The maximum calculated production rates in the cold source aluminum vessel for the HEU and LEU cores at BOC were determined to be $2.8 \times 10^{12}$ and $3.2 \times 10^{12}$ (g$\mathrm{s})^{-1}$, respectively, and the maximum EOC production rates for both cores were about $3.2 \times 10^{12}(\mathrm{~g}-\mathrm{s})^{-1}$. The BOC volume-averaged production rate for the regions analyzed is about $12.0 \%$ greater for the reactor operating with the reference LEU core compared to the reactor operating with the HEU core. The EOC volume-averaged production rate due to the LEU core is about $2.7 \%$ greater than that due to the HEU core. The accrual of silicon in the cold source moderator vessel will be slightly greater for the LEU core, 
and thus, the aluminum moderator vessel's mechanical property changes due to silicon generation will be slightly greater for the LEU core than for the HEU core. 


\section{REFERENCES}

[1] G. Ilas and R. T. Primm, III, Low Enriched Uranium Fuel Design with Two-Dimensional Grading for the High Flux Isotope Reactor, ORNL/TM-2010/318, Oak Ridge National Laboratory, March 2011.

[2] C. O. Slater, R. T. Primm, III, D. A. Pinkston, D. H. Cook, D. L. Selby, P. D. Ferguson, J. A. Bucholz, E. Popov, Measured and Calculated Heating and Dose Rates for the HFIR HB4 Beam Tube and Cold Source, ORNL/TM-2009/012, Oak Ridge National Laboratory, March 2009.

[3] C. O. Slater and R. T. Primm, III, Nuclear Heating Rates in and around the Cold Source and HB4 Beam Tube, C-HFIR-2005-113, March 2005 (archived, internal document available upon request to the division director, Research Reactors Division, Oak Ridge National Laboratory).

[4] C. O. Slater, Nuclear Heating Rate in the HFIR Cold Source, C-HFIR-2005-142, April 2005 (archived, internal document available upon request to the division director, Research Reactors Division, Oak Ridge National Laboratory).

[5] D. Chandler, Cold Source Nuclear Heating Rates for the HEU and LEU Fueled HFIR, C-HFIR2012-014, December 2013 (archived, internal document available upon request to the division director, Research Reactors Division, Oak Ridge National Laboratory).

[6] R. T. Primm, III and N. Xoubi, Modeling of the High Flux Isotope Reactor Cycle 400, ORNL/TM2004/251, Oak Ridge National Laboratory, August 2005.

[7] D. Ilas, Impact of HFIR LEU Conversion on Spectral Characteristics of Experiment Locations, ORNL/LTR-2012/414, Oak Ridge National Laboratory, September 2012.

[8] D. Ilas, Impact of HFIR LEU Conversion on Beryllium Reflector Degradation Factors, ORNL/TM2013/441, Oak Ridge National Laboratory, October 2013.

[9] X-5 Monte Carlo Team, MCNP-A General Monte Carlo N-Particle Transport Code, Version 5, LA-CP-03-0245, Los Alamos National Laboratory, April 2003.

[10] W. Haeck, VESTA User's Manual - Version 2.0.0, Institut de Radioprotection et de Sûreté Nucléaire Report, DSU/SEC/T/2008-331 Indice A, France, 2009.

[11] D. Chandler, R. T. Primm, III, and G. I. Maldonado, Burnup and Spatially-Dependent Uranium Isotopic Calculations for the High Flux Isotope Reactor, American Nuclear Society Transaction, Vol. 103, 768 - 769, November 2010.

[12] SCALE: A Comprehensive Modeling and Simulation Suite for Nuclear Safety Analysis and Design, ORNL/TM-2005/39, Version 6.1, June 2011 (Available from Radiation Safety Information Computational Center at Oak Ridge National Laboratory as CCC-785), Oak Ridge, TN, 2011.

[13] D. Chandler and R. W. Hobbs, Neutronics Analyses of $\mathrm{NpO}_{2}$ Single Pellet Irradiations at HFIR to Support the Pu-238 Production Project, American Nuclear Society Transaction, Vol . 108, 753755, June 2013.

[14] MATLAB, Release 2012a, The MathWorks, Inc., Natick, MA.

[15] D. Chandler, Nuclear Heating and Radionuclide Inventory Calculations to Support NpO2 Single Pellet Irradiations in HFIR, C-HFIR-2012-006, May 2012 (archived, internal document available upon request to the division director, Research Reactors Division, Oak Ridge National Laboratory).

[16] F. X. Gallmeier and J. C. Gehin, MCNP-Cross Section Modifications for Reactor Physics Calculations, Unpublished document, August 1996. 
[17] Chart of Nuclides, National Nuclear Data Center, Brookhaven National Laboratory, $<$ www.nndc.bnl.gov/chart/>

[18] J. Peterson and G. Ilas, Calculation of Heating Values for the High Flux Isotope Reactor, Proceedings of PHYSOR 2012 - Advances in Reactor Physics - Linking Research, Industry, and Education, Knoxville, TN, April 15-20, 2012.

[19] F. B. Brown, W. R. Martin, and R. D. Mosteller, Monte Carlo - Advances and Challenges, (workshop presentation at PHYSOR 2008, Interlaken Switzerland), LA-UR-08-05891, Los Alamos National Laboratory, Los Alamos, NM, 2008.

[20] B. R. Betzler, E. E. Sunny, J. C. Lee, and W. R. Martin, Coupled Nuclear-Thermal-Hydraulic Calculations for Fort St. Vrain Reactor, NURETH14-421, The $14^{\text {th }}$ International Topical Meeting on Nuclear Reactor Thermalhydraulics, September 2011. 


\section{APPENDIX. METHODS AND PREVIOUS CALCULATION COMPARISONS}

During the developmental stages of this study, several Monte Carlo N-Particle (MCNP) calculations were executed to compare the different methods and cross section sets being used. The primary purpose of these calculations was to eliminate the need for using specialized cross sections based on the older ENDF/B-V and Institut für Kernenergetik und Energiesysteme (University of Stuttgart, Institute for Nuclear Technology and Energy Systems; IKE) data because it was desired to use the more recent ENDF/B-VII.0 data.

The volume-averaged heat generation rates for the cold source $\mathrm{LH}_{2}$ and aluminum regions at beginningof-cycle (BOC) for the high enriched uranium (HEU) core are provided in Table A-1 for several calculations. The results from the calculation labeled as 2005-113 are from [A1], and the results from the calculation labeled as 2005-142 are from [A2]. The ENDF/B-V data and the specialized ${ }^{27} \mathrm{Al},{ }^{235} \mathrm{U}$, and $\mathrm{LH}_{2}$ cross sections (based on ENDF/B-V and IKE) were used in both of these calculations. Calculation 2005-113 used kcode calculations and 2005-142 used fixed source calculations. The surface source was determined by the same input used in 2005-113. Thus, the results from these two calculations should be and are in good agreement with each other (within the statistical uncertainties).

Table A-1. Comparison of average beginning-of-cycle HEU heat generation rates $(\mathrm{W} / \mathrm{g})$

\begin{tabular}{lccccccc}
\hline \multirow{2}{*}{ Calculation } & \multirow{2}{*}{$\mathbf{k}_{\text {eff }}$} & \multirow{2}{*}{$\boldsymbol{\sigma}_{\text {keff }}$} & \multicolumn{2}{c}{$\mathbf{L H}_{2}$} & \multicolumn{3}{c}{ Aluminum } \\
\cline { 4 - 8 } & & & neutron & photon & neutron & photon & beta \\
\hline $2005-113$ & 1.00712 & 0.00009 & 4.142 & 2.746 & 0.0151 & 1.526 & 0.274 \\
$2005-142$ & \multicolumn{2}{c}{ fixed source } & 4.200 & 2.783 & 0.0154 & 1.545 & 0.272 \\
$\mathrm{~A}$ & 1.00717 & 0.00004 & 4.144 & 2.849 & 0.0150 & 1.581 & 0.273 \\
$\mathrm{~B}$ & 1.00996 & 0.00005 & 4.188 & 2.614 & 0.0146 & 1.451 & 0.278 \\
$\mathrm{C}$ & 1.00996 & 0.00005 & 4.172 & 2.618 & 0.0147 & 1.448 & 0.273 \\
$\mathrm{D}$ & 1.01274 & 0.00004 & 4.020 & 2.716 & 0.0145 & 1.498 & 0.268 \\
$\mathrm{E}^{a}$ & 0.99716 & 0.00003 & 3.935 & 2.460 & 0.0142 & 1.337 & 0.233 \\
\hline
\end{tabular}

${ }^{a} \mathrm{E}$ is the $85 \mathrm{MW}$ HEU BOC calculation documented in the body of this report.

The MCNP input used in [A1] to calculate the source around horizontal beam tube number 4 (HB-4) was used in calculations A, B, C, and D. Therefore, the geometry and material compositions used in the first six calculations listed in Table A-1 are identical except the cold source geometry in 2005-113 is not subdivided into as many cells as the other geometries.

Calculation A was created by replacing the specialized ENDF/B- ${ }^{235} \mathrm{U}$ cross section library (named 92235.02c) with the default ENDF/B-V ${ }^{235} \mathrm{U}$ cross section library (named 92235.50c) to exclude the delayed photons. The pikmt card was used in a separate run to estimate the delayed photon contribution.

As shown in Table A-1, the average neutron energy deposition in the cold source $\mathrm{LH}_{2}$ decreased by $1.3 \%$ and the photon heating increased by $2.3 \%$ relative to $2005-142$. The only change between the two calculations was the method used in calculating the delayed photon contribution, and therefore, the neutron energy deposition should be equal. The 1.3\% decrease in neutron heating falls within the calculated statistical uncertainty (see differences between 2005-113 and 2005-142). A slight increase of $2.3 \%$ in the average photon energy deposition shows that the pikmt method is valid and is slightly conservative with respect to using the specialized ${ }^{235} \mathrm{U}$ cross sections (for this application/system). 
All three of the specialized cross section libraries $\left(\mathrm{LH}_{2},{ }^{235} \mathrm{U},{ }^{27} \mathrm{Al}\right)$ were used in calculation $\mathrm{B}$, but the cross sections for all other isotopes were updated to ENDF/B-VII.0 cross sections. This calculation was performed to assess the differences between the two sets of cross sections. The calculated effective multiplication factor increased from 1.00717 to 1.00996 ( $\sim 36$ cents using $\beta_{\text {eff }}=0.00762$ ). These changes caused a decrease of 6.1\% (relative to 2005-142) in the average photon heating in the cold source $\mathrm{LH}_{2}$ regions, a decrease of $5.4 \%$ in the average neutron heating in the cold source aluminum, and a decrease of $6.1 \%$ in photon heating in the cold source aluminum.

The only difference between calculations $\mathrm{C}$ and $\mathrm{B}$ is that $\mathrm{C}$ used the ENDF/B-VII.0 cross sections for the cold source $\mathrm{LH}_{2}$, whereas $\mathrm{B}$ used the specialized $\mathrm{LH}_{2}$ cross section library. No differences (within the calculated statistical uncertainties) are observed between the calculations. Thus, it is reasonable to eliminate the use of the specialized $\mathrm{LH}_{2}$ data and use the ENDF/B-VII.0 data.

Calculation D used the same geometry and material compositions as those used in the calculation to obtain the source around HB-4 for the calculation labeled 2005-142, but the methods and cross sections used in D were the same as those used and described in the set of calculations described in the body of this report. Thus, ENDF/B-VII.0 cross sections were used for all isotopes (including $\mathrm{LH}_{2}$ and ${ }^{235} \mathrm{U}$ ), and the pikmt method was used. The modified ENDF/B-VII. $0{ }^{27} \mathrm{Al}$ cross section library discussed in the body of this report was also used for calculation D. Relative to 2005-142, the average heating rates decreased between $1.3 \%$ and $6.0 \%$ for all of the radiation heating means in the cold source $\mathrm{LH}_{2}$ and aluminum zones.

In conclusion, the largest differences in nuclear heat generation rates between the methods implemented in previous studies [A1-A3] and those used in this calculation are attributable to differences between ENDF/B-V and ENDF/B-VII.0 cross sections. It was shown in this Appendix that the pikmt method produces slightly greater photon heat generation values than those calculated with the specialized ${ }^{235} U$ data. Also, no statistically identifiable differences were observed in the heat generation rates when using the ENDF/B-VII.0 $\mathrm{LH}_{2}$ data or the specialized $\mathrm{LH}_{2}$ data.

As shown in Table A-2, using ENDF/B-VII.0 data and the pikmt method instead of using ENDF/B-V data and specialized cross sections results in average cold source $\mathrm{LH}_{2}$ and aluminum heating rate differences ranging between $1.3 \%$ and $6.0 \%$. Because the cycle 400 model was used in the calculations documented in the body of this report, it is also necessary to examine the effects due to differences between the cycle 400 model and the model used in [A1-A3]. When using the cycle 400 model (labeled $\mathrm{E}$ in Tables A-1 and A-2) and the same method as that used in calculation D, the average cold source $\mathrm{LH}_{2}$ and aluminum heat generation rates range from $6.3 \%$ to $14.1 \%$ less than those calculated in [A2] (see Table A-2). Since the same cross sections and methods are used for both $\mathrm{D}$ and $\mathrm{E}$, the differences between the average cold source $\mathrm{LH}_{2}$ and aluminum heat generation rates calculated in $\mathrm{D}$ and $\mathrm{E}$ are attributable to using different models.

The BOC fuel element compositions are the same for both inputs, but the experimental facility loadings differ. The model used in [A1-A3] includes 12 curium targets, a combination of aluminum and stainless steel targets, and aluminum peripheral target positions (PTPs) in the flux trap target region (FTT). The cycle 400 FTT includes mostly shrouded and solid aluminum targets with various PTP loadings (Al, SiC, $\mathrm{W}, \mathrm{Mo}, \mathrm{V}$, etc.). Although the flux trap loading impacts reactivity, it does not have a large impact on the neutron leakage into the beryllium reflector. 
Table A-2. Percent differences between average beginning-of-cycle HEU heating rates

\begin{tabular}{cccccc}
\hline \multirow{2}{*}{ Case } & \multicolumn{2}{c}{$\mathbf{L H}_{2}$} & \multicolumn{3}{c}{ Al } \\
\cline { 2 - 6 } & neutron & photon & neutron & photon & beta \\
\hline$\frac{\mathrm{D}-(2005-142)]}{2005-142}$ & $-4.29 \%$ & $-2.39 \%$ & $-6.04 \%$ & $-3.04 \%$ & $-1.25 \%$ \\
$\frac{[\mathrm{E}-(2005-142)]}{2005-142}$ & $-6.30 \%$ & $-11.57 \%$ & $-7.85 \%$ & $-13.44 \%$ & $-14.13 \%$ \\
$\frac{\mathrm{E}-\mathrm{D}}{\mathrm{D}}$ & $-2.10 \%$ & $-9.41 \%$ & $-1.92 \%$ & $-10.72 \%$ & $-13.04 \%$ \\
\hline
\end{tabular}

All of the removable beryllium (RB; 8 large and 4 small) and control rod access plug (CRAP; 8) facilities are filled with beryllium plugs in the [A1-A3] model. The cycle 400 model includes beryllium plugs in the CRAP facilities, the small RB facilities, and three of the large RB facilities. However, four of the large RBs are filled with aluminum plugs and one of the RBs has an europium liner and contains experiment materials. The experiment facility loadings near the cold source for the cycle 400 and the [A1-A3] model are shown in Fig. A-1. The loading differences in the RB7A and RB7B facilities between the two models will have the largest impact. The RB7A and RB7B facilities include beryllium plugs in the [A1-A3] model and accommodate europium and aluminum in the cycle 400 model.

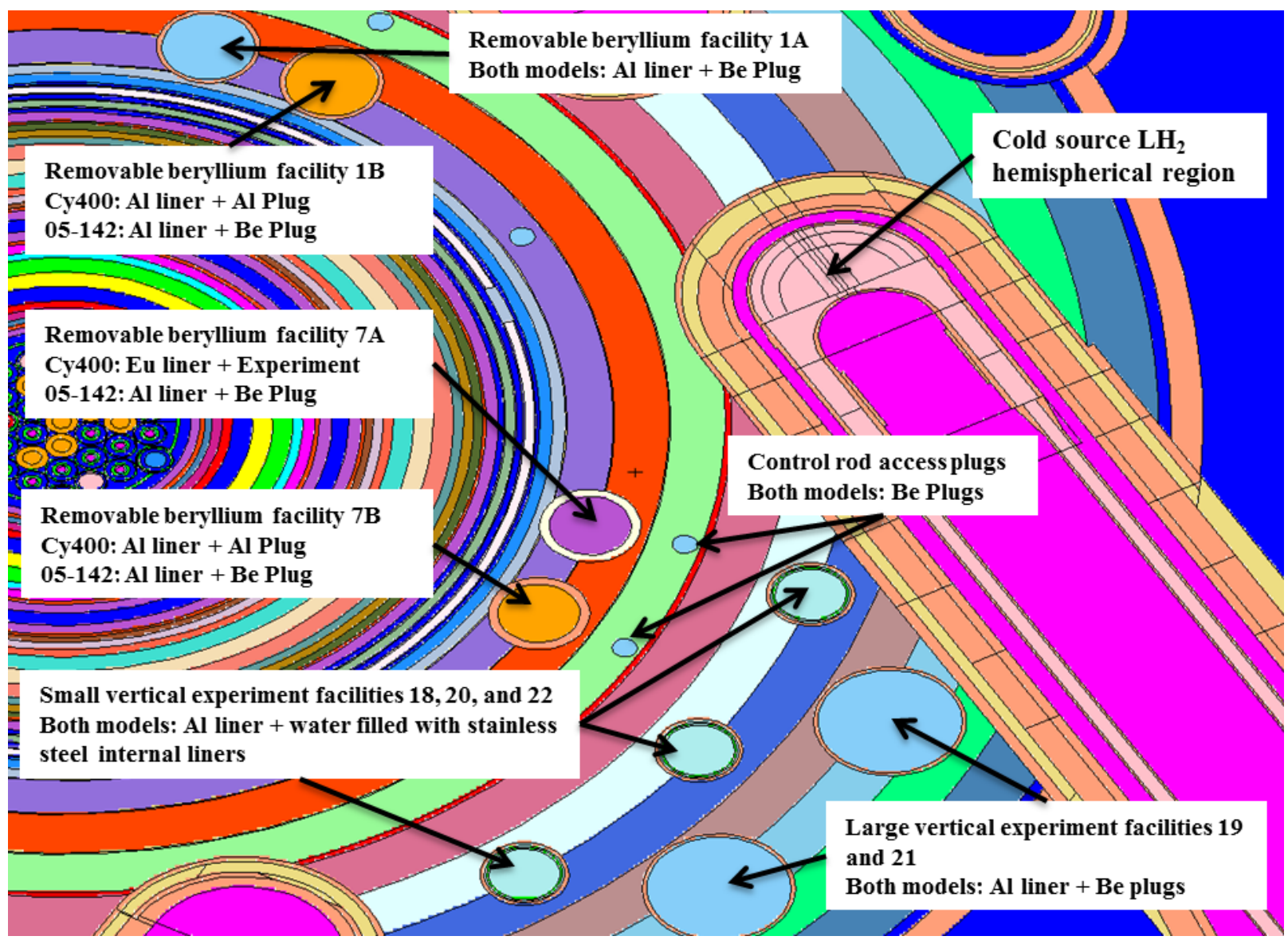

Fig. A-1. Beryllium reflector experiment loading around horizontal beam tube 4 . 
The isotopic makeup of the control elements (CEs) also differs between the two models. The composition of the CE regions in the [A1-A3] model are fresh (i.e., never irradiated). However, the compositions of the CEs in the cycle 400 model were determined by depletion calculations that account for the irradiation history of the CEs used in cycle 400 [A4 and A5]. The inclusion of "burned" control elements introduces negative reactivity into the core (relative to using fresh CEs) and increases the neutron absorbing capabilities of the elements.

Note that other than the FTT loading, which should have a minimal impact on the cold source heat generation rates, the experiment and CE materials used in the HEU and LEU models are the same.

\section{REFERENCES}

[A1] C. O. Slater and R. T. Primm, III, Nuclear Heating Rates in and around the Cold Source and HB4 Beam Tube, C-HFIR-2005-113, March 2005 (archived, internal document available upon request to the division director, Research Reactors Division, Oak Ridge National Laboratory).

[A2] C. O. Slater, Nuclear Heating Rate in the HFIR Cold Source, C-HFIR-2005-142, April 2005 (archived, internal document available upon request to the division director, Research Reactors Division, Oak Ridge National Laboratory).

[A3] C. O. Slater, R. T. Primm, III, D. A. Pinkston, D. H. Cook, D. L. Selby, P. D. Ferguson, J. A. Bucholz, E. Popov, Measured and Calculated Heating and Dose Rates for the HFIR HB4 Beam Tube and Cold Source, ORNL/TM-2009/012, Oak Ridge National Laboratory, March 2009.

[A4] G. Ilas and R. T. Primm, III, Low Enriched Uranium Fuel Design with Two-Dimensional Grading for the High Flux Isotope Reactor, ORNL/TM-2010/318, Oak Ridge National Laboratory, March 2011.

[A5] G. Ilas and R. T. Primm, III, Methodology for Simulating the Irradiation of the Control Elements in HFIR, American Nuclear Society Transaction, Vol. 103, 396-398, November 2010. 
ORNL/TM-2014/12

\section{INTERNAL DISTRIBUTION}

1. B. J. Ade (adebj@ornl.gov)

2. K. J. Beierschmitt (beierschmitt@ornl.gov)

3. G. I. Bell (bellgi@ornl.gov)

4. S. M. Bowman (bowmansm2ornl.gov)

5. D. Chandler (chandlerd@ornl.gov)

6. D. H. Cook (dhc@ornl.gov)

7. R. A. Crone (cronera@ornl.gov)

8. R. J. Ellis (ellisrj@ornl.gov)

9. J. D. Freels (freelsjd@ornl.gov)

10. J. C. Gehin (gehinjc@ornl.gov)

11. C. R. Hyman (hymancriii@ornl.gov)

12. A. S. Icenhour (icenhouras@ornl.gov)

13. G. Ilas (ilasg@ornl.gov)

14. P. K. Jain (jainpk@ornl.gov)
15. M. W. Kohring (kohringmw@ornl.gov)

16. Y.S. Kwon (kwonys@ornl.gov)

17. R. S. McKeehan (mckeehanrs@ornl.gov)

18. C. V. Parks (parkscv@ornl.gov)

19. J. L. Peterson (petersonjl@ornl.gov)

20. D. L. Pinkston (pinkstondl@ornl.gov)

21. T. Powers (powerstp@ornl.gov)

22. D. G. Renfro (renfrodg@ornl.gov)

23. K. A. Smith (smithka@ornl.gov)

24. E. E. Sunny (sunnyee@ornl.gov)

25. W. J. Toth (tothwj@ornl.gov)

26. ORNL Laboratory Records (hamrindr@ornl.gov)

27. RRD-DCC-RC (hugginscn@ornl.gov)

\section{EXTERNAL DISTRIBUTION}

28. A. Adams, U.S. Nuclear Regulatory Commission, One White Flint North, 11555 Rockville Pike, Rockville, Maryland 20852-2738 (axa@nrc.gov)

29. Aurelien Bergeron, Argonne National Laboratory, 9700 S. Cass Avenue, Argonne, IL 60439

(abergeron@anl.gov)

30. Douglas Burkes, Pacific Northwest National Laboratory (douglas.burkes@nnsa.doe.gov)

31. R. A. Butler, Director, Research Reactor Center, 1513 Research Park Drive, Columbia, MO 65211 (ButlerRa@missouri.edu)

32. G. S. Chang, Idaho National Laboratory, P.O. Box 1625, Idaho Falls, ID 83415-3885 (gray.chang@inl.gov)

33. M. D. DeHart, Idaho National Laboratory, P.O. Box 1625, Idaho Falls, Idaho 83415-8370 (Mark.DeHart@inl.gov)

34. D. Diamond, Brookhaven National Laboratory, P.O. Box 5000, Upton, NY 11973-5000 (diamond@bnl.gov)

35. J. Dwight, Idaho National Laboratory, P.O. Box 1625, Idaho Falls, ID 83415-3750 (John.Dwight@inl.gov)

36. L. Foyto, Research Reactor Center, 1513 Research Park Drive, Columbia, MO 65211 (foytol@missouri.edu)

37. D. Kutikkad, Assistant Reactor Manager-Physics, University of Missouri Research Reactor Facility, Columbia, MO65211(kutikkadk@missouri.edu)

38. C. Landers, NA-212, U.S. Department of Energy, 1000 Independence Avenue SW, Washington, DC 20585 (Christopher.landers@nnsa.doe.gov)

39. J. Matos, Argonne National Laboratory, 9700 S. Cass Avenue, Argonne, IL 60439 (jim.matos@anl.gov)

40. D. McDaniel, Idaho National Laboratory, P.O. Box 6188, Idaho Falls, ID 83415 (David.McDaniel@inl.gov)

41. C. McKibben, University of Missouri Research Reactor Facility, Columbia, MO 65211 (mckibbenj@missouri.edu)

42. Mitch Meyer, P.O. Box 1625, Idaho Falls, ID 83415-3750 (Mitchell.Meyer@inl.gov)

43. J. O. Moore, U.S. Department of Energy (moorejo@ornl.gov)

44. S. R. Morrell, Idaho National Laboratory (sean.morrell@inl.gov)

45. T. Newton, MIT Nuclear Reactor Laboratory, 138 Albany St., Cambridge, MA 02139 (tnewton@mit.edu)

46. S. O’Kelly, NIST Center for Neutron Research, 100 Bureau Drive, Stop 8560, Gaithersburg, MD 20899-8560 (sean.okelly@nist.gov)

47. R. T. Primm III, Primm Consulting, Laurel Hill Road, Knoxville, TN 37923 (trentprimm@primmconsultingllc.com)

48. D. Reed, U.S. Department of Energy (reeddr@ornl.gov) 
49. W. Richards, NIST Center for Neutron Research, 100 Bureau Drive, Stop 8561, Gaithersburg, MD 208998561 (wade.richards@nist.gov)

50. J. Roglans, Argonne National Laboratory, 9700 S. Cass Avenue, Argonne, IL 60439 (roglans@anl.gov)

51. K. E. Rosenberg, Idaho National Laboratory (kenneth.rosenberg@inl.gov)

52. D. Rosine, U.S. Department of Energy (rosinedb@ornl.gov)

53. C. Sohn, Office of Basic Energy Sciences, U.S. Department of Energy, 1000 Independence Avenue SW, Washington, DC 20585 (carol.sohn@pnso.science.doe.gov)

54. P. Staples, NA-212, U.S. Department of Energy, 1000 Independence Avenue SW, Washington, DC 20585 (Parrish.Staples@nnsa.doe.gov)

55. J. G. Stevens, Argonne National Laboratory, 9700 S. Cass Avenue, Argonne, IL 60439 (johnstevens@anl.gov)

56. D. M. Wachs, MFC 791 B-147, Idaho National Laboratory, P.O. Box 6188, Idaho Falls, ID 83415 (Daniel.Wachs@inl.gov)

57. R. E. Williams, NIST Center for Neutron Research, 100 Bureau Drive, Stop 8560, Gaithersburg, MD 208998560 (robert.williams@nist.gov)

58. E. H. Wilson, Argonne National Laboratory, 9700 S. Cass Avenue, Argonne, IL 60439 (erikwilson@anl.gov)

59. E. C. Woolstenhulme, P.O. Box 1625, Idaho Falls, ID 83415-3750 (Eric.Woolstenhulme@inl.gov) 